MARCIO JOSÉ DA SILVA

Modelagem de um sistema para auralização musical utilizando Wave Field Synthesis

São Paulo

2014 
Marcio José da Silva

\title{
Modelagem de um sistema para auralização musical utilizando Wave Field Synthesis
}

\author{
Dissertação apresentada à Escola de Comunica- \\ ções e Artes da Universidade de São Paulo para \\ obtenção do título de Mestre em Música. \\ Área de concentração: \\ Processos de Criação Musical \\ Orientador: \\ Prof. Dr. Regis Rossi Alves Faria
}

Esta é a versão corrigida desta dissertação. A versão original se encontra disponível tanto na Biblioteca da ECA/USP quanto na Biblioteca Digital de Teses e Dissertações da USP (BDTD)

São Paulo

2014 
Autorizo a reprodução e divulgação total ou parcial deste trabalho, por qualquer meio convencional ou eletrônico, para fins de estudo e pesquisa, desde que citada a fonte.

Catalogação na Publicação Serviço de Biblioteca e Documentação

Escola de Comunicações e Artes da Universidade de São Paulo Dados fornecidos pelo(a) autor(a)

Silva, Marcio José da

Modelagem de um sistema para auralização musical

utilizando Wave Field Synthesis / Marcio José da Silva. --

São Paulo: M. J. Silva, 2014.

80 p.: il.

Dissertação (Mestrado) - Programa de Pós-Graduação em Música - Escola de Comunicações e Artes / Universidade de São Paulo.

Orientador: Regis Rossi Alves Faria

Bibliografia

1. Wave Field Synthesis 2. auralização musical 3.

espacialização sonora 4. áudio espacial 5. programação

dinâmica I. Faria, Regis Rossi Alves II. Título.

CDD 21.ed. -780 
Marcio José da Silva

Modelagem de um sistema para auralização musical utilizando Wave Field Synthesis

Dissertação apresentada à Escola de Comunicações e Artes da Universidade de São Paulo para obtenção do título de Mestre em Música.

Área de concentração:

Processos de Criação Musical

Orientador:

Prof. Dr. Regis Rossi Alves Faria

Aprovação em: 31 de outubro de 2014.

Banca examinadora:

Prof. Dr. Regis Rossi Alves Faria

Instituição: FFLCRP-USP

Prof. Dr. Fernando Henrique de Oliveira Iazzetta

Instituição: ECA-USP

Prof. Dr. José Augusto Mannis

Instituição: IA-UNICAMP 


\section{Agradecimentos}

À FAPESP por todo o apoio dado a esta pesquisa, através do processo 2012/17263-1 e pelo financiamento do desenvolvimento do array de alto-falantes e equipamentos utilizados, através do processo FAPESP 2008/08632-8 (projeto temático MOBILE - Processos Musicais Interativos).

Aos pesquisadores César Daniel Salvador Castañeda, Thilo Koch, Flávio Luiz Schiavoni e a todos aqueles que direta ou indiretamente colaboraram com esta pesquisa. 


\section{Resumo}

\section{SILVA, Marcio. J. Modelagem de um sistema para auralização musical utilizando Wave}

Field Synthesis. 2014. 80 f. Dissertação de mestrado - Escola de Comunicações e Artes, Universidade de São Paulo, São Paulo, 2014.

Buscando-se a aplicação prática da teoria de Wave Field Synthesis (WFS) na música, foi feita uma pesquisa visando à modelagem de um sistema de sonorização capaz de criar imagens sonoras espaciais com a utilização desta técnica. Diferentemente da maioria das outras técnicas de sonorização, que trabalham com uma região de escuta pequena e localizada, WFS permite projetar os sons de cada fonte sonora - como instrumentos musicais e vozes - em diferentes pontos do espaço de audição, em uma região de escuta que pode abranger quase toda a área compreendida por este espaço, dependendo da quantidade de alto-falantes instalados. $\mathrm{O}$ desenvolvimento de um código de estrutura modular para WFS foi baseado na plataforma orientada a patches Pure Data $(P d)$, e no sistema de auralização AUDIENCE, desenvolvido na USP, sendo integrável como ferramenta para espacialização sonora interativa. A solução emprega patches dinâmicos e uma arquitetura modular, permitindo flexibilidade e manutenabilidade do código, com vantagens frente a outros software existentes, particularmente na instalação, operação e para lidar com um número elevado de fontes sonoras e alto-falantes. Para este sistema também foram desenvolvidos alto-falantes especiais com características que facilitam seu uso em aplicações musicais.

Palavras-chave: Wave Field Synthesis, auralização musical, espacialização sonora, áudio espacial, síntese de campo sonoro, programação dinâmica. 


\begin{abstract}
SILVA, Marcio. J. Modeling a system for musical auralization using Wave Field Synthesis. 2014. 80 f. Masters dissertation - Escola de Comunicações e Artes, Universidade de São Paulo, São Paulo, 2014.

Seeking the practical application of the theory of Wave Field Synthesis (WFS) in music, a research aimed at modeling a sound system capable of creating spatial sound images with the use of this technique was made. Unlike most other techniques for sound projection that work with a small, localized listening area, WFS allows projecting the sounds of each sound source - such as musical instruments and voices - at different points within the hearing space, in a region that can cover almost the entire area comprised by this space, depending on the amount of installed speakers. The development of a modular structured code for WFS was based on the patch-oriented platform Pure Data (Pd), and on the AUDIENCE auralization system developed at USP, and it is integrable as a tool for interactive sound spatialization. The solution employs dynamic patches and a modular architecture, allowing code flexibility and maintainability, with advantages compared to other existing software, particularly in the installation, operation and to handle a large number of sound sources and speakers. For this system special speakers with features that facilitate its use in musical applications were also developed.
\end{abstract}

Keywords: Wave Field Synthesis, music auralization, sound spatialization, spatial audio, sound field synthesis, dynamic programming. 
Sumário

1 UM SISTEMA DE SONORIZAÇÃO BASEAdO EM SÍNTESE DE FRENTE





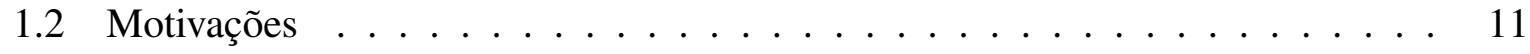

1.3 Utilização das técnicas de espacialização . . . . . . . . . . . . . . . . 13

1.3.1 Sistemas de sonorização espacial . . . . . . . . . . . . . . . 13

1.3 .2 Espacialização na música . . . . . . . . . . . . . . . . . . . 15

1.3.3 Instrumentação musical virtual espacial . . . . . . . . . . . . 15

1.4 A escolha das plataformas de desenvolvimento . . . . . . . . . . . . 16

2 TEORIA BÁSICA SOBRE WAVE FIELD SYNTHESIS $\ldots \ldots \ldots \ldots \ldots$

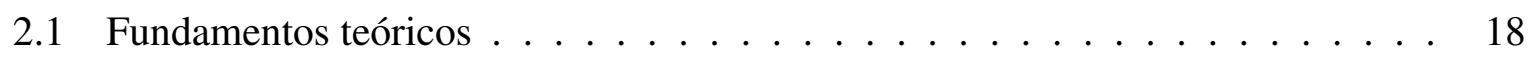

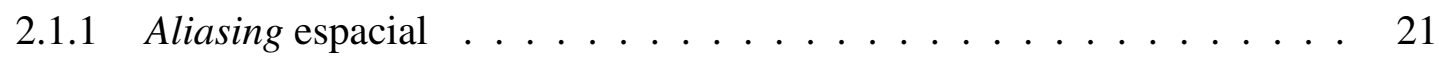

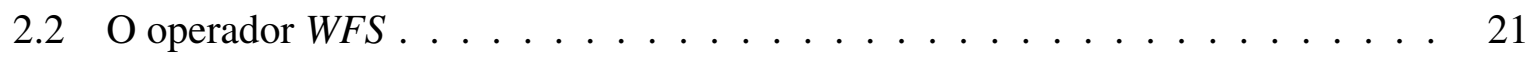

2.2.1 O operador WFS segundo Ranjan e Gan _ . . . . . . . . . . . 23

2.2.2 O operador WFS segundo Wittek . . . . . . . . . . . . . . . . 24

2.2.3 O operador WFS segundo Spors, Rabenstein e Ahrens . . . . . . . . 25

2.2.4 O operador WFS segundo Marije Baalman . . . . . . . . . . . . 25

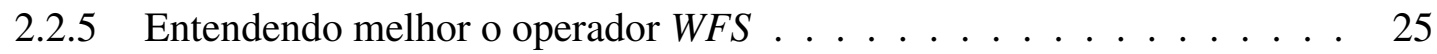

2.2.5.1 Cálculo das amplitudes . . . . . . . . . . . . . . . 27

2.2.5.2 Cálculo dos atrasos . . . . . . . . . . . . . . . . . 28

2.3 Aplicações de Wave Field Synthesis . . . . . . . . . . . . . . . . . . . 28

2.4 Projetos e trabalhos de referência . . . . . . . . . . . . . . . . . . . . . 29

2.4 .1 O projeto CARROUSO . . . . . . . . . . . . . . . . . . . . . . 29

2.4 .2 Casa del Suono . . . . . . . . . . . . . . . . . . . . . . . . . 29

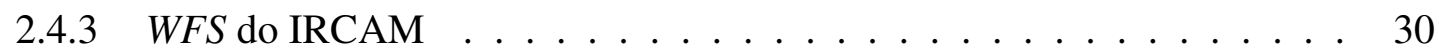

2.4.4 WFS da Technical University - Berlin . . . . . . . . . . 30

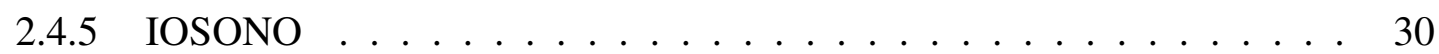

3 ESTUDOS INICIAIS PARA DESENVOLVIMENTO DE PROTÓTIPOS _ . . 31

3.1 Programas de referência para $W F S \ldots \ldots \ldots \ldots$

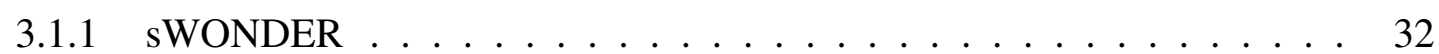

3.1.2 WFSPlayer de Daniel Salvador . . . . . . . . . . . . . . . . 33

3.1 .3 SoundScape Renderer $(S S R)$. . . . . . . . . . . . . . . . 35

3.2 Diagramas de blocos dos programas de referência . . . . . . . . . . 36 
4 IMPLEMENTAÇÃO E TESTES BÁSICOS . . . . . . . . . . . . . . . . 40

4.1 Operador $W F S$ para o projeto . . . . . . . . . . . . . . . 40

4.2 Montagem e infra-estrutura básica . . . . . . . . . . . . . . . 41

4.2.1 Projeto e fabricação de alto-falantes especiais . . . . . . . . . . . . . . . . . . . . . . . 44

4.3 Protótipo inicial em Pure Data . . . . . . . . . . . . . . . . . . . . . . . . . . 44

4.4 Avaliação básica do funcionamento do protótipo inicial . . . . . . . . . . . 47

4.5 Protótipo final . . . . . . . . . . . . . . . . . 51

4.5.1 Aspectos gerais do projeto . . . . . . . . . . . . 53

4.5.2 Implementação do processador WFS com programação dinâmica . . . . 54

4.5.3 Integração ao sistema AUDIENCE . . . . . . . . . . . . . . 56

4.5.4 Construção do protótipo final . . . . . . . . . . . . . . . . 57

4.6 Testes de funcionamento realizados no protótipo final . . . . . . . . . . . . 62

4.6.1 Apresentação dos resultados do teste subjetivo . . . . . . . . . . . . . 67

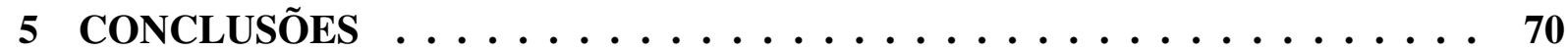

5.1 Discussão dos resultados . . . . . . . . . . . . . . . . . 70

5.2 Principais contribuições deste trabalho . . . . . . . . . . . . . . . 71

5.3 Trabalhos futuros . . . . . . . . . . . . . . . 72

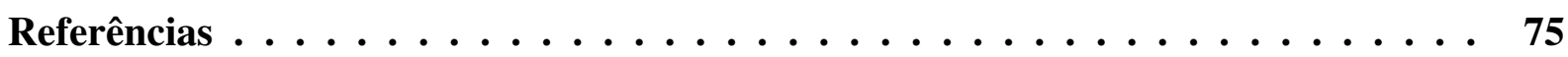

APÊNDICE A Configurações do $S S R \ldots \ldots \ldots \ldots \ldots \ldots$

APÊNDICE B Método para o cálculo da posição da fonte sonora . . . . . . . . 79 


\section{UM SISTEMA DE SONORIZAÇÃO BASEADO EM SÍNTESE DE FRENTE DE ONDA}

Wave Field Synthesis - ou Síntese de Campo de Onda - representada pela sigla WFS, é uma técnica de sonorização que visa reproduzir os atributos físicos de um campo sonoro no espaço de audição, como auditórios e cinemas, permitindo teoricamente perfeita localização da fonte virtual, numa grande área de reprodução, ao contrário das técnicas convencionais que permitem a criação de uma ilusão acústica sobre uma área de escuta muito pequena conhecida como sweet spot (RANJAN; GAN, 2012).

Nesta pesquisa de mestrado modelou-se uma implementação computacional modular e flexível da técnica de sonorização de Wave Field Synthesis (WFS), projetada de modo a facilitar sua integração a um sistema de auralização ${ }^{1}$ desenvolvido na Universidade de São Paulo, o AUDIENCE ${ }^{2}$.

O projeto do sistema de auralização AUDIENCE (AUDio Immersion ExperieNce by Computer Emulation) teve início em 2003 no Laboratório de Sistemas Integráveis da Escola Politécnica da Universidade de São Paulo (LSI-EPUSP) visando pesquisar tecnologias para imersão sonora, produção e reprodução de áudio 2D/3D, com aplicações em multimídia, realidade virtual, home-theaters e sonorização surround (FARIA et al., 2005; FARIA; ZUFFO, 2006; THOMAZ et al., 2006; FARIA; ZUFFO; ZUFFO, 2005).

Em 2005 o sistema foi utilizado numa instalação multicanal cúbica ( 8 alto-falantes) para a Caverna Digital ${ }^{3}$, gerando a primeira versão do software de auralização AUDIENCE. Na versão atual, o programa consiste numa biblioteca de objetos e abstrações para a plataforma Pure Data que permite construir aplicações genéricas de áudio espacial. Está disponível em duas versões - uma completa e restrita (AUDIENCE4Pd) e outra básica e aberta, que pode ser baixada da internet gratuitamente a partir do website do projeto $^{4}$, denominada OpenAUDIENCE (OA), utilizada como arquitetura de sistema e plataforma de referência de programação neste projeto.

\subsection{Objetivos da pesquisa}

Este projeto propôs a modelagem e prototipagem de um sistema de sonorização espacial como aplicação prática da teoria de Wave Field Synthesis, caracterizado pela manipulação e distribuição espacial de cenas sonoras virtuais, usando um mapeamento controlável, de modo a poder alterar a posição dos sons emitidos. Para controlar este sistema, deveria ser desenvolvido

Auralização é o processo que usa modelagem física ou matemática para criar um campo sonoro.

2 AUDIENCE: Sistema e Software para Imersão Sonora e Auralização. Acesso em: <http://www.lsi.usp.br/neac/ audience>

3 O site do projeto CAVERNA Digital pode ser acessado em <http://www.lsi.usp.br/ rv/p/cave_p.html >

4 OpenAUDIENCE. Acesso em <http://www.lsi.usp.br/neac/pt-br/openaudience> 
um código de programação de estrutura modular, segundo os requisitos da plataforma de auralização AUDIENCE, de maneira a ser integrado como ferramenta para espacialização sonora interativa, particularmente útil para aplicações de espacialização musical.

\subsection{Motivações}

Até o século XX, a música só pôde ser apreciada no momento da sua execução, com cada ouvinte próximo aos seus executantes. Indo mais além, para que as fontes sonoras ${ }^{5}$ possam ser ouvidas, não basta a distância ser curta se o ambiente não é acusticamente favorável. Se houver centenas de pessoas próximas a um violão tocado numa rua ao ar livre, provavelmente, para grande parte dos presentes, o instrumento não será ouvido de forma satisfatória. Como comentado por Thomaz (2007, p. 23): "Por exemplo, em uma orquestra, a escolha da posição dos instrumentos deve-se principalmente ao volume sonoro que cada instrumento produz, de forma que todos possam ser ouvidos claramente".

Para apresentações musicais são desenvolvidas salas com acústica apropriada, e até ajustável, como por exemplo a Sala São Paulo, sede da Orquestra Sinfônica do Estado de São Paulo. Outra solução comum é a instalação de um sistema de reforço de áudio (com microfones e alto-falantes) que distribua o som no ambiente em questão, usado inclusive em salas de concerto, para que o público, independentemente de sua distribuição no espaço do evento, possa ouvir bem o que está sendo executado.

É antiga a preocupação e o interesse pelo desenvolvimento da música por meio das possibilidades trazidas pela tecnologia. Esta influência pode ser ilustrada pela evolução dos instrumentos musicais, as cada vez mais modernas salas de concerto ou a construção de estúdios de gravação cada vez mais sofisticados, e a relação destes com os processos de execução, transmissão, conservação e a criação de novos sons. Nas últimas décadas surgiram novas possibilidades técnicas para o universo musical. Porém, tal evolução, na maioria dos casos, não é direcionada aos ouvintes, o que implica uma ausência de ferramentas para forjar e adequar o espaço de audição, já que a ênfase está na criação e execução musicais, vide as interfaces que estão entre o sistema de autoria (instrumentos, computadores, etc.) e os músicos. As diversas pesquisas relacionadas à sonorização mostram que tem havido um aumento do interesse na experiência de audição e, mais especificamente no áudio espacial. A evolução das técnicas de espacialização de campo sonoro, como consequência das novas tecnologias de áudio e do aumento do poder de processamento dos computadores, levou à otimização e expansão do uso do espaço auditivo, o que sugere explorar cada vez mais as possibilidades técnicas disponíveis.

A tecnologia não se resume exclusivamente à eletrônica ou à informática, mas, a partir do século XX e, mais especificamente, da segunda metade do século, tanto uma, quanto outra,

5 Instrumentos musicais, sejam eles acústicos ou eletrônicos (como os sintetizadores), são exemplos de fontes sonoras. 
passam a estar cada vez mais presentes no próprio processo criativo. Conforme constata Braun (Baltimore, 2000):

A tecnologia foi sempre inseparável do desenvolvimento da música. Mas, no século XX, uma rápida aceleração tomou lugar: uma nova 'música da máquina' veio à existência, instrumentos musicais eletrônicos foram desenvolvidos e compositores frequentemente transformaram-se em pesquisadores sonoros.

A evolução tecnológica dos equipamentos de som foi, e continua sendo, incorporada a shows musicais, auditórios, salas de cinema, jogos de computador e sonorização de eventos teatrais, entre outras aplicações. Cada vez mais são assistidas gravações de vídeos musicais e concertos por meio das mídias como a televisão, aparelhos de DVD e internet. Há uma evolução nas possibilidades de escuta musical, através: da evolução das salas de concerto; da evolução dos instrumentos musicais (acústicos ou não); das novas estéticas e de novos conceitos, como a da música eletroacústica; da possibilidade de tornar o mais realístico possível a escuta das grandes orquestras; do uso de microfones, amplificadores e caixas de som na música ao vivo ou gravada, ou até mesmo gerada através de circuitos eletrônicos e computadores. Tudo isso nos motiva a buscar uma nova e aperfeiçoada forma de projeção e escuta dos sons, otimizando e expandindo o uso do espaço auditivo.

De acordo com Ranjan e Gan (2013, pg. 19) e Baalman (2007), WFS produz imagens sonoras mais definidas e estáveis e é adequada para situações de concertos, pois, diferentemente das outras técnicas, tem a capacidade de induzir a percepção de objetos sonoros localizados numa grande área de audição, podendo assim atender um maior número de ouvintes simultaneamente. Ao contrário de técnicas como a de reprodução em dois canais, as posições das fontes virtuais percebidas pelo ouvinte não mudam conforme este se desloca, mas sim como se realmente estivessem numa dada posição no ambiente. Além disso, permite outros tipos de movimento das fontes sonoras, tais como movimentos que usam controle mais preciso sobre a localização de fontes de som e movimentação através do espaço de audição, podendo haver uma fonte com uma posição fixa ou uma fonte que se move quando o ouvinte atravessa a região de audição. Segundo Brandenburg, Brix e Sporer (2004), as salas de concerto com WFS podem se transformar em espaços multifuncionais com adaptações acústicas para cada tipo de música e posicionar os instrumentos musicais de uma orquestra com informação angular espacial e boa noção de distância das cenas acústicas no palco. O artigo de Faria (2011b), sugere uma proposta diferente de escutar e perceber os sons, com a possibilidade dos sons serem decompostos em parciais (harmônicos, por exemplo) que poderiam ser ouvidos separados em posições diferentes, numa projeção em WFS.

É interessante salientar que, no Brasil, até a presente data, ainda não encontramos estudos voltados a desenvolvimentos com o uso de WFS. Este trabalho proporciona, em língua portuguesa, um arcabouço de referência novo sobre este assunto, fazendo uma integração com as áreas de 
música, computação musical e engenharia de áudio, para a aplicação de $W F S$, por exemplo na auralização musical, focalizando na construção de cenas sonoras musicais integrado ao framework do sistema de auralização AUDIENCE. A provável utilização de sistemas baseados em WFS, com a perspectiva de que se possa gerar implementações inéditas no Brasil e se possa avaliar equipamentos fabricados em outros países que se utilizam desta técnica, dependerá de pessoal qualificado para extrair o máximo de recursos dos equipamentos usados para tal finalidade, como programadores, técnicos e engenheiros de som. Espera-se que esta pesquisa sirva de base informativa inicial para que estes profissionais possam realizar treinamentos e desenvolvimentos técnicos no Brasil.

\subsection{Utilização das técnicas de espacialização do campo sonoro}

O desenvolvimento de novas técnicas de sonorização e execução musical são importantes para o desenvolvimento da música e motivam a exploração de novos caminhos. Conforme observado por Schafer (2001), sons distantes no tempo e no espaço, composições do passado e sons de culturas estrangeiras foram incorporados à paisagem sonora, graças às novas possibilidades de captar e reproduzir os sons. Desta forma, os ouvintes passaram a experimentar a dissociação entre a escuta e a fonte sonora, já que os sons passam a ser reproduzidos por alto-falantes.

Este projeto buscou a adequação do espaço sonoro aos ouvintes, o que significa garantir qualidade e integridade de audição das cenas sonoras e individualizar o espaço de audição em cada ponto do espaço físico. Entretanto, para pesquisas neste campo é importante lembrar que, segundo Faria (2005, p. 150):

(...) a simulação e reprodução realista de um campo sonoro (...) é uma meta somente alcançável através de refinamentos e melhoramentos sucessivos, tanto nos modelos utilizados quanto nas técnicas de implementação. Um resultado de alta qualidade é alcançável após iterados ciclos de implementações, testes, e melhoramentos.

\subsubsection{Sistemas de sonorização espacial}

Desde o seu aparecimento, as técnicas de auralização vêm evoluindo e tendem a utilizar um número cada vez maior de alto-falantes necessários a implementações mais sofisticadas. Isto pode ser observado comparando-se, como feito por Faria (2005) e Thomaz (2007), alguns sistemas de sonorização, como, por exemplo, os sistemas monofônico, quadrifônico, surround (5.1, 7.1, etc.) e Ambisonics.

A história da reprodução de som espacial começou originalmente com o aparecimento da reprodução estereofônica. O efeito estéreo, surgiu por volta de 1930, quando percebeu-se que a gravação feita com dois microfones (um para cada canal de gravação) poderia gerar, com os alto-falantes, uma reprodução com sugestão de espacialização sonora. A partir do estéreo, diversas técnicas de gravação foram propostas. Como desvantagens, a reprodução em estéreo 
apresenta uma grande interferência entre as ondas (cross-talk), além de ser muito limitada quando busca-se a localização precisa de objetos sonoros no campo de audição. Tanto em estéreo quanto na maioria das técnicas de auralização, o ouvinte não pode se deslocar da área de audição correta, pois as fontes sonoras tendem a emergir das caixas, não mais das posições virtuais esperadas.

Faria (2005, pg. 30) e Thomaz (2007, pg. 48) explicam que o método bi-aural, assim como a reprodução estereofônica, utiliza um canal de áudio para cada ouvido e usa técnicas para tentar reproduzir neles, via fones de ouvido, um som originalmente emitido por uma fonte sonora qualquer. Conforme as posições de cada objeto em relação ao ouvinte variam, temos que o som chega primeiro ao ouvido que estiver mais perto desta fonte emissora, que é uma das causas de um objeto não ter o mesmo som para ambos os ouvidos. Estas diferenças levaram ao estudo das funções de transferências, aplicadas ao processamento desta técnica, chamadas de Head Related Transfer Function (HRTF), sendo individualizadas para o ouvido direito e esquerdo. Como desvantagem, para vários usuários, a técnica necessita que o sistema reprodutor se conecte a vários fones de ouvido, pois os fones não podem ser compartilhados.

De acordo com Faria (2005, pg. 19-20), os sistemas surround criam efeitos complexos de envolvimento e uma melhor ideia sobre a posição e o movimento dos objetos sonoros numa cena sonora do que as antigas técnicas, baseadas na reprodução em dois canais. Estes sistemas têm cada vez mais múltiplos canais independentes, se utilizando de técnicas digitais para o processamento de sinais.

O Sistema Vetorial de Panorama por Amplitude (SVPA), ou em inglês Vector Based Amplitude Panning (VBAP), conforme descrito por (FARIA, 2005, pg. 31-32) e Thomaz (2007, pg. 55-56) é um método que permite posicionar as fontes virtuais no espaço que tem boa precisão. O sistema é formado por diferentes arranjos de alto-falantes no qual são reproduzidos sinais sonoros com diferentes amplitudes. Esta técnica é de implementação fácil e barata e de baixo custo computacional, mas não leva em conta parâmetros psicoacústicos importantes, como a relação entre frequência e variação da amplitude.

Ambiophonics, de acordo com Faria (2005, pg. 41) e Thomaz (2007, pg. 57), é uma técnica de gravação e reprodução de som multicanal que emprega princípios psicoacústicos para tratar os sinais que irão aos alto-falantes, em função do posicionamento destes e dos ouvintes, podendo resultar num elevado nível de realismo na reprodução de salas de concerto e excelente posicionamento das fontes sonoras virtuais no ambiente de projeção. A técnica consiste em separar o som direto, reproduzido por pares de alto-falantes, da ambiência, reproduzida por outro arranjo de alto-falantes. Como limitação, Ambiophonics comporta somente de um a dois usuários.

De acordo com Thomaz (2007, pg. 61), Ambisonics é um sistema capaz de gravar e reproduzir campos sonoros, buscando reconstruir a onda sonora original, levando também em consideração parâmetros psicoacústicos. Segundo Ranjan e Gan (2013), assim como em Wave Field Synthesis, Ambisonics se baseia na reprodução do campos de ondas acústicas, o que 
permitiria ótima localização das fontes sonoras. Ambisonics tem como vantagem poder sintetizar o campo de onda com qualquer número de alto-falantes arranjados em formatos arbitrários.

Segundo Faria (2005), WFS traz como vantagem diminuir o número de pontos de interferência das ondas geradas, produzindo uma frente de onda mais próxima daquela que um instrumento real produziria no espaço de audição, através da sua projeção por um número bem mais elevado de alto-falantes que os usados nos sistemas comuns de áudio espacial. Além disso, WFS não apresenta as limitações de hot spots de outras técnicas e pode ser usada para produzir imagens sonoras holográficas na frente dos alto-falantes.

A evolução das técnicas de espacialização de campo sonoro levou à otimização e expansão do uso do espaço auditivo. Isto tem melhorado com as novas tecnologias de áudio e o aumento do poder de processamento dos computadores.

\subsubsection{Espacialização na música}

Thomaz (2007, pg. 23) aborda o uso e a importância de espacialização na música descrevendo apresentações musicais nas quais há uma distribuição dos instrumentos musicais em várias posições do ambiente de execução. Nas palavras do próprio autor:

Então, aplica-se o termo de música espacializada para toda música na qual, por meio do posicionamento incomum das fontes, da movimentação das fontes e do uso da ambientação, o compositor eleva a espacialização das fontes sonoras a um mesmo patamar de importância que os outros elementos da música como a harmonia, o ritmo e o timbre, entre outros.

No trabalho de Baalman (2007), são comentadas composições de Hans Tuschku, Christian Calon, Victor Lazzarini, André Bartetzki e Shintaro Imai nas quais foram utilizadas técnicas de espacialização durante as respectivas apresentações ao vivo destas peças. Para estas e outras obras que precisem de recursos para espacializar, localizar ou movimentar o som no espaço sonoro sejam executadas em território brasileiro, é necessária a instalação de um sistema de espacialização sonora, que é o foco deste projeto.

\subsubsection{Instrumentação musical virtual espacial}

Nas diversas formas de comunicação, um indivíduo tem um pensamento e quer transmitilo a outro. A execução musical é uma destas formas de comunicação, uma maneira pela qual os compositores transmitem suas ideias a outras pessoas. Para a criação de músicas cada vez mais elaboradas e complexas, foi necessário o desenvolvimento, dentre outras coisas, da técnica dos executantes e de instrumentos musicais de construção cada vez mais complexa para aumentar a qualidade e a gama de timbres disponíveis para os arranjos ou orquestrações (SILVA; FARIA, 2013). Desta forma, nota-se que o estudo e o desenvolvimento tecnológico foram importantes 
para a evolução da música, notadamente em relação aos instrumentos musicais, o que vai ao encontro do que afirma Iazzetta (1997):

“(...) Instrumentos musicais podem ser vistos como extensões tecnológicas de nossas habilidades de produzir sons. Porém, é necessário que se desenvolvam técnicas para manipulação desses aparatos tecnológicos para que se alcance os resultados desejados".

Segundo Chion (1994) e o seu "mito da alta fidelidade", a gravação não se aproxima da realidade do concerto, pois não seria possível ouvir as características gerais da execução de uma obra, como a percepção espacial dos instrumentos. Porém, a aproximação com a realidade do concerto tende a melhorar com a evolução das tecnologias de áudio espacial, podendo os instrumentos musicais, fugir da lógica da acústica imposta pelo corpo físico dos instrumentos tradicionais.

A técnica de WFS pode ser usada na pesquisa com instrumentação musical virtual espacial. Como proposto por Faria (2011b), a modelagem do espaço pode ser feita pensando-o como a interface de um instrumento de execução musical, ou como uma matriz mapeada de escuta de domínio do ouvinte, em que é possível controlar o som e algumas de suas características. Impressões causadas pela simulação acústica de salas e pela posição dos instrumentos musicais, sob controle dos instrumentistas, ajudam a definir diferentes cenas sonoras virtuais propostas aos ouvintes.

O artigo escrito por Valbom e Marcos (2005) apresenta um ambiente de áudio virtual, chamado WAVE, cuja implementação abrange um modelo de instrumento musical que utiliza técnicas de som tridimensionais de áudio envolvente, combinada com a visualização e tecnologias de realidade virtual. Este ambiente-protótipo visava estender a ideia de um instrumento musical em um novo sistema de áudio, com a incorporação de conceitos musicais tradicionais, integrando música e som. A arquitetura do sistema foi baseada em hardware de baixo custo e software open source profissional com preços acessíveis e equipamento de áudio para manter uma qualidade de som adequado. Várias aplicações deste ambiente virtual são discutidas no artigo, incluindo a forma de satisfazer ao mesmo tempo compositores, artistas, estudantes de música e de áudio ou mesmo simples usuários ocasionais.

\subsection{A escolha das plataformas de desenvolvimento}

Neste trabalho é utilizada a plataforma computacional Pure Data ${ }^{6}$ (PUCKETTE et al., 1996) (Pd) e bibliotecas feitas para ela como o AUDIENCE. O Pd é um sistema que funciona como um ambiente gráfico de programação musical. Pode ser simultaneamente programado e operado em tempo-real, sendo amplamente utilizado por músicos, artistas e sound designers.

6 Pure Data-PD Community Site. Acesso em $<$ http://puredata.info/> 
A programação em Pure Data é bastante simples por utilizar o conceito de fluxos e blocos, o que permite a utilização de expressões matemáticas que alterem um fluxo de áudio. Um programa de Pd é chamado de patch. Outra vantagem deste ambiente é a sua capacidade em aceitar extensões, através da criação de novos objetos que podem ser feitos na forma de externals em linguagem $\mathrm{C}$ ou na forma de abstractions quando feitos em patches, com outros objetos do próprio ambiente.

Além de preencher os requisitos necessários à implementação deste projeto, o Pure Data ainda tem outras vantagens como ser uma ferramenta opensource, ser multiplataforma e funcionar em vários sistemas operacionais. Além disto, a escolha deste ambiente simplifica a integração do módulo de WFS ao sistema AUDIENCE/OpenAUDIENCE, também implementado na mesma plataforma. 


\section{TEORIA BÁSICA SOBRE WAVE FIELD SYNTHESIS (SÍNTESE DE CAMPO DE ONDA)}

Segundo Vries (2009) e Melchior (2011, pg. 16-17), a técnica de Wave Field Synthesis foi introduzida em 1988 por A. J. Berkhout (Universidade TU Deft, Holanda). É baseada na teoria formulada, no final do século XVII, pelo físico holandês Christiaan Huygens (1629-1695), tendo como princípio fundamental obter o modelamento físico da propagação de frentes de ondas sonoras através da propagação e superposição de várias pequenas frentes de onda, o que requer uma formulação computacionalmente elaborada. Em 1818, o princípio de Huygens foi complementado por Fresnel, e passou a se chamar princípio de Huygens-Fresnel. A formulação matemática deste princípio foi dada por Kirchhoff em 1882, que propôs um teorema mais geral mostrando que o princípio de Huygens-Fresnel pode ser considerado um caso especial deste teorema. O teorema de Kirchhoff pode ser simplificado levando à formulação dos teoremas de Rayleigh, que formam a base para a teoria de WFS.

\subsection{Fundamentos teóricos}

O objetivo principal em WFS é emular a frente de onda que seria produzida por objetos sonoros reais em um ambiente acústico específico, através de matrizes de alto-falantes densamente distribuídas na área de audição. De acordo com Menzies (2013), a configuração mais comum da matriz de alto-falantes fica disposta num plano horizontal em que estes direcionam os sons para a área de audição, à custa de perda de resolução espacial para posições cada vez mais distantes deste plano.

Segundo Baalman (2008) e Ranjan e Gan (2013), cada alto-falante emite um sinal de áudio com atraso e atenuação controlados, correspondentes à sua posição, para que a soma das contribuições destes sinais possa sintetizar uma frente de onda, buscando manter as características espaciais e temporais que seriam emitidas por uma fonte sonora real. Na parte esquerda da figura 1 é mostrada uma fonte sonora real e a representação da emissão de suas ondas sonoras, enquanto na parte direita tem-se uma fonte sonora correspondente projetada atrás da matriz de alto-falantes, o que ilustra o princípio de emulação por WFS.

Em WFS, o controle da sensação de localização e distribuição do som de cada fonte sonora melhora com o aumento do número de alto-falantes disponíveis instalados. Os objetos sonoros podem ser projetados em frente ou atrás dos alto-falantes. Na figura 2, podem ser observadas duas possibilidades de criação de imagens sonoras virtuais. Na primeira, tem-se a sensação de que a fonte sonora encontra-se atrás dos alto-falantes, enquanto na segunda, à direita, temos a fonte sonora formada em frente aos alto-falantes, como numa projeção holográfica.

Segundo Baalman (2008), em WFS, considerando que o ouvinte está em frente à matriz 




Figura 1 - À esquerda ondas sonoras reais e à direita ondas sonoras correspondentes sintetizadas por WFS. Figura extraída da página LIMSI - Augmented and Virtual Reality \& Áudio Interfaces <http: //www.limsi.fr/Scientifique/aa/thmsonesp/IRV_web>
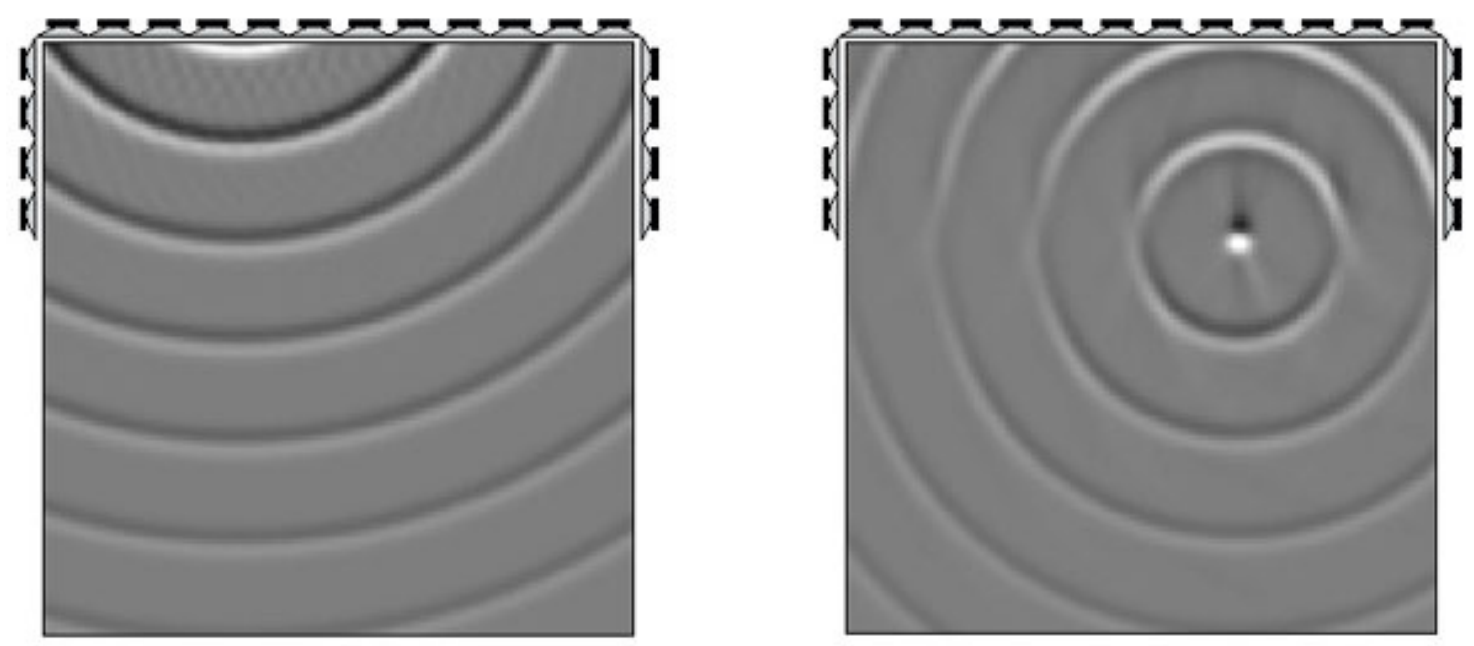

Figura 2 - Fontes sonoras produzidas por WFS, como numa projeção holográfica. À esquerda tem-se a impressão que a fonte sonora encontra-se atrás dos alto-falantes, enquanto à direita temos a fonte sonora formada em frente aos alto-falantes. Figura extraída da página MEI - Meios Eletrônicos Interativos $<$ www.lsi.usp.br/interativos/neac/audience/ambiwave.html>

de alto-falantes e a observa, a fonte sonora deve ser renderizada atrás da matriz, sobre ela ou entre ela e o ouvinte. A fonte sonora não deve ser renderizada atrás de nenhum ouvinte, que, neste caso, ouviria o som dos alto-falantes partindo em direção à fonte sonora, o que é o contrário do que é esperado. Por esta limitação, é determinada, em função das posições dos ouvintes, a linha de referência que serve para determinar até onde o sistema pode projetar o objeto sonoro, que é também o limite no qual o ouvinte deve se posicionar para que a WFS surta efeito. A figura 3 ilustra a linha de referência num sistema de coordenadas cartesiano, indicada por $y_{r e f}$ e, como prevê a teoria, posicionada em frente a uma matriz de alto-falantes.

Segundo Baalman (2008, pg. 23-24) e Hulsebos (2004, pg. 11-12), para que a onda sintetizada por WFS tenha as propriedades físicas de uma onda sonora real, a pressão do ar 


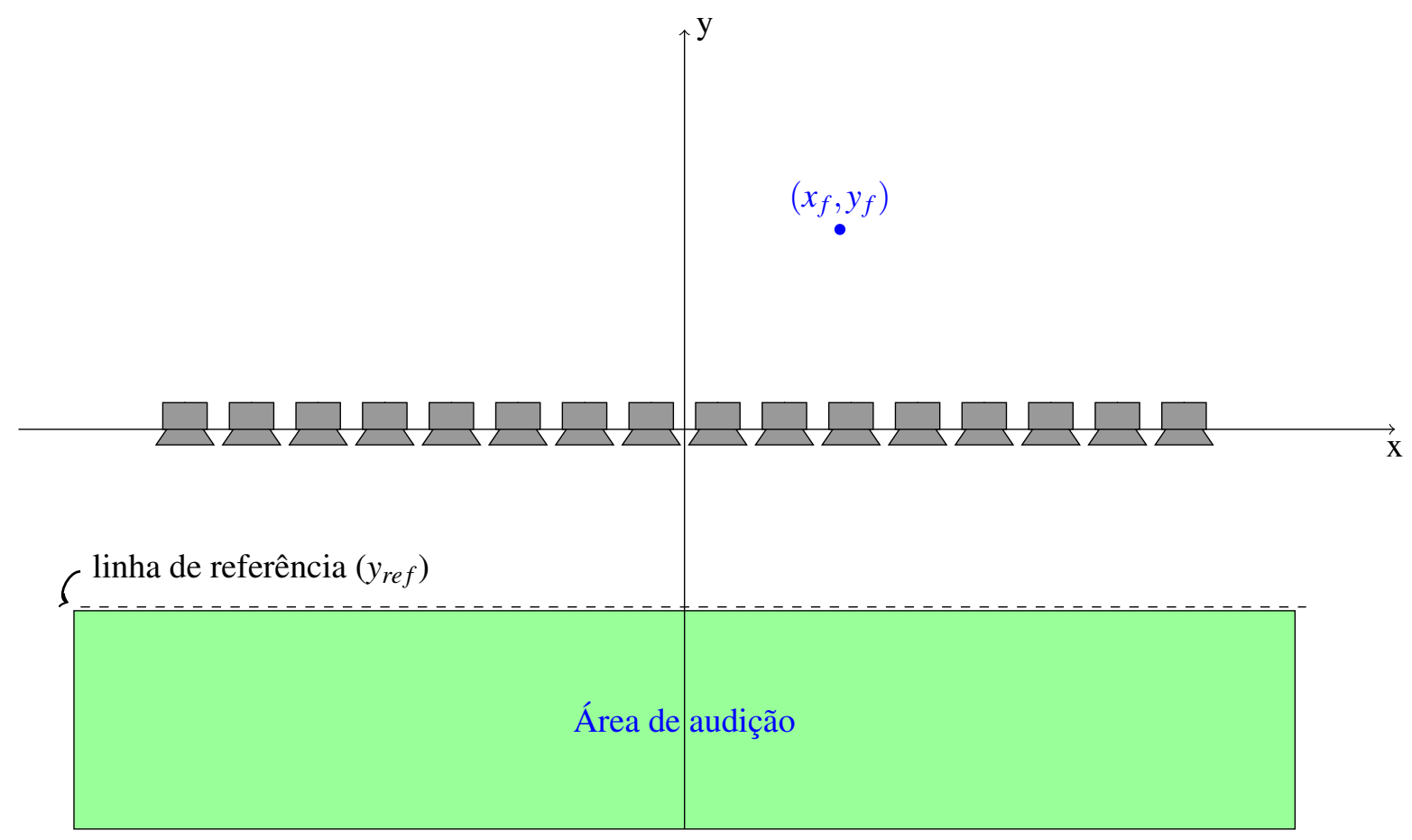

Figura 3 - O posicionamento das caixas de som, num sistema de coordenadas cartesiano, formando uma matriz linear para WFS. As coordenadas $\left(x_{f}, y_{f}\right)$ correspondem à posição do objeto sonoro (fonte sonora). A linha de referência, indicada por $y_{r e f}$, é obrigatoriamente projetada antes da área de audição, ou seja, antes da região em que o ouvinte deve estar para ouvir as fontes sonoras sintetizadas por WFS.

em cada ponto em frente às caixas de som, representada pela função $p(\vec{r}, t)$, deve satisfazer a equação 2.1 (equação de onda), onde o módulo de $\vec{r}$ representa a distância entre a fonte sonora virtual e a frente de onda que a sintetiza e $t$ é o instante de tempo em que a pressão foi medida.

$$
\nabla^{2} p(\vec{r}, t)-\frac{1}{c^{2}} \frac{\partial^{2}}{\partial t^{2}} p(\vec{r}, t)=0
$$

Nesta equação, o laplaciano $\nabla^{2} p(\vec{r}, t)=\sum_{i=1}^{n} \frac{\partial^{2}}{\partial r_{i}^{2}} p(\vec{r}, t)$ equivale à soma das derivadas parciais da função $p(\vec{r}, t)$ em relação às componentes do vetor $\vec{r}=\left(r_{1}, r_{2}, \ldots, r_{n},\right), \frac{\partial^{2}}{\partial t^{2}} p(\vec{r}, t)$ é a derivada parcial da função $p(\vec{r}, t)$ em relação ao tempo e $c$ representa a velocidade do som no ar $(343,4 \mathrm{~m} / \mathrm{s})$.

Baalman (2008) mostra como a pressão pode ser representada no domínio da frequência $\omega$, usando-se a equação 2.2, conhecida como Transformada de Fourier.

$$
P(\vec{r}, \omega)=\int_{-\infty}^{\infty} p(\vec{r}, t) e^{-j \omega t} d t
$$

onde $j=\sqrt{-1}$ (número imaginário). 
Com a Transformada Inversa de Fourier (equação 2.3) obtém-se novamente a função no domínio do tempo.

$$
p(\vec{r}, t)=\frac{1}{2 \pi} \int_{-\infty}^{\infty} P(\vec{r}, \omega) e^{j \omega t} d t
$$

A função de onda no domínio da frequência deve satisfazer a equação 2.4.

$$
\nabla^{2} P(\vec{r}, \omega)+\left(\frac{\omega}{c}\right)^{2} P(\vec{r}, \omega)=0
$$

\subsubsection{Aliasing espacial}

Apesar da técnica ser considerada por muitos autores a que mais permite aproximar a criação de campos sonoros sintéticos dos naturais, há limitações reconhecidas que devem ser observadas no projeto de sistemas para usos musicais, principalmente para que não se inviabilize a geração dos efeitos desejados. Uma das principais limitações está no fenômeno de aliasing espacial, uma vez que o campo sonoro é mostrado em posições descritas no espaço de audição.

A frequência máxima para que se opere sem aliasing espacial é determinada pela diferença máxima de tempo entre a viagem do som de um alto-falante a um ouvinte e a viagem do som de outro alto-falante ao mesmo ouvinte, incluindo os atrasos necessários para que ocorra a síntese WFS, sendo, portanto, a frequência máxima de operação do sistema, acima da qual artefatos e a dispersão da imagem sonora tornam imprecisa a técnica.

Segundo Berkhout, Vries e Vogel (1993), a frequência máxima para que um sistema de WFS opere sem aliasing espacial, $f_{\max }$, é dada pela equação 2.5 .

$$
f_{\max }=\frac{c}{\Delta x_{\max }}
$$

onde $\Delta x_{\text {max }}$ é a distância máxima entre o centro de duas caixas de som consecutivas e $c$ é a velocidade do som no ar.

Conforme pode ser percebido pela equação 2.5, distâncias pequenas entre os cones dos alto-falantes possibilitam trabalhar com $f_{\text {max }}$ mais altas, o que é importante para que os sons de instrumentos de registros bem agudos possam ser ouvidos nas posições previstas pelo uso de WFS. Assim, deve-se buscar o menor espaçamento possível entre os transdutores, para que se possa minimizar esta limitação.

\subsection{O operador WFS}

$\mathrm{Na}$ literatura sobre $W F S$, encontram-se passagens teóricas que mostram as expressões para a função fundamental em qualquer implementação desta técnica. Esta função determina o 
fator para o ganho de amplitude sonora correspondente a cada alto-falante e é chamada de operador WFS (do inglês operator), ou ainda, driving function ou driving signal. Além dos trabalhos destacados no transcorrer desta seção, um bom embasamento pode ser encontrado em Wittek (2007), Montag (2011) e, principalmente Hulsebos (2004), que abordam o desenvolvimento teórico desde suas bases, passando por diversas equações, chegando a aplicações imediatas, principalmente descrições sobre sistemas de WFS para matrizes lineares de alto-falantes. Já no texto de Salvador (2010), encontra-se a teoria de forma bem resumida. A seguir, são examinados os principais operadores encontrados na literatura pesquisada, que serviram de base ao desenvolvimento deste projeto.

Conforme comentado no início do capítulo 2, os teoremas de Rayleigh, formam a base da teoria de WFS. Estes teoremas são soluções da equação 2.2, abordada na seção 2.1. Adaptando esta teoria para que sejam usadas com matrizes de alto-falantes, obtém-se função da pressão no domínio da frequência, $P(\vec{r}, \omega)$. Estas soluções são descritas por Salvador (2010) e Ranjan e Gan (2012), que afirmam que o somatório das contribuições das frentes de onda geradas em cada alto-falante, representada por $P(\vec{r}, \omega)$, obedece a equação 2.6.

$$
P(\vec{r}, \omega)=\frac{1}{4 \pi} \sum_{n=1}^{N} D\left(x_{n}, \omega\right) \frac{e^{-j \frac{\omega}{c}\left|r_{n}-r_{r}\right|}}{\left|r_{n}-r_{r}\right|} \Delta x
$$

onde $x_{n}$ é a abscissa ${ }^{1}$ de cada caixa de som, $\left|r_{n}-r_{r}\right|$ é a distância entre a caixa de som $n$ e a posição do ouvinte, $\Delta x$ é a distância entre o centro de duas caixas de som consecutivas e $k=\frac{\omega}{c}$ é o número de onda. O operador $W F S$, representado na equação 2.6 como $D\left(x_{n}, \omega\right)$, é a função usada para calcular a contribuição de pressão gerada em cada caixa de som do sistema.

Esta mesma abordagem é feita por Belloch et al. (2013). Ele ilustra um sistema básico de WFS com $N$ caixas de som, através da figura 4, e propõe a equação 2.7 , onde $r_{p}$ é a diferença entre as posições da fonte sonora e da $n$-ésima caixa de som e $r_{d n}$ é a diferença entre as posições da $n$-ésima caixa de som e do ponto de coordenadas $\left(x_{0}, y_{0}\right)$ (posição do ouvinte).

$$
P_{\left(x_{0}, y_{0}\right)}(f)=\sum_{n=0}^{N-1} Q_{n}(f) \frac{e^{-j \frac{\omega}{c} r_{d n}}}{r_{d n}}
$$

Segundo Belloch et al. (2013), o operador WFS (representado por $Q_{n}(f)$, onde $f$ neste caso representa a frequência do sinal de áudio) da $n$-ésima caixa de som é dado pela equação 2.8 , onde $\tau_{n}\left(r_{p}\right)$ e $A_{n}\left(r_{p}\right)$ são os fatores de atraso e amplitude, respectivamente. Ambos dependem da distância $r_{p}$, entre a posição da fonte sonora virtual (representada pelo piano) à $n$-ésima caixa de som. O filtro $H(f)$ equivale à expressão $K \sqrt{j f}$, onde $K$ é uma constante que depende da 


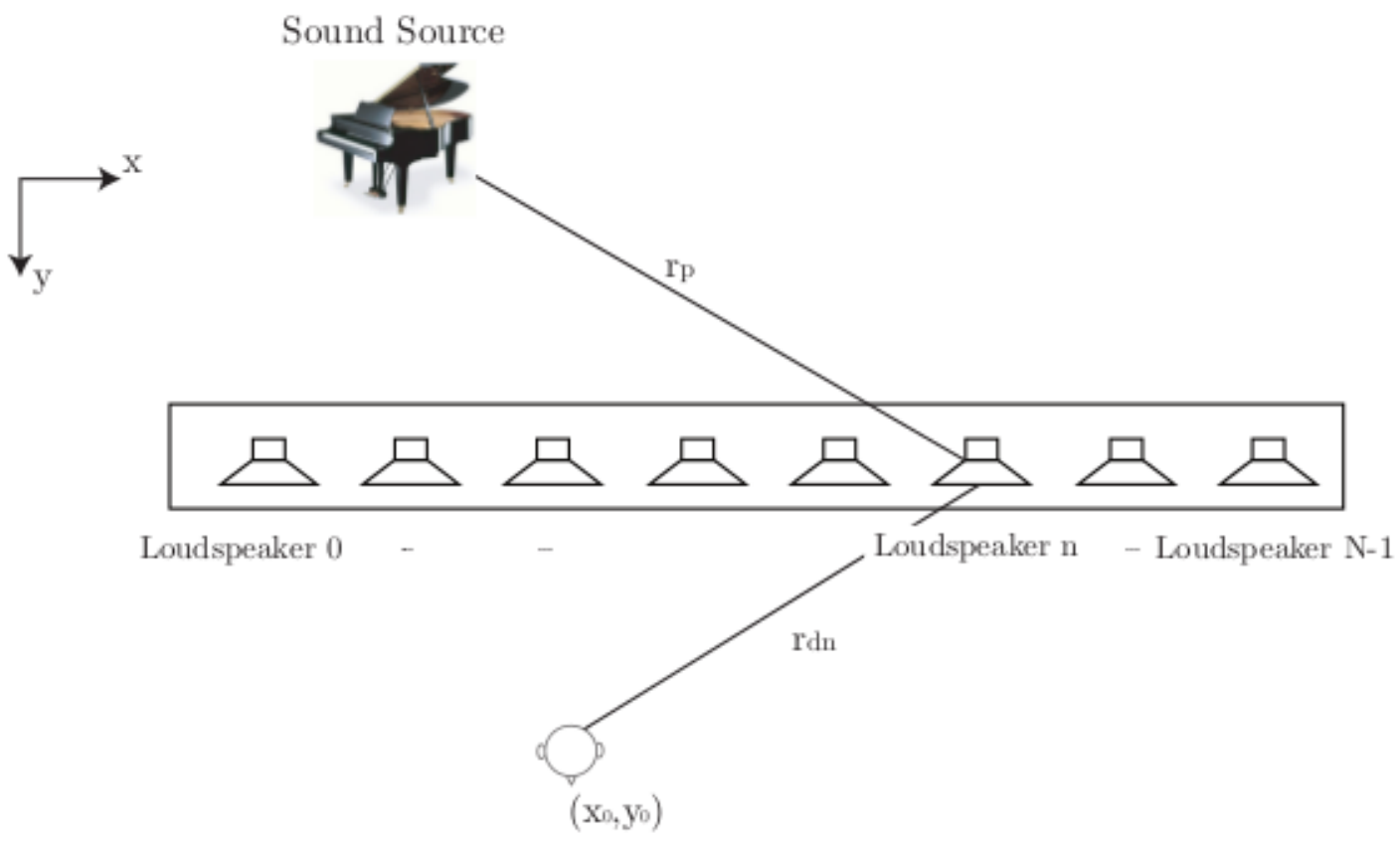

Figura 4 - Um sistema de WFS com N alto-falantes, onde são destacadas as distâncias $r_{p}$, entre fonte sonora e alto-falante $n$, e $r_{d n}$ entre alto-falante $n$ e ouvinte (BELLOCH et al., 2013).

geometria da configuração. Este termo vem da integral de Rayleigh I. O som da fonte sonora virtual é representada por $X(f)$.

$$
Q_{n}(f)=X(f) \cdot H(f) \cdot e^{-j \omega \tau_{n}\left(r_{p}\right)} \cdot A_{n}\left(r_{p}\right)
$$

Como base para a versão de operador escrito neste projeto, foram estudadas as versões apresentadas em Baalman (2008), Ranjan e Gan (2012), Spors, Rabenstein e Ahrens (2008) e Wittek (2007, pg. 58).

\subsubsection{O operador WFS segundo Ranjan e Gan}

A figura 5 descreve a geometria do sistema para WFS proposto por Ranjan e Gan (2012). O plano onde estão o objeto sonoro (fonte), as caixas de som e o ouvinte, indicados por $S, n$ e $R$, respectivamente, tem coordenadas definidas pelos eixos $x$ e $z$.

A equação 2.9 mostra o operador WFS proposto por Ranjan e Gan (2012).

$$
D_{w f s}(n, \omega)=S(\omega) \sqrt{\frac{j \omega}{2 \pi}} \sqrt{\frac{\left|Z_{R}-Z_{n}\right|}{\left|Z_{R}-Z_{S}\right|}} \cos \left(\theta_{S, n}\right) \frac{e^{-j \frac{\omega}{c}\left|r_{n}-r_{S}\right|}}{\sqrt{\left|r_{n}-r_{S}\right|}}
$$




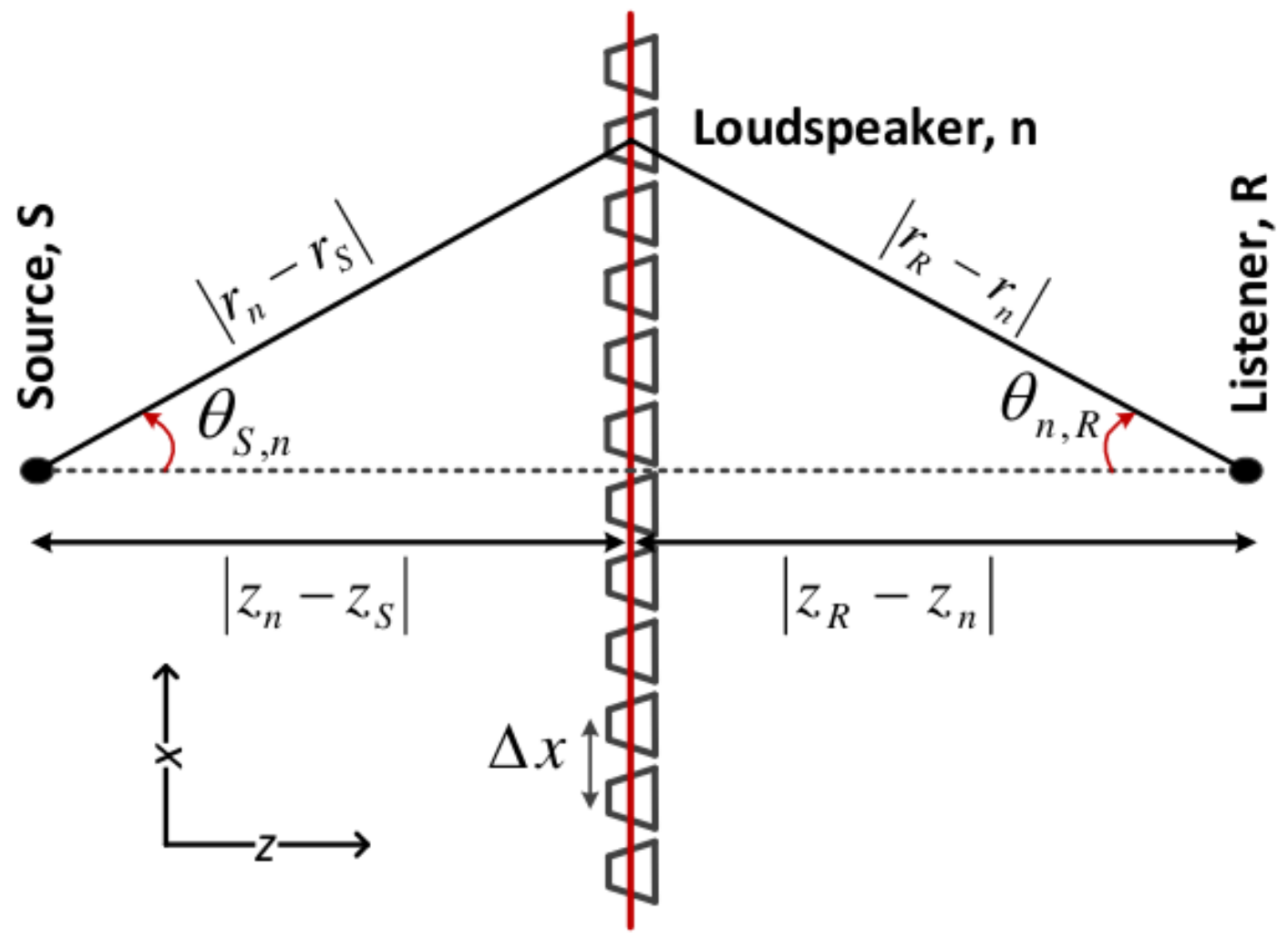

Figura 5 - Descrição geométrica do sistema para WFS (RANJAN; GAN, 2012).

\subsubsection{O operador WFS segundo Wittek}

A figura 6 descreve a geometria do sistema para WFS proposto por Wittek (2007, pg. 58).

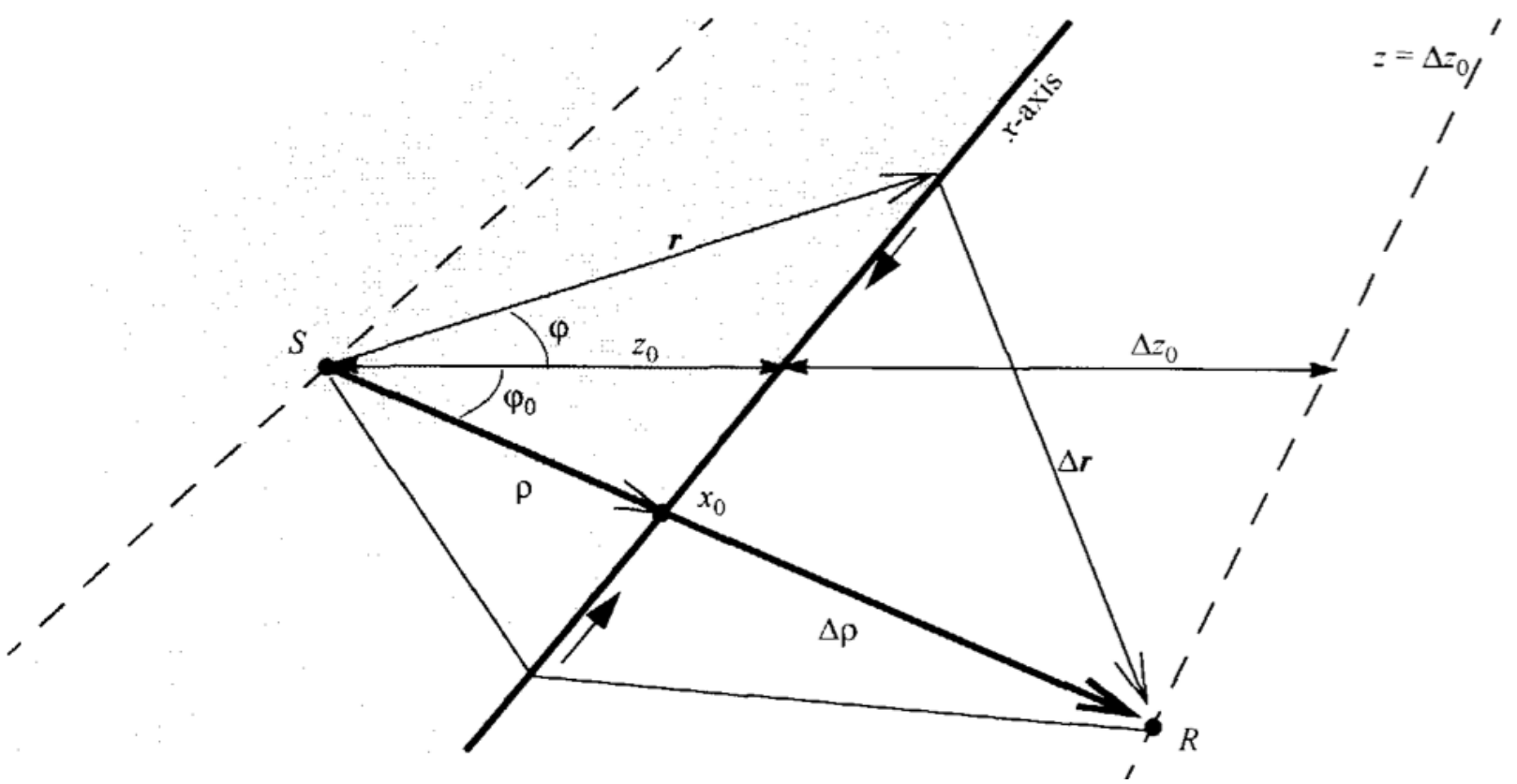

Figura 6 - Fonte virtual reproduzida num plano horizontal por uma matriz linear WFS. Wittek em seu trabalho faz referência a esta figura que está na tese de doutorado de E. Verheijen (VERHEIJEN, 1998, pg. 41). 
Na figura 6, o plano onde estão o objeto sonoro (fonte), indicado por $S$, e o ouvinte, indicado por $R$, tem coordenadas definidas pelos eixos $x$ e $z$.

A equação 2.10 mostra o operador WFS proposto por Wittek (2007, pg. 58).

$$
Q_{m}(r, \omega)=S(\omega) \sqrt{\frac{j k}{2 \pi}} \sqrt{\frac{\Delta Z_{0}}{Z_{0}+\Delta Z_{0}}} \cos \phi \frac{e^{-j k r}}{\sqrt{r}}
$$

2.2.3 O operador WFS segundo Spors, Rabenstein e Ahrens

A equação 2.11 mostra o operador WFS proposto por Spors, Rabenstein e Ahrens (2008, seção 4.4).

$$
D_{\text {trad }}\left(\vec{x}_{0}, \omega\right)=S(\omega) \sqrt{\frac{j \frac{\omega}{c}}{2 \pi}} \sqrt{\frac{\left|\vec{x}_{r e f}-\vec{x}_{0}\right|}{\left|\vec{x}_{S}-\vec{x}_{0}\right|+\left|\vec{x}_{r e f}-\vec{x}_{0}\right|}} \cos \phi \frac{e^{-j \frac{\omega}{c}\left|\vec{x}_{S}-\vec{x}_{0}\right|}}{\sqrt{\left|\vec{x}_{S}-\vec{x}_{0}\right|}}
$$

onde $\vec{x}_{S}$ é a posição do objeto sonoro $\vec{x}_{0}$ é a posição do alto-falante, $\cos \phi=\frac{-y_{S}}{\left|\vec{x}_{S}-\vec{x}_{0}\right|}$ e $\vec{x}_{r e f}$ é a posição da linha de referência.

\subsubsection{O operador WFS segundo Marije Baalman}

Segundo Baalman (2008), o operador é expresso pela equação 2.12, seguindo os parâmetros ilustrados na figura 7.

$$
Q_{\Psi}\left(x, y_{0}, \omega\right)=S(\omega) \sqrt{\frac{j k}{2 \pi}} \sqrt{\frac{\Delta r_{0}}{\Delta r_{0}+r_{0}}} \cos \left(\phi_{0}\right) \frac{e^{-j k r_{0}}}{\sqrt{r_{0}}}
$$

Onde $x$ é a abscissa da posição da caixa de som, $k=\frac{\omega}{c}$ é o número de onda, $S(\omega)$ é o sinal de áudio, $\frac{r_{0}}{c}$ é o fator de atraso, $\sqrt{\frac{1}{2 \pi}} \sqrt{\frac{\Delta r_{0}}{\Delta r_{0}+r_{0}}} \cos \left(\phi_{0}\right) \frac{1}{\sqrt{r_{0}}}$ é o fator de amplitude e $\sqrt{j k}$ é o fator de filtragem.

\subsubsection{Entendendo melhor o operador WFS}

Levando-se em consideração as informações passadas pelas equações 2.9, 2.10, $2.11 \mathrm{e}$ 2.12, é proposta uma versão para o operador WFS (equação 2.13) que tenta unificar e sintetizar o que foi proposto por elas. Estes quatro operadores são praticamente idênticos, se diferenciando basicamente pela escolha das variáveis que representam cada grandeza que tem correspondência nestas quatro versões.

Para a versão de operador proposta, como referência, que pode ser escolhida arbitrariamente, é usado o sistema de coordenadas cartesianas ilustrado na figura 8. Nesta a figura, 


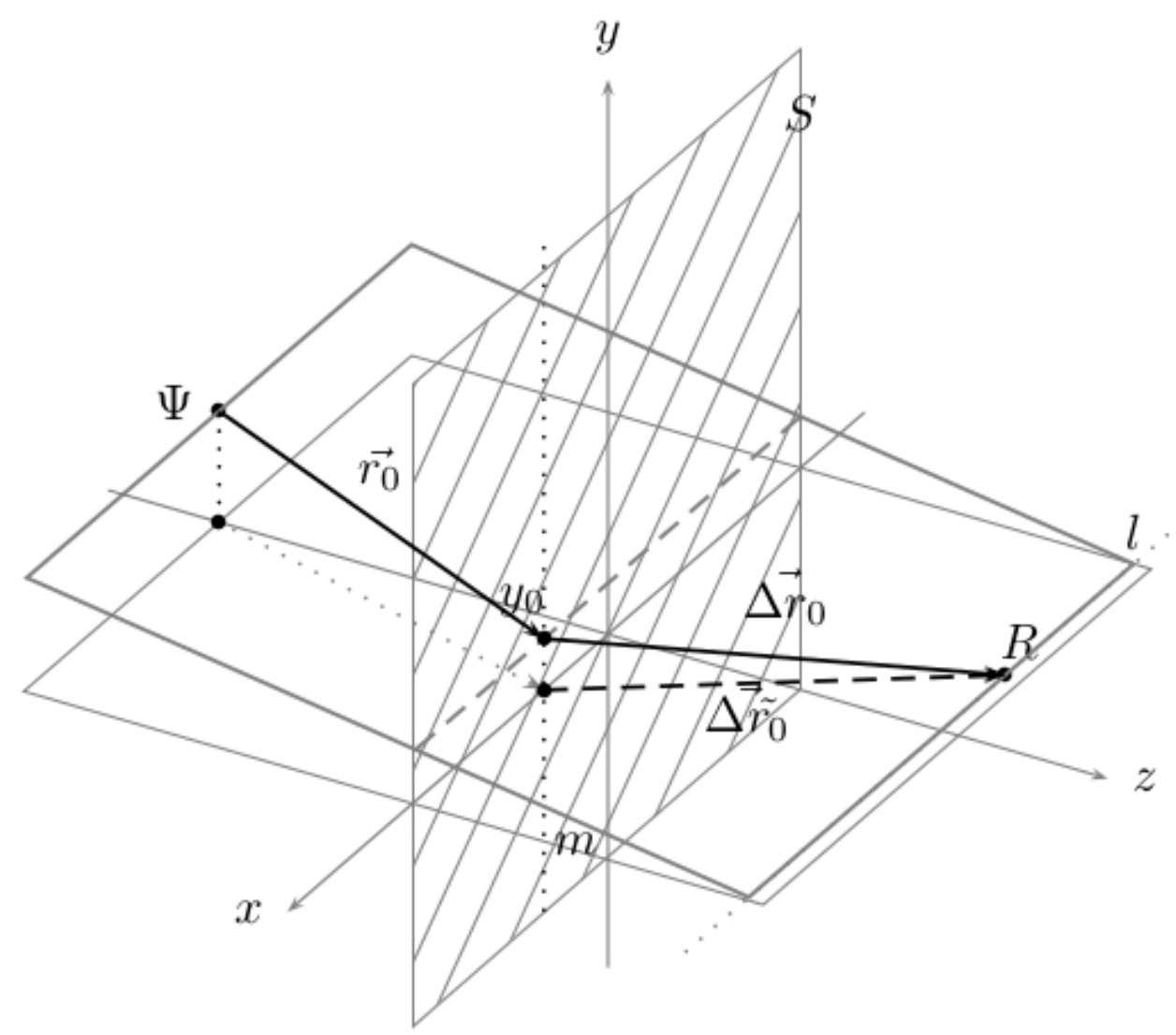

Figura 7 - Parâmetros usados no cálculo feito pelo operador WFS relacionados às posições do objeto sonoro $\psi$, caixas de som $\left(y_{0}\right)$ e linha de referência.

o vetor $\vec{r}_{f, n}$ representa a diferença entre a posição da fonte sonora virtual $(f$, não confundir com frequência que é representada aqui por $\omega)$ e a posição da caixa de som $(n)$, então tem-se $\vec{r}_{f, n}=\left(x_{f}-x_{n}, y_{f}-y_{n}\right)$. O vetor $\vec{r}_{f, r e f}$ é a diferença entre a posição da fonte sonora virtual e a posição de referência para a escuta, que pode ser a linha de referência ou posição de um ouvinte. $\mathrm{O}$ vetor $\vec{r}_{n, r e f}$ é a diferença entre a posição da caixa de som e a posição de referência para a escuta. Nestes casos, foi adotada a linha de referência para que os cálculos não privilegiem a escuta em um ponto, levando em consideração toda a área de audição.

$$
D_{W F S}=S_{f} \sqrt{\frac{j \frac{\omega}{c}}{2 \pi}} \sqrt{\frac{\left|\vec{r}_{n, r e f}\right|}{\left|\vec{r}_{f, r e f}\right|}} \cos \theta \frac{e^{-j \frac{\omega}{c}\left|\vec{r}_{f, n}\right|}}{\sqrt{\left|\vec{r}_{f, n}\right|}}
$$

O operador $D_{W F S}$ é usado para determinar como o sinal de áudio $S_{f}$ deve ser processado para que ocorra a WFS. É construído em função das posições dos ouvintes e da posição de sua correspondente cada caixa de som, ou seja, cada caixa de som tem seu próprio operador. Além disso, deve receber as informações da posição das fontes sonoras em tempo real. Segundo Baalman (2008), $\sqrt{j \frac{\omega}{c}}$ é o fator de filtragem e, de acordo com Wittek (2007, pg. 59), corresponde a um filtro de amplitude em função da frequência, com ganho de $3 \mathrm{~dB}$ por oitava.

Além do fator de filtragem, tem-se no restante da equação do operador WFS os cálculos 


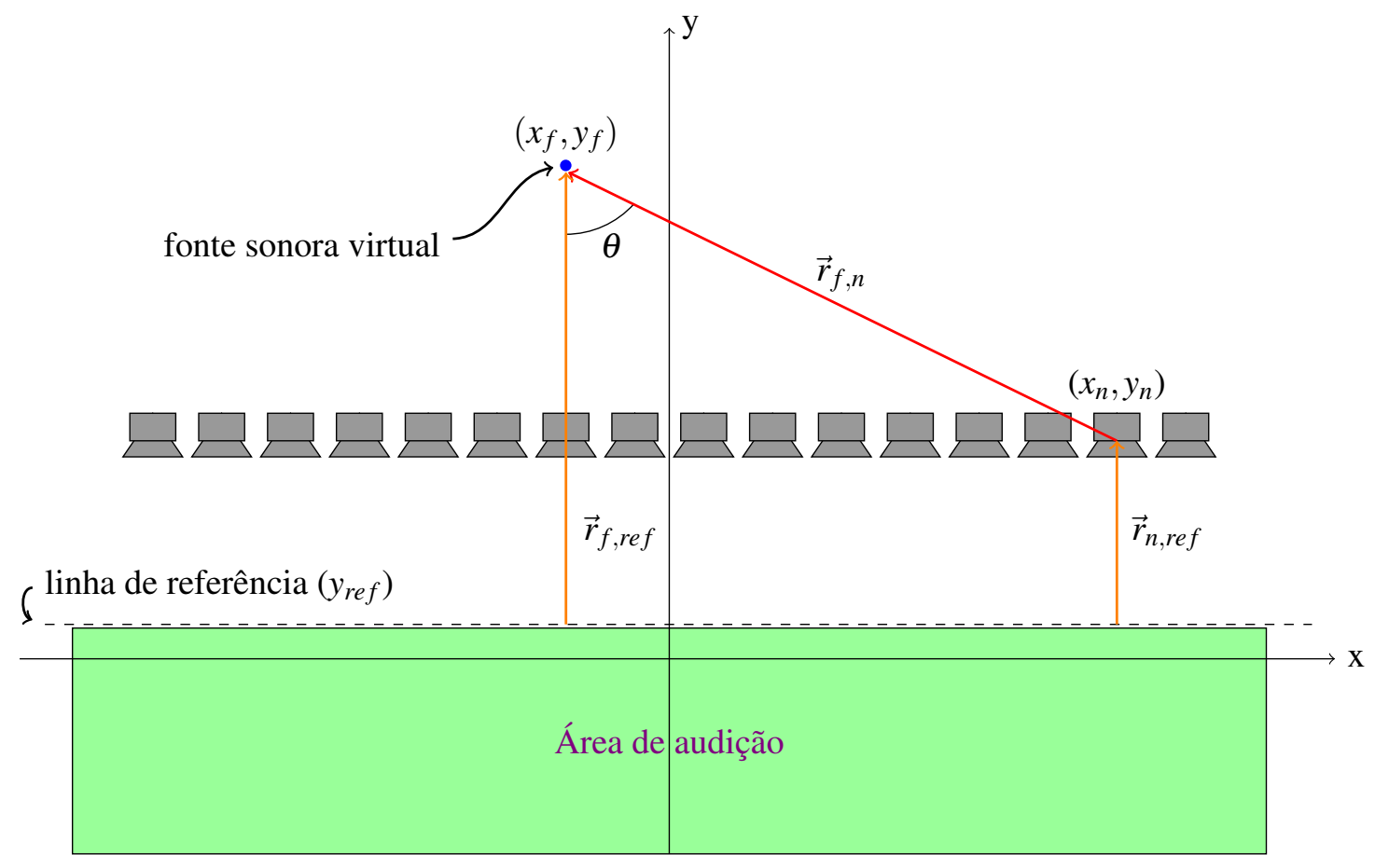

Figura 8 - Sistema de coordenadas cartesianas e vetores usados no operador WFS.

de amplitude e atrasos do sinal de entrada. Desta forma, este operador pode ser expresso pela equação 2.14 , onde os índices $f$ e $n$ se referem à fonte sonora e à n-ésima caixa de som, respectivamente.

$$
D_{w f s}=S_{f} \sqrt{j \frac{\omega}{c}}\left(A_{f, n}\right) e^{-j \frac{\omega}{c} d_{f, n}}
$$

sendo $A_{f, n}$ o fator de amplitude.

\subsubsection{Cálculo das amplitudes}

A partir das equações 2.13 e 2.14, conclui-se que o cálculo do fator de amplitude para o sinal de áudio pode ser feito usando-se a equação 2.15 .

$$
A_{f, n}=\sqrt{\frac{1}{2 \pi}} \sqrt{\frac{\left|\vec{r}_{n, r e f}\right|}{\left|\vec{r}_{f, r e f}\right|}} \cos \theta \frac{1}{\sqrt{\left|\vec{r}_{f, n}\right|}}
$$

Conforme a discussão sobre o referencial ilustrado na figura 8, temos que $\cos \theta=\frac{y_{f}-y_{n}}{\left|\vec{r}_{f, n}\right|}$, então o fator de amplitude pode ser calculado pela equação 2.16.

$$
A_{f, n}=\sqrt{\frac{1}{2 \pi}} \sqrt{\frac{\left|\vec{r}_{n, r e f}\right|}{\left|\vec{r}_{f, r e f}\right|}}\left(\frac{y_{f}-y_{n}}{\left|\vec{r}_{f, n}\right|}\right) \frac{1}{\sqrt{\left|\vec{r}_{f, n}\right|}}
$$




\subsubsection{Cálculo dos atrasos}

Segundo Baalman (2008), o cálculo dos delays (atrasos), que cada caixa de som $n$ deve efetuar ao transmitir sua contribuição sonora no domínio da frequência, é dado por $e^{-j \frac{\omega}{c}\left|\vec{r}_{f, n}\right|}$. Considerando o índice $f$ representando a fonte sonora e $\vec{r}_{f, n}$ sendo a diferença vetorial entre as posições da fonte sonora e da n-ésima caixa de som e $r_{f, n}$ seu valor escalar, para o domínio do tempo, é usada a equação 2.17 .

$$
t_{f, n}=\frac{r_{f, n}}{c}
$$

\subsection{Aplicações de Wave Field Synthesis}

Nos sistemas mais usados nas residências, como os home-theaters, para que se possa obter o resultado de espacialização oferecido em cada um deles, é necessário que o ouvinte se posicione num determinado ponto entre as caixas de som, normalmente ficando numa poltrona fixa. A maioria das técnicas de sonorização tem uma região de escuta muita pequena (hot spot), pois a mudança da posição do ouvinte muda a percepção do ponto onde o som está localizado. Se várias pessoas, ao mesmo tempo, tentarem ouvir o som gerado por uma destas técnicas, não poderão ficar nesta pequena área e não ouvirão o resultado da projeção do som de forma satisfatória. Em aplicações de WFS, cada ouvinte deve ter a mesma sensação de distribuição e percepção das fontes sonoras no espaço de audição. A técnica WFS se diferencia por permitir a localização do objeto independentemente da posição do ouvinte, de forma semelhante ao que ocorre com a projeção de imagens nos filmes em 3D.

Segundo Lopez et al. (2010), sistemas de videoconferência têm como objetivo fornecer uma maneira de realizar reuniões, sem a necessidade de ter a presença física dos participantes. No entanto, o senso de realismo alcançado por esses sistemas tradicionais é geralmente longe do esperado pelas pessoas envolvidas na comunicação. A introdução de WFS pode contribuir para o aumento do realismo em sistemas 3D de videoconferência.

A utilização de WFS é imediata em salas de cinema, nos jogos de computador e em eventos teatrais. A espacialização sonora por WFS pode ser aplicada para aumentar as possibilidades musicais, podendo ser utilizada em conjunto com imagens ou objetos móveis. Músicos e maestros teriam a opção de realizar ensaios em meio a orquestras virtuais, pois esta técnica facilita discriminar o som de cada instrumento, mesmo quando vários deles são ouvidos simultaneamente. Produtores em estúdio de gravação, compositores ou arranjadores poderiam pensar em diferentes formas de arranjos ou orquestrações musicais, em função da posição em que gostariam que cada som fosse reproduzido. 


\subsection{Projetos e trabalhos de referência}

A leitura de vários trabalhos ajudou a traçar uma visão teórica geral sobre WFS e suas aplicações práticas. A seguir são comentados projetos de referência que faziam parte deste levantamento.

\subsubsection{O projeto CARROUSO}

Segundo Baalman (2008) e Brandenburg, Brix e Sporer (2004), o CARROUSO (Creating, Assessing and Rendering in Real Time Of high quality aUdioviSual envirOnments in MPEG-4 context) foi um projeto financiado pela Comunidade Européia e realizado de janeiro 2001 até junho de 2003, objetivando o desenvolvimento de áudio 3D, com a construção de um sistema de WFS para a renderização de cenas sonoras, bem como desenvolver técnicas para gravá-las. Para sua realização se juntaram, em colaboração, empresas privadas, institutos de pesquisa e universidades, como Delft University, France Telecom R\&D, IRCAM, e Fraunhofer Institute IIS AEMT.

\subsubsection{Casa del Suono}
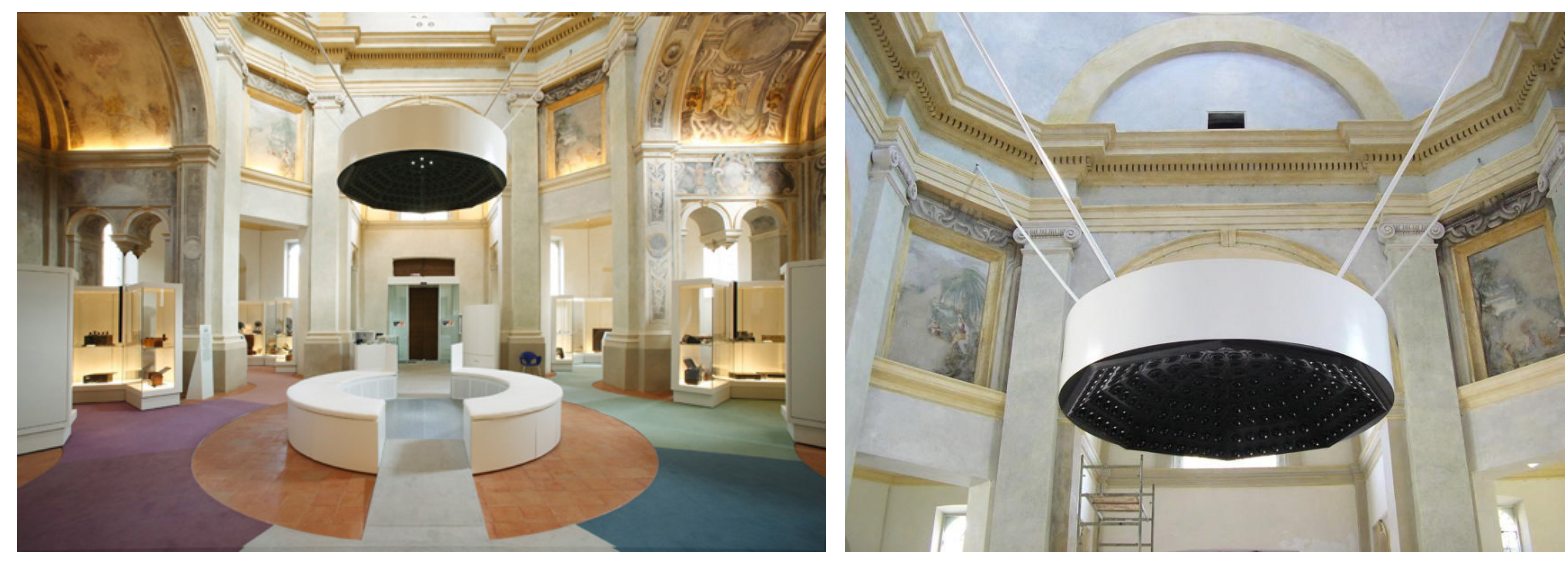

Figura 9 - Lampadario Acustico. Fotos retiradas de http://www.casadelsuono.it/project/default.asp

Segundo Baalman (2008), na Casa del Suono² em Parma na Itália, foram instalados dois sistemas baseados em WFS. O primeiro deles para equipar um auditório e o segundo é uma matriz esférica, montado como um lustre, conhecido como Lampadario Acustico (figura 9). Usado para formar fontes sonoras pontuais bem focalizadas, o Lampadario consegue espacializá-las com deslocamento em tempo real no espaço sob a cúpula, em todas as três dimensões. Um computador, que usa o sistema operacional Debian GNU/Linux, faz o processamento dos sons, que serão reproduzidos pelos alto-falantes, oriundos da entrada da placa de som, ou de qualquer tipo de software que usa o servidor de áudio Jack Audio Connection Kit (JACK) ${ }^{3}$, um programa

2 Acesso em: Casa del Suono - Comune di Parma <http://www.casadelsuono.it/project/default.asp $>$

3 Acesso ao site do projeto em <http://jackaudio.org/> 
que, por meio de um servidor de áudio, interliga os programas de áudio e os conecta às entradas e saídas de hardware disponíveis. O controle da posição de cada fonte pode ser feito via Open Sound Control ou MIDI.

Martino Traversa compôs uma peça de nome NGC 353 para a inauguração da Casa del Suono. A execução desta composição cria aos espectadores a sensação de que podem tocar os sons que dançam ao redor e acima da cabeça de cada ouvinte (BAALMAN, 2008).

\subsubsection{WFS do IRCAM}

Segundo Baalman (2008), foi instalado no IRCAM ${ }^{4}$ em Paris (França), em 2008, um sistema WFS equipado com 128 alto-falantes. Este sistema é combinado com um outro sistema para a captura de movimento com câmaras de infravermelhos. Este equipamento é usado para experimentar novos métodos de espacialização para a criação musical e para os experimentos científicos com a realidade virtual e cognição espacial. O IRCAM colaborou com o projeto CARROUSO e nos últimos anos estabeleceu parceria com a empresa suíça Sonic Emotion, para desenvolver sistemas de espacialização baseados em WFS.

\subsubsection{WFS da Technical University - Berlin}

A Technical University de Berlim, Alemanha, entre 2006 e 2007 lançou um projeto para equipar um de seus auditórios usando um sistema WFS, com um total de 840 canais de áudio. O sistema é controlado pelo software de código aberto sWONDER proposto por Baalman et al. (TU Berlin, 2007). O programa é controlado via Open Sound Control (OSC), possibilitando a comunicação com outros sistemas, além disso, permite ao usuário definir o movimento das fontes sonoras.

\subsubsection{IOSONO}

A plataforma comercial IOSONO ${ }^{5}$ é o resultado do emprego da técnica de WFS para a sonorização espacial de amplos espaços, como cinemas e teatros. O sistema é o resultado de anos de pesquisa e desenvolvimento de diversas universidades europeias, e foi aperfeiçoado pelo Instituto Fraunhofer, da Alemanha. Reporta-se desde 2003, há um cinema de 100 lugares em Ilmenau (Alemanha) equipado com 198 alto-falantes. O sistema tem sido desenvolvido para aplicações domésticas, sendo comercializadas versões home-theater. Pode-se verificar a aplicação feita em um sistema de sonorização da IOSONO, usando-se tecnologia baseada em WFS, numa versão adaptada da ópera "Neither"6, escrita por Morton Feldman and Samuel Beckett.

\footnotetext{
Institut de Recherche et Coordination Acoustique/Musique. Acesso em: <http://www.ircam.fr $>$ IOSONO, the future of spatial audio. Acesso em: <http://www.iosono-sound.com/>

6 3D Audio Opera Goes International. Acesso em: <http://neitherphase7.wordpress.com/about-neither/ about-neither-by-sven-soren-beyer/>
} 


\section{ESTUDOS INICIAIS PARA DESENVOLVIMENTO DE PROTÓTIPOS}

Como base para o desenvolvimento do programa proposto para este projeto foram levantadas informações buscando-se entender o funcionamento dos programas de referência, através de testes operacionais e da documentação disponível correspondente. A documentação de cada programa serviu para compreender o funcionamento de seus respectivos módulos de algoritmos utilizados, para que pudessem ser determinados aspectos em comum das implementações, resultando numa estratégia de implementação para os módulos de programação desenvolvidos neste trabalho que consistiu na elaboração de diagramas de funcionamento em bloco que ilustram e ajudam a explicar o emprego da técnica de WFS na estrutura de cada programa.

\subsection{Programas de referência para WFS}

A seguir é feita uma análise dos programas de referência pesquisados. As informações levantadas sobre estes programas foram fundamentais como referência para a construção do sistema de WFS proposto.

Foram realizados testes de instalação, configuração e uso de três programas de referência (WFSPlayer de Daniel Salvador, SSR, sWONDER). Também buscou-se avaliar o potencial de exploração da distribuição espacial de elementos sonoros em aplicações e peças musicais auralizadas com WFS e as condições de uso destes programas como framework para possíveis implementações artísticas.

A instalação dos programas SSR e $s W O N D E R$ exigiu um aprendizado considerável sobre os sistemas operacionais baseados em Linux. Houve algumas experiências com as distribuições Ubuntu, Debian, Fedora e Ubuntu Studio. A experiência com estas distribuições mostra que, embora funcionais, têm-se ainda que usar tempo considerável para solucionar problemas de configuração, principalmente com as interfaces de som multicanal, item obrigatório em um sistema que pode empregar dezenas (ou centenas) de canais. Além de seguir o manual de instalação com um número considerável de procedimentos via terminal de comando, deve-se resolver a pendência da falta de várias bibliotecas exigidas pelos programas citados.

Dificuldades com múltiplas instalações de sistemas operacionais e das placas de som, de sistemas auxiliares (como o JACK) e com o setup de matrizes de alto-falantes tornaram a tarefa de realizar os testes mais complexa do que o previsto inicialmente. As seções seguintes resumem os levantamentos realizados sobre os softwares de referência. 


\subsection{1 sWONDER}

O projeto de pesquisa do sWONDER (Wave field synthesis Of New Dimensions of Electronic music in Realtime) iniciou-se em 2003, na TU Berlin, com M. Baalman. Em 2007, para poder ser instalado e usado com muitos canais num grande auditório na TU Berlim, Alemanha, foi reestruturado por uma equipe de desenvolvedores para se adaptar a grandes instalações ficando com uma estrutura distribuída (BAALMAN et al., TU Berlin, 2007). O propósito do projeto é servir de ferramenta para composição musical e apresentações ao vivo.

O programa $s W O N D E R^{1}$ é construído em $\mathrm{C} / \mathrm{C}++$, e também se utiliza de $\mathrm{Qt}^{2}$ para a interface de usuário, patches para Pure Data e plugins VST, roda sob a plataforma Linux e é dividido em alguns programas que podem rodar em diferentes computadores e que podem se comunicar em rede, através do protocolo OpenSoundControl (OSC).

Pode ser configurado para operar com matrizes de alto-falantes linear ou retangular, mas não circular. É necessário modificar os arquivos de configuração para usar o sistema com eficiência. É possível definir parâmetros geométricos da sala virtual que o sistema deve conceber, para que o usuário possa mover fontes virtuais dentro da região definida. Isto também permite aos usuários simular as reflexões do som nas paredes da sala virtual.

O sWONDER opera em realtime e é controlado via JACK. Para diversas funções, como gravação e reprodução de áudio em múltiplos canais, o manual do software sugere a utilização do programa Ardour ${ }^{3}$, uma estação de trabalho de áudio digital multicanal.

É possível escolher entre fontes virtuais pontuais ou fontes do tipo ondas planas com direção definida. As imagens dos objetos sonoros podem se formar atrás, em frente ou sobre a matriz de alto-falantes. O controle do movimento dos objetos sonoros é feita via mouse interagindo com a interface de usuário, com a vantagem de poder optar entre o modo fade out na posição de origem e um fade in na posição de destino ou o modo que tenta movimentar continuamente o objeto, simulando o efeito Doppler. Tanto as cenas sonoras estáticas como as que têm objetos móveis podem ser salvas.

Segundo Belloch et al. (2013), a mudança de posição usando a técnica de crossfade ("fade-out" e "fade-in"), que consiste em incrementar sinal sonoro numa posição e decrementar noutra, usa mais do que o dobro da demanda computacional o que fica muito mais complicado com vários objetos sonoros.

A única instalação do $s$ WONDER bem sucedida foi feita num computador antigo do NEAC (com processador Intel Pentium IV de $2.80 \mathrm{GHz}$ e 1 GB de RAM). Depois da difícil instalação das bibliotecas auxiliares para que o programa pudesse ser compilado, constatou-se que o sistema operacional instalado nesta máquina, Debian 6.0 (32 bits), usa um compilador

\footnotetext{
Para baixar o $s W O N D E R$, deve-se acessar: <http://sourceforge.net/projects/swonder/>.

Qt. Acesso em: <http://qt.digia.com/>

Ardour - the digital audio workstation. Acesso em http://ardour.org/
} 




Figura 10 - GUI do $s$ WONDER. Fonte: <http://retiary.org/idea/idea7/idea_7/marijeb/marije.htm>

$\mathrm{C}++$ em versão anterior aos usados nas outras máquinas com outros sistemas operacionais de 64 bits, como por exemplo o Ubuntu 12.04 LTS. O som do $s$ WONDER foi ouvido quando este computador foi conectado em rede a um computador iMAC (com processador Intel Core 2 Duo de $2.4 \mathrm{GHz}$ e 4 GB de RAM), onde estava instalada a interface Echo Audiofire 12 que suporta 12 canais de áudio, através de uma ponte de áudio com a utilização do servidor JACK. Como a demonstração e os testes com este programa dependiam desta configuração em rede, sua análise mais detalhada foi deixada para o futuro, já que a prioridade ficou com as instalações que utilizavam apenas um computador. A figura 10 mostra a interface gráfica de usuário (GUI) do programa, ilustrando o módulo de composição da cena.

\subsubsection{WFSPlayer de Daniel Salvador}

O WFSPlayer é uma aplicação construída no ambiente de programação Pure Data por César Daniel Salvador Castañeda, ex-pesquisador da Universidad de San Martín de Porres (USMP), Peru, que concedeu o código-fonte do sistema de WFS para esta pesquisa. Trata-se de um conjunto de patches (abstrações) desenvolvidos por ele no $P d$, que são incluídos no patch principal, onde se encontra a interface que pode ser controlada via mouse.

O programa não tem documentação formal nem site de distribuição. Tem um caráter experimental, não tem manual de instruções e quase não existem comentários em seu código-fonte. Foi projetado para um sistema com arranjo de 35 alto-falantes dispostos em uma matriz circular horizontal de 1,5 m de raio. Não é difícil alterar seus parâmetros, desde que a configuração seja 
sempre circular, uma particular limitação (ou característica) desta implementação. Para outro tipo de configuração, como a linear, são necessárias modificações em quase todo o código e, provavelmente, alguns acréscimos em sua estrutura, o que não foi realizado por estar além do escopo proposto nesta pesquisa.

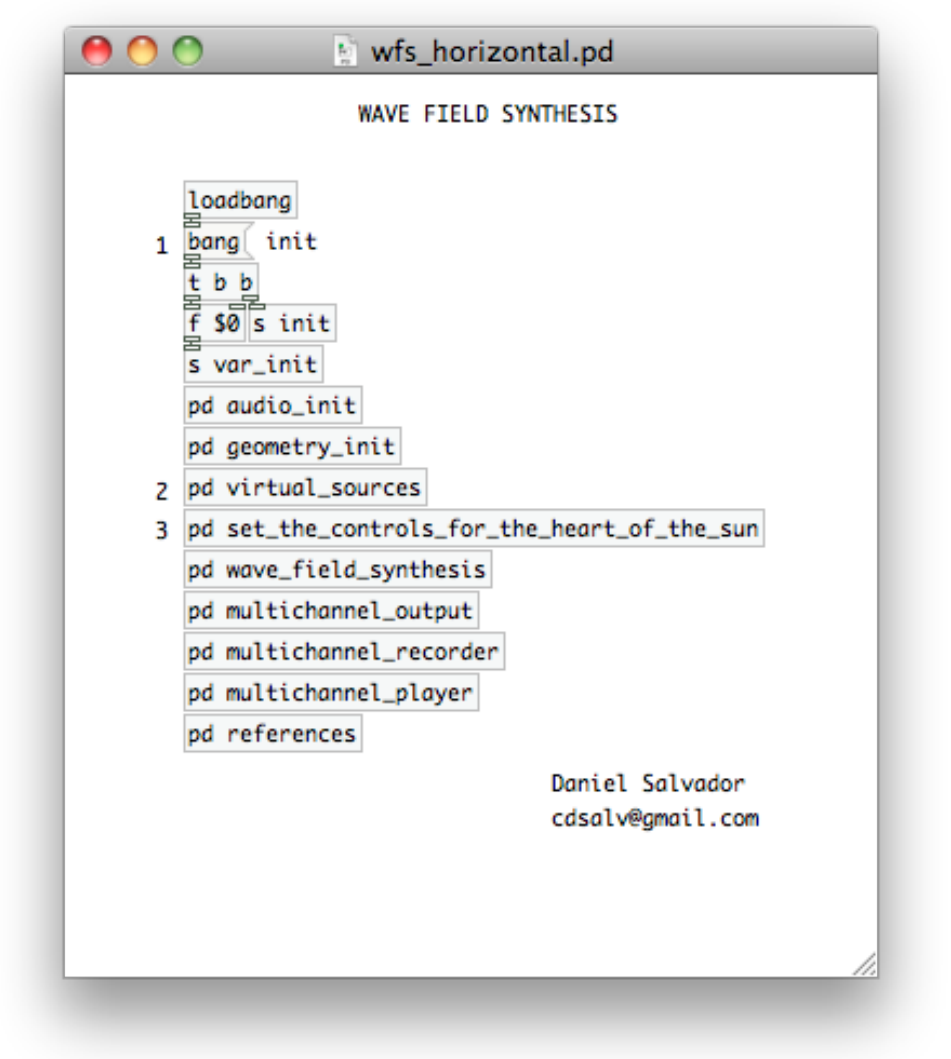

Figura 11 - Patch principal do WFSPlayer, mostrando seus diversos módulos de configuração e uso acessível em subpatches.

Para a instalação inicial do programa, devem ser acrescentadas ao $P d$ as bibliotecas "iemgui" e "bsaylor", que não vêm na pasta enviada pelo pesquisador. Deve ser instalada, como uma nova biblioteca para a $P d$, uma pasta chamada "Wave_field_synthesis", pois nela estão os módulos de processamento. O núcleo é a abstração "wfs_sta_sw_2.5D_driving.pd", onde fica a função operador WFS usada para gerar as ondas sonoras esféricas.

O programa é dividido em alguns blocos, e seu patch principal, “wfs_horizontal.pd”, pode ser visto na figura 11, onde está o programa propriamente dito, começa com "bangs" para disparar os parâmetros iniciais contidos no audio_init, onde estão os parâmetros de áudio para todo o processo. No geometry_init está a distribuição com as coordenadas de cada um dos 35 alto-falantes. No virtual_sources estão os arquivos de audio a renderizar.

$\mathrm{Na}$ interface de controle, que que fica dentro do subpatch pd set_the_controls_for_the_heart_of_the_sun, é necessário controlar o objeto room_sim_2d, colocando o mouse sobre o círculo central (cursor) e movimentá-lo, pressionando a tecla Shift. 
Um tipo de configuração diferente da circular, como a linear, precisaria de modificações em quase todo o código e, provavelmente, alguns acréscimos em sua estrutura, o que fortaleceu a motivação inicial em construir um patch totalmente novo em $P d$, aproveitando as "dicas" de alguns objetos utilizados por Salvador.

Foram feitas algumas alterações para que o programa funcionasse com 6 caixas de som passivas, ligadas a um amplificador de 8 canais, suportadas em pedestais de 1,8 $\mathrm{m}$ de altura e dispostas em uma circunferência de raio $0,5 \mathrm{~m}$.

Com o uso de arquivos de áudio, disponibilizados juntos com código-fonte, foram feitos testes onde percebeu-se que havia um efeito de deslocamento em circulo das fontes, seguindo a distribuição geométrica das caixas. Sabendo-se das limitações da técnica empregada, este efeito foi provavelmente consequência do grande espaçamento entre os alto-falantes.

\subsubsection{SoundScape Renderer (SSR)}

O SoundScape Renderer (SSR) é um programa usado para reprodução de áudio espacial executado em GNU/Linux e Mac OS X. Foi desenvolvido por Jens Ahrens, Matthias Geier e Sascha Spors, um grupo de pesquisa da Universidade Técnica de Berlim, em colaboração com Telekom Inovation Laboratories. O programa foi escrito em linguagem C++ e também utiliza QT, Python e Puredata. A versão atual do projeto é a $0.4 .2^{4}$, lançada em 24 de julho de 2014 . A primeira foi publicada em maio de 2010.

O SSR tem como propósito ser um framework para possíveis implementações de estado da arte com várias técnicas de reprodução de áudio espacial para uso e pesquisa. Ele é capaz de processar cenas acústicas virtuais usando WFS, reprodução bi-aural Head Related Transfer Functions (HRTF), Ambisonics e Vector Base Amplitude Panning (VBAP). Também pode ser configurado para operar com array de alto-falantes linear, retangular ou circular.

Qualquer programa que envia dados de áudio e qualquer entrada do hardware de áudio pode ser conectado ao $S S R$ e pode servir como fonte de entrada, em tempo real. Seu manual recomenda que as conexões de áudio sejam feitas através do JACK. Desta forma, o SSR pode ser interligado a programas como players e gravadores, ou a qualquer programa que obrigatoriamente tenha suporte ao JACK (AHRENS; GEIER; SPORS, 2012).

Como o arquivo disponibilizado para a instalação do programa era pré-compilado para o sistema operacional Mac OS X, sua instalação foi relativamente simples. Antes disso, houve uma tentativa de instalação no computador mais moderno (Intel Core i7-2600), sob o sistema operacional Ubuntu Studio 12.04 LTS (64 bits), que exigia compilar o programa e as bibliotecas necessárias para seu funcionamento, o que tornou esta atividade relativamente complexa. Mesmo depois deste procedimento, sua instalação não foi finalizada para este sistema operacional,

4 Os arquivos para a instalação, bem como o manual de instruções, encontram-se disponíveis em <https:// bitbucket.org/spatialaudio/ssr/downloads> 
apresentando mensagens de erro enquanto estava sendo compilado.

As imagens dos objetos sonoros no SSR podem se formar atrás, em frente ou sobre a matriz de alto-falantes. Pode-se trabalhar com fontes virtuais do tipo pontuais ou com ondas planas, o que leva a impressão que o objeto está bem distante (no infinito). É possível colocar os objetos sonoros em movimento fazendo o controle através do mouse na interface de usuário. A técnica consiste em fazer um fade out na posição de origem e um fade in na posição de destino. Cenas sonoras estáticas podem ser salvas, porém o mesmo não ocorre com as cenas em que os objetos sonoros se movem (AHRENS; GEIER; SPORS, 2012). O programa cria as imagens sonoras que podem ser controladas via interface gráfica de usuário (GUI), que é ilustrada pela figura 12.

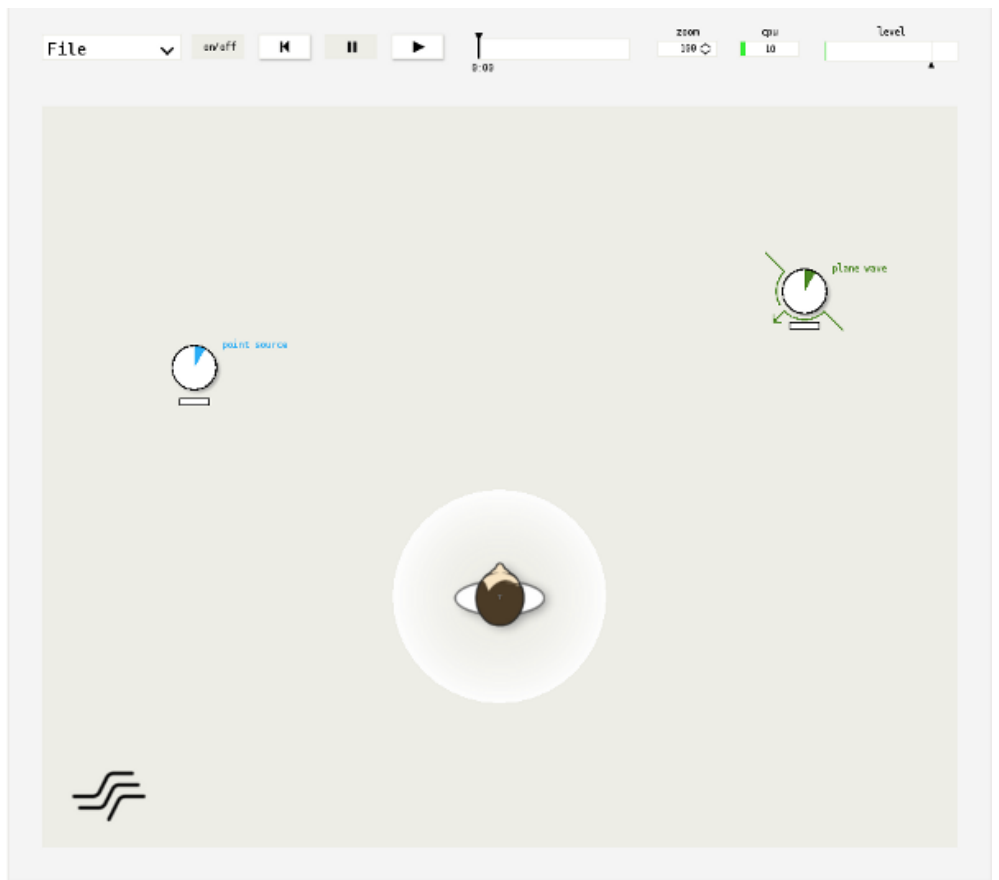

Figura 12 - GUI do SSR para controle das posições das imagens sonoras, com a utlização da técnica bi-aural.

Foram feitas anotações gerais da reprodução de WFS pelo programa SSR, como forma de deixar o equipamento pronto para os testes seguintes. Deveria-se testar as impressões causadas quando as fontes sonoras pontuais encontravam-se paradas atrás ou em frente aos alto falantes, tentando, de forma subjetiva, classificá-las em precisas ou dispersas, quanto à sua focalização. As impressões iniciais foram satisfatórias, com fontes soaram bem localizadas para quaisquer pontos, com focalização precisa.

\subsection{Diagramas de blocos dos programas de referência}

Analisando-se as informações do artigo de Geier, Ahrens e Spors (2008) foi possível derivar um diagrama geral de funcionamento do SSR, conforme mostrado na figura 13. Dadas as 
configurações iniciais da cena (bloco à direita) e é feito o controle das informações do usuário via GUI.

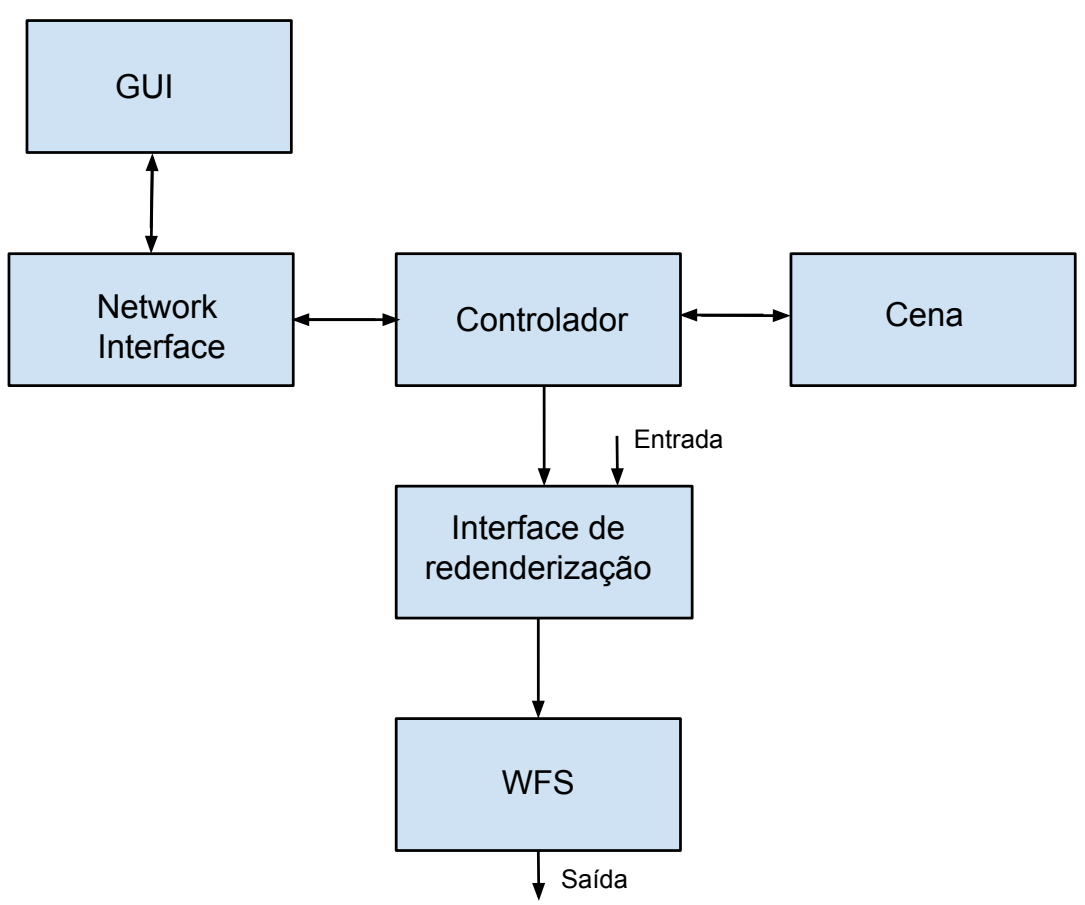

Figura 13 - Diagrama de blocos geral de funcionamento do SSR.

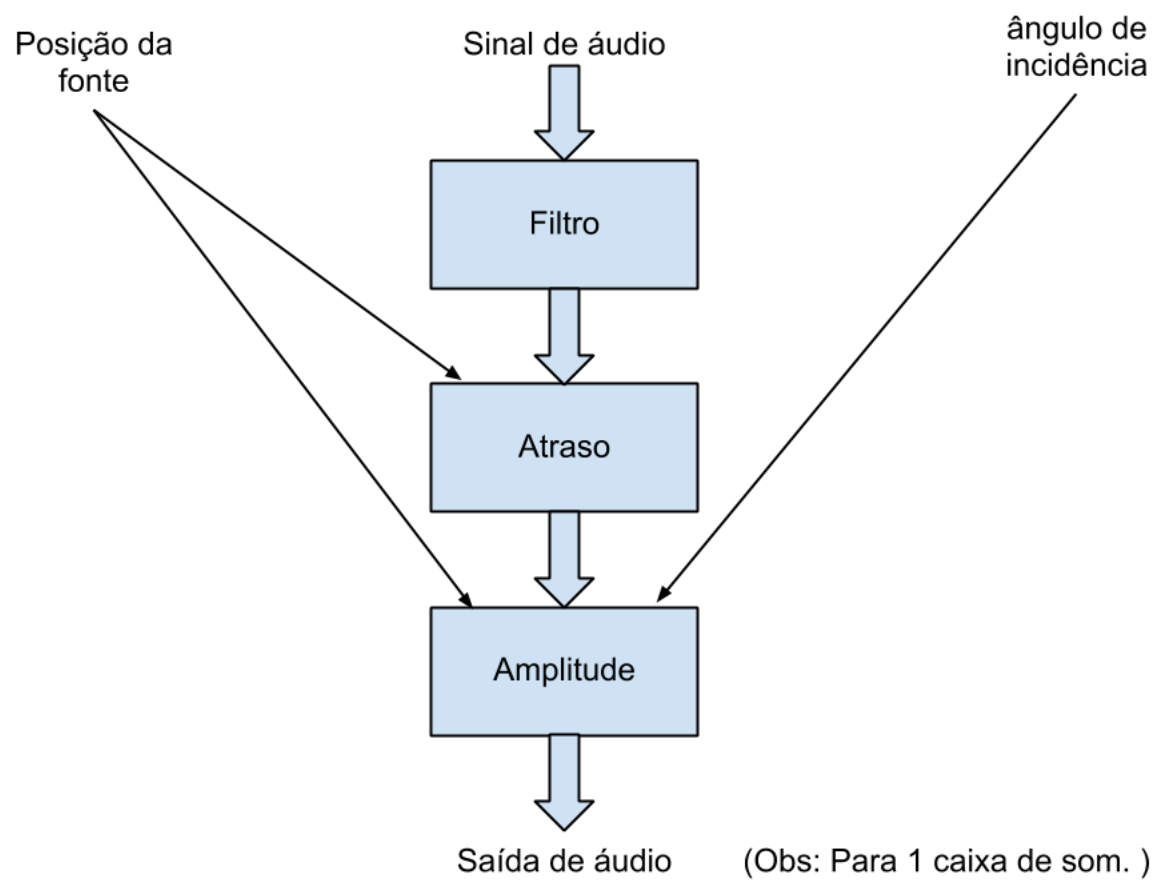

Figura 14 - Fluxo de operações por canal do módulo WFS do SSR.

O módulo WFS do SSR tem o funcionamento mostrado no diagrama da figura 14. O sinal de áudio passa por um filtro de frequências e, com os dados originados na GUI e na descrição da 
cena, adicionam atrasos e diferentes amplitudes do sinal de áudio para cada caixa de som do sistema.



Figura 15 - Diagrama em blocos do sWONDER.

Para o sWONDER, o artigo Baalman et al. (TU Berlin, 2007) permitiu chegar ao diagrama da figura 15, no qual pode-se perceber que cada um dos $\mathrm{N}$ canais tem sua unidade de renderização (Render unit), onde são feitos os cálculos para que ocorra a WFS. O usuário deve enviar os dados de localização dos objetos sonoros para a Unidade de Controle via xWonder (GUI), enquanto o áudio é enviado a partir do bloco Score Player.

Os módulos de WFS (Render unit) do sWONDER têm o funcionamento mostrado no diagrama da figura 16. Este diagrama mostra que são aplicados atrasos correspondentes a cada canal de áudio e que também é simulado um efeito de reverberação. Entretanto, as informações coletadas não mostraram como ocorreria a execução de cálculos para o controle de amplitude de cada sinal de áudio. A região destacada à esquerda mostra $\mathrm{N}$ unidades de Render unit que recebem informações de rede em tempo real, enquanto a região destacada à direita não opera em rede.

A análise do patch em $P d$ do WFSPlayer de Daniel Salvador levou ao diagrama em blocos da figura 17. Na primeira camada do programa é feita a configuração dos parâmetros relativos ao áudio e a distribuição das caixas de som. Na segunda camada é feito o envio dos sinais de áudio para a terceira camada. Esta última recebe as informações enviadas pelo usuário à interface de controle da cena e processa os cálculos para a renderização dos sinais de áudio para o módulo de WFS, que depois são enviados à saída de áudio do sistema. A ausência 


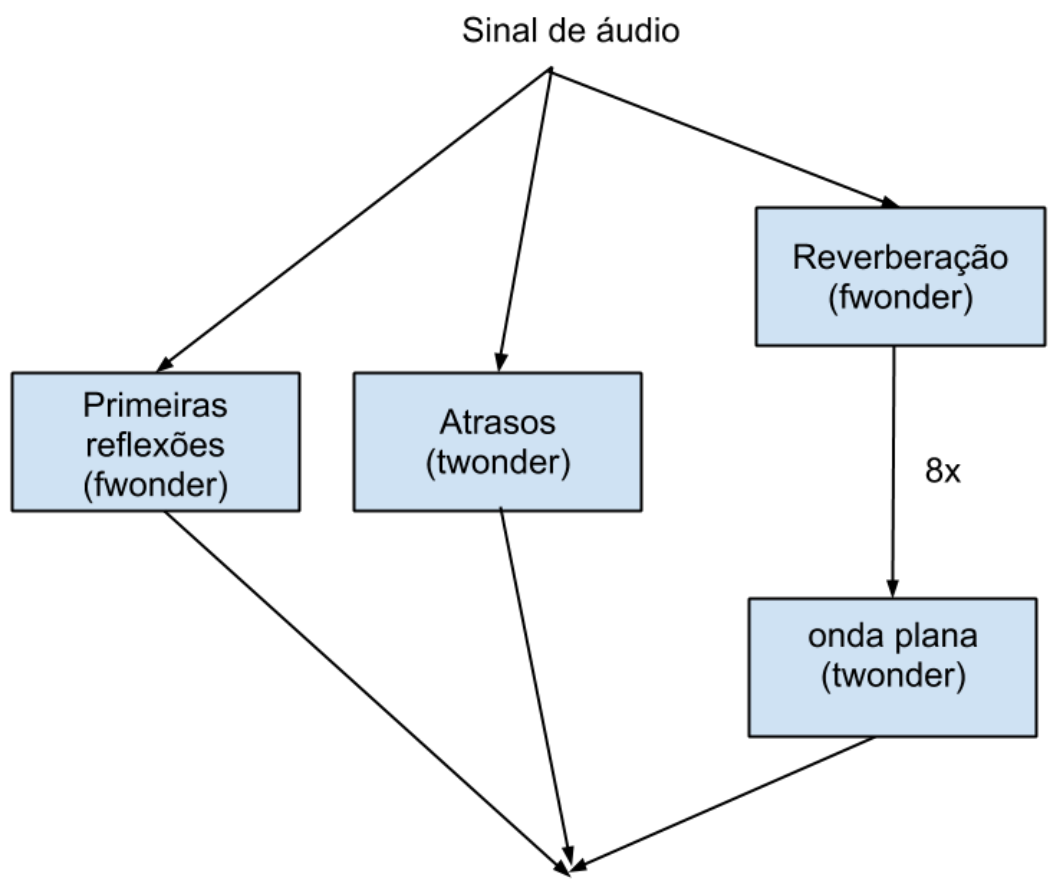

Saída de áudio (Obs: Para 1 caixa de som. )

Figura 16 - Funcionamento do módulo WFS do $s W O N D E R$.

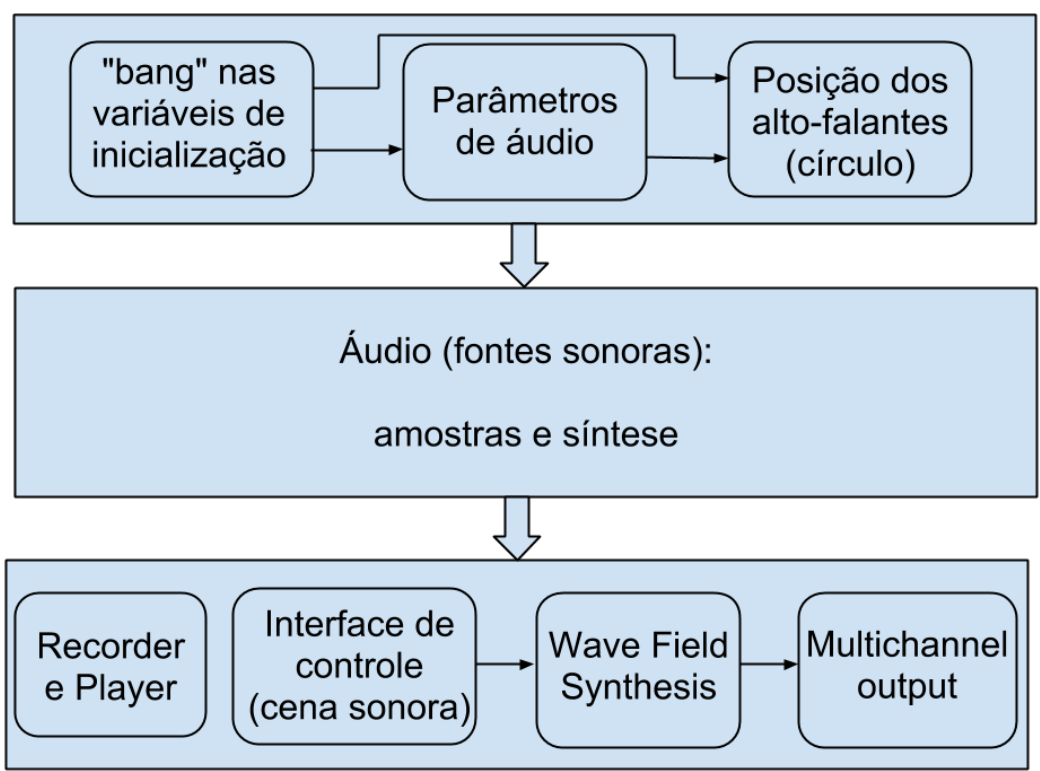

Figura 17 - Diagrama em blocos do WFSPlayer.

de documentação dificultou uma elaboração precisa de um diagrama mostrando claramente o funcionamento do módulo de WFS.

Em todos os diagramas, o módulo WFS correspondente distribui o sinal de áudio de cada um dos canais de entrada a cada caixa, com seus respectivos atrasos, atenuações e filtragens. 


\section{IMPLEMENTAÇÃO E TESTES BÁSICOS}

Neste capítulo são apresentados a formulação de um operador WFS, os protótipos desenvolvidos, os testes realizados, as possibilidades de implementação e a solução encontrada para a sonorização do sistema de espacialização com WFS, articulando-se progressivamente os requisitos e os aspectos de projeto envolvidos.

Esta pesquisa foi realizada nas dependências do Núcleo de Engenharia de Áudio e Codificação Sonora $\left(\mathrm{NEAC}^{1}\right)$, sediado na Universidade de São Paulo.

A metodologia de desenvolvimento para este trabalho incluiu primeiramente a realização de instalação dos softwares de referência e testes preliminares. Parte da metodologia usada foi baseada em ciclos de avaliação dos software de referência, testes de funcionamento, avaliação dos operadores WFS e diagrama de blocos de cada um para avaliar suas funções e operações principais. Depois vieram os projetos de uma implementação em $P d$ que atendesse aos requisitos (arquitetura de referência). As implementações vieram em dois ciclos basicamente (protótipo inicial e final), a cada ciclo comparou-se o funcionamento do protótipo com os software de referência.

\subsection{Operador WFS para o projeto}

Nesta seção é apresentada a formulação de um operador WFS que combina as operações de ponderação e atrasos, de uma forma adequada para uma implementação modular básica. Esta versão, a usada no projeto, é o resultado da adaptação e da aplicação da proposta teórica de operador WFS explicitada na seção 2.2.5.

A figura 3, da seção 2.1, mostra o sistema de coordenadas cartesianas adotado, onde $\left(x_{f}, y_{f}\right)$ são as coordenadas da posição do objeto sonoro (fonte sonora) e a delimitação do espaço de escuta previsto, iniciando-se a partir da linha de referência $\left(y_{r e f}<0\right)$. As caixas de som, dispostas em uma matriz linear, estão sobre o eixo $x$, o que implica em $y_{n}=0$. Conforme é mostrado na equação 2.16, a amplitude do sinal de áudio depende da definição da linha de referência, da posição de cada caixa de som e da posição de cada fonte sonora virtual.

Como $y_{n}>y_{\text {ref }}$ e $y_{f}>y_{\text {ref }}$ tem-se que $\left|\vec{r}_{n, r e f}\right|=-y_{\text {ref }}$ e $\left|\vec{r}_{f, r e f}\right|=y_{f}-y_{\text {ref }}$. Para evitar a divisão por $0 \mathrm{em} \frac{1}{\sqrt{\left|\vec{r}_{f, n}\right|}}$ foi acrescentado um erro de $0,001 \mathrm{~m}$, que é praticamente desprezível em relação as dimensões de $\left|\vec{r}_{f, n}\right|$, então $\frac{1}{\sqrt{\left|\vec{r}_{f, n}\right|}} \simeq \frac{1}{\sqrt{\left|\vec{r}_{f, n}\right|+0,001 m}}$.

Quando na expressão $\left(\frac{y_{f}-y_{n}}{\left|\vec{r}_{f, n}\right|}\right), y_{f}=y_{n}=0$, com exceção de caso em que $x_{f}=x_{n}$, no qual esta expressão deveria resultar em 1, tem-se 0 como resultado, implicando em fatores de

1 NEAC-LSI-EPUSP (Núcleo de Engenharia de Áudio e Codificação Sonora do Laboratório de Sistemas Integrávies da EPUSP). Acesso ao site em: <www.lsi.usp.br/neac> 
amplitude nulos para todas as caixas. Para que nas proximidades das coordenadas de projeção da fonte sonora virtual, a amplitude do sinal de áudio nos alto-falantes não fosse nula foi proposta a seguinte aproximação: $\left(\frac{y_{f}-y_{n}}{\left|\vec{r}_{f, n}\right|}\right) \simeq\left(\frac{y_{f}-y_{n}+10^{-10} m}{\left|\vec{r}_{f, n}\right|+10^{-10} m}\right)$.

A equação 4.1 determina qual deve ser o fator de amplitude no processamento de áudio em cada módulo de WFS do sistema, para cada fonte sonora $f$ e cada canal de saída $n$.

$$
A_{f, n}=\frac{1}{\sqrt{2 \pi}} \sqrt{\frac{-y_{r e f}}{y_{f}-y_{r e f}}}\left(\frac{y_{f}+10^{-10}}{\left|\vec{r}_{f, n}\right|+10^{-10}}\right) \frac{1}{\sqrt{\left|\vec{r}_{f, n}\right|+0,001}}
$$

Onde $x_{n}$ é a abscissa de cada caixa de som (a ordenada $y_{n}=0$ ), $y_{r e f}$ é a ordenada da linha de referência, $\left|\vec{r}_{f, n}\right|=\sqrt{\left(x_{f}-x_{n}\right)^{2}+y_{f}^{2}}$ é a distância entre a posição da fonte virtual (objeto sonoro) e da caixa de som $n, y_{\text {ref }}<0$ (conforme coordenadas mostradas na figura 3 , da seção 2.1).

Conforme ilustrado na figura 2, que está na seção 2.1, os objetos sonoros podem ser projetados em frente, sempre antes da linha de referência, ou atrás dos alto-falantes, sendo possíveis duas possibilidades de criação de imagens sonoras virtuais. Para o operador WFS usado neste projeto, é acrescentado o fator $\frac{y_{f}}{\left|y_{f}\right|}$ que altera a curvatura de onda de acordo com as duas possibilidades explicadas. Como este fator geraria valores de tempo negativo, o que significaria adiantar (antecipar) a emissão da frente de onda em cada alto-falante, é adicionado um atraso de valor $\frac{\left|\vec{r}_{f, n(\max )}\right|}{c}$, onde $\vec{r}_{f, n(\max )}$ corresponde à posição da caixa de som da matriz que está mais afastada da projeção do objeto sonoro. Para o cálculo dos delays (atrasos) correspondentes a cada um dos $N$ canais de áudio é usada a equação 4.2 .

$$
t_{f, n}=\frac{\left|\vec{r}_{f, n(\max )}\right|+\left(\frac{y_{f}}{\left|y_{f}\right|}\right)\left|\vec{r}_{f, n}\right|}{c}
$$

O módulo WFS, que processa o som de uma entrada de áudio para apenas uma saída de som, é mostrado na figura 18. Esta abordagem permite mapear de forma direta o processo que gera o som da n-ésima caixa de som com o sinal da fonte sonora auralizada.

\subsection{Montagem e infra-estrutura básica}

Para a implementação dos códigos e testes do sistema WFS, foram usados:

- um computador com a seguinte configuração: um processador Intel Core i7-2600, de 3.40 GHz, memória de 16 GB e um disco rígido de 1 TB. O sistema operacional instalado é um Linux, Ubuntu Studio 12.04 LTS (64 bits);

- 1 interface de som Echo AudioFire 12, com 12 canais; 


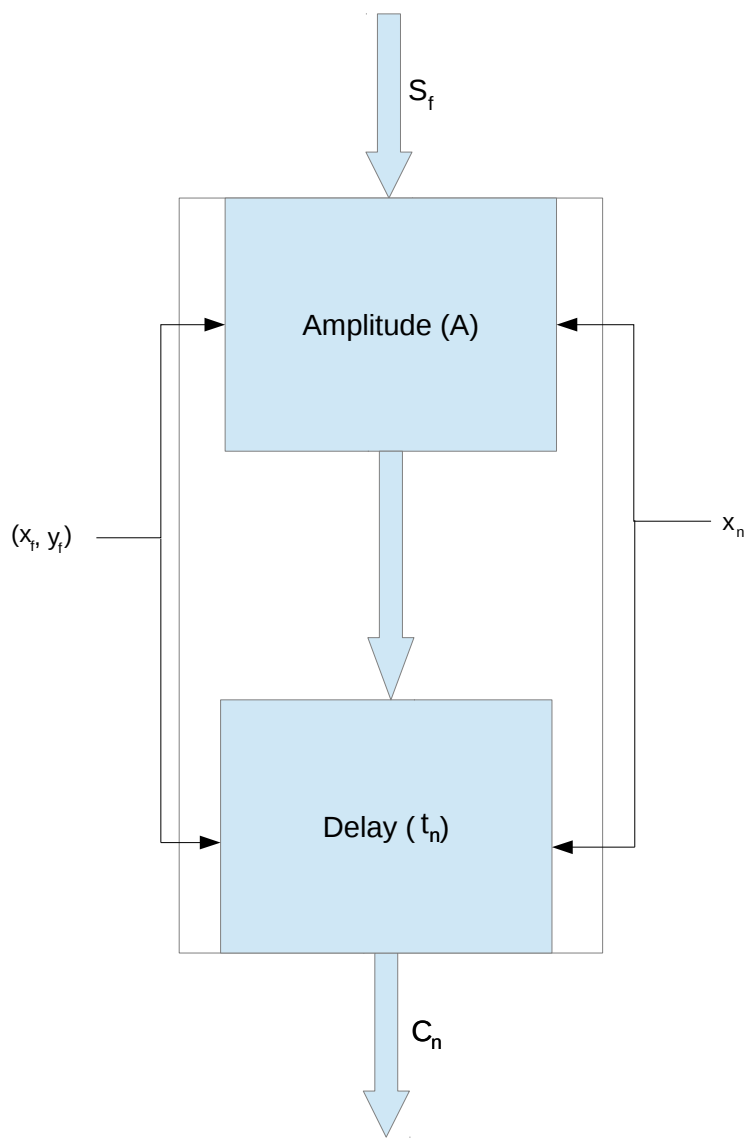

Figura 18 - Módulo básico de WFS que processa o som de uma entrada para uma saída de áudio. A auralização de uma cena com $\mathrm{F}$ objetos sonoros vai requerer $\mathrm{F}$ fluxos de processamento, um para cada fonte sonora.

- 2 interfaces de som M-Audio Delta 1010, totalizando 16 canais de saída analógica (8 canais para cada interface);

- 16 alto-falantes (entre 18 disponíveis) ativos full-range da marca Lando ${ }^{2}$, especificados e fabricados sob encomenda, adquiridos em abril de 2013, especialmente para pesquisa em WFS (Ver item 4.2.1);

- 1 notebook MacBook Pro (13 polegadas, Meados de 2010), com sistema operacional Mac OS X v10.6 (Snow Leopard), uma porta FireWire 800 (até $800 \mathrm{Mbps}$ ), processador Intel Core 2 Duo de 2,4 GHz e 4GB (duas 2 GB SO-DIMMs) de memória DDR3 de 1066 MHz;

- 1 cabo firewire para conectar o MacBook Pro à interface de som Echo AudioFire 12;

- 16 cabos de áudio para a conexão das interfaces de áudio (saídas analógicas P10) às caixas de som (entradas RCA).

Este projeto foi todo desenvolvido com a versão 0.43 .4 do $P d$-extended.

2 Acesso ao site da empresa em <www.lando.ind.br $>$ 
A configuração para a sincronização das duas interfaces de som M-Audio Delta 1010 não foi uma tarefa trivial. Foi preciso ser configurado um arquivo chamado asoundrc, que tem que ser colocado na pasta de usuário (home), no Linux. Após baixar este arquivo e seguir todas as instruções de configuração e instalação encontradas no site do $\operatorname{ALSA}^{3}$ (Advanced Linux Sound Architecture), foi feita a sincronização das placas M-Audio via conexão word-clock, controlada por um servidor de áudio de baixa latência, o software livre jackd (jackdmp versão 1.9.8), que é o servidor do Jack Audio Connection Kit (JACK). Desta forma, foi montada uma interface virtual que soma todos os canais disponíveis de ambas as interfaces físicas. A latência da interface de som foi admitida como constante no referencial de tempo, já que se aplicava igualmente a todos os alto-falantes, não interferindo diretamente sobre a técnica de WFS.

O comando para acionamento e configuração do servidor jackd é:

jackd -R -d alsa -C multi_capture -P multi_playback-r 44100

Para os testes, foi adotada a distância mínima entre as caixas de som, equivalente à largura das mesmas $(\Delta x=0,091 \mathrm{~m})$. A distância máxima poderá ser definida pelo usuário em razão do sistema de alto-falantes que possui e principalmente considerando-se a limitação da frequência máxima (em Hertz) que os sons devem ter para evitar-se o aliasing espacial que pode provocar a dispersão (má formação) das imagens sonoras no espaço daqueles sons com frequências acima do limite previsto. Com o uso da equação 2.5, determinou-se, em função do $\Delta x$ escolhido, a frequência máxima para que o sistema opere sem aliasing espacial em $f_{\max }=$ $3774 \mathrm{~Hz}$.

\subsubsection{Projeto e fabricação de alto-falantes especiais}

Devido à falta de alto-falantes com os requisitos técnicos desejados no mercado, foi realizada parceria com a empresa nacional Lando para a fabricação de protótipos especiais. Após receber as especificações técnicas, a empresa construiu as 18 caixas de som modulares que seriam usadas neste projeto.

A figura 19 mostra 16 caixas formando uma matriz linear (bloco básico de frente com aproximadamente 1,456 m) instalada no laboratório. Para reduzir os reflexos acústicos, painéis absorventes foram colocados atrás da linha de alto-falantes. A área de audição de testes também foi ladeada de painéis absorventes para reduzir a interferência da acústica local.

Estes alto-falantes foram desenvolvidos e comprados com recursos da FAPESP, através do projeto temático MOBILE ${ }^{4}$ (processo no. 08/08632-8). Os protótipos são caixas ativas, que tem dimensões de altura igual a $25 \mathrm{~cm}$, largura de $9,1 \mathrm{~cm}$ e profundidade de $13 \mathrm{~cm}$, com 2 taps de amplificação selecionáveis, utilizam drivers cônicos de 3" full-range, e conectividade analógica RCA-P10 para interfaces digitais M-Audio 1010 e Echo AudioFire12. A montagem

3 AlsaProject. Acesso em: <www.alsa-project.org>

4 MOBILE: Processos Musicais Interativos. Acesso ao site em < http://www.eca.usp.br/mobile/portal/> 


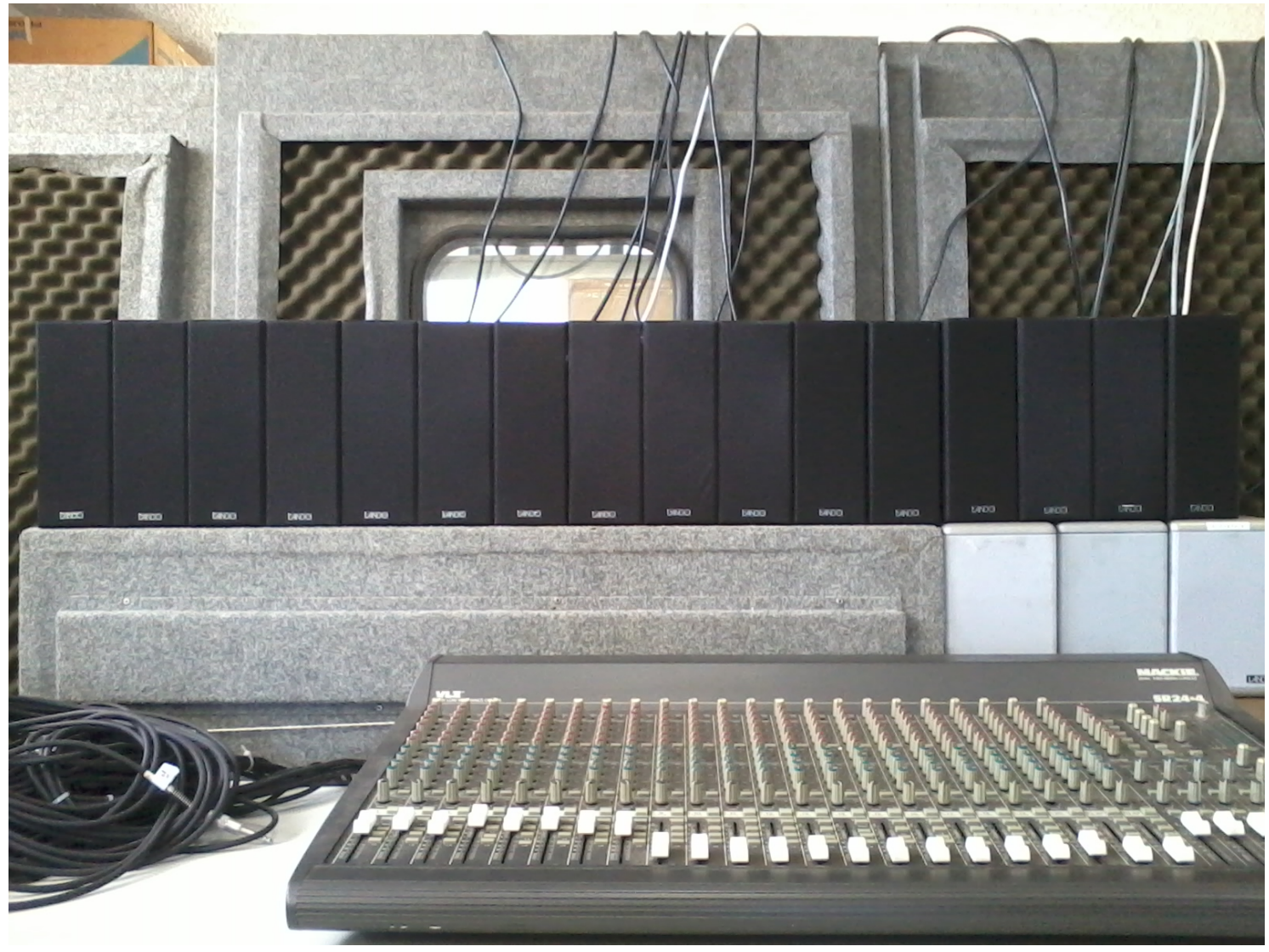

Figura 19 - Caixas acústicas fabricadas pela Lando para o NEAC.

entre os cones (drivers) numa montagem linear é de $0,091 \mathrm{~m}$, o que teoricamente proporciona uma frequência máxima de trabalho $\left(f_{\max }\right)$ de aproximadamente $3774 \mathrm{~Hz}$, conforme abordado na seção 4.2.

\subsection{Protótipo inicial em Pure Data}

Foi desenvolvido e testado em Pure Data um patch com 12 canais para WFS, para ser usado com a interface de som Echo AudioFire 12, dividido em uma implementação computacional modular e flexível para que pudesse ser integrado ao AUDIENCE, como parte do desenvolvimento do protótipo final.

A figura 20 mostra o diagrama geral em blocos, para a aplicação de WFS, que servirá para o desenvolvimento dos protótipos. O (patch) inicial tem estrutura dividida em três módulos independentes: a interface de usuário, o módulo de processamento de WFS e a saída de áudio multicanal. Este programa sintetiza a frente de onda através dos cálculos da amplitude e do atraso do sinal de áudio que chega a cada uma das caixas de som. A seguir é feita a descrição das partes do primeiro protótipo relacionadas, bem como a operação de cada uma delas.

A interface gráfica de usuário, ilustrada na figura 21, possui controles para: posiciona- 


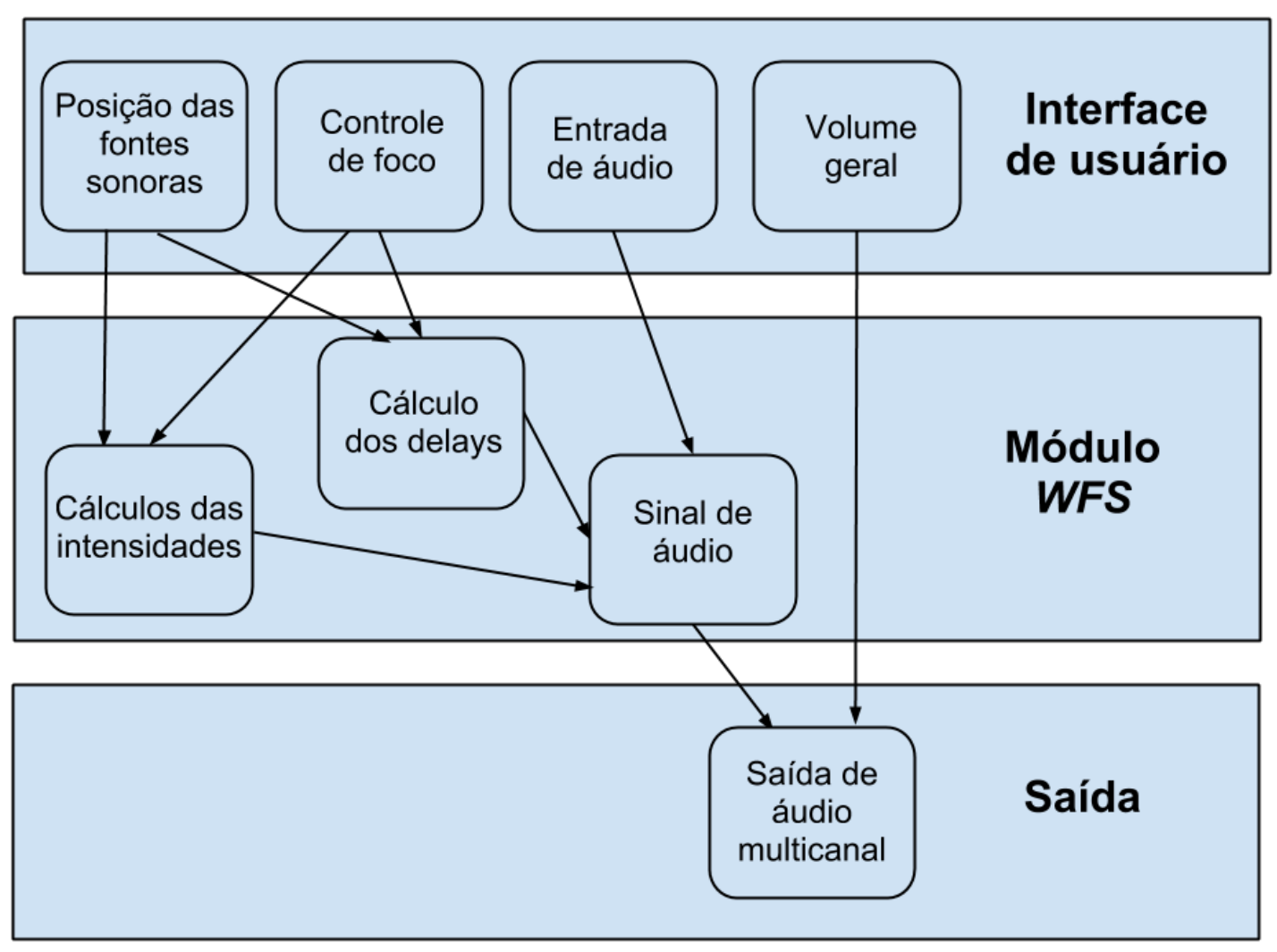

Figura 20 - Diagrama geral em blocos para os protótipos desenvolvidos em Pure Data.

mento da fonte sonora, controle de foco ${ }^{5}$, entrada de áudio e o controle de volume geral do patch. A posição de cada fonte, num máximo de 4, é controlada pelo objeto grid (cada um dos quatro retângulos grandes que estão na parte inferior da figura) que fornece as coordenadas $x$ e $y$ para o módulo de WFS. A entrada de áudio envia o sinal que pode ser de um arquivo de áudio do computador, da entrada de som externa (via interface de som) ou um som sintetizado no próprio patch. O painel no canto superior esquerdo serve para selecionar um arquivo de áudio para reprodução, possuindo quatro sliders de volumes dos canais de entrada. Para mudar a posição dos objetos sonoros deve-se usar o objeto grid (um dos quatro retângulos maiores inferiores), que determina a região real onde se podem mover as fontes sonoras e está delimitada de $-1 \mathrm{~m}$ a 1 m no eixo $x$ e -1 m a 10 m no eixo vertical. Ao lado destes objetos grid estão os medidores de volume dos canais de entrada.

Cada módulo de WFS recebe o sinal de áudio, as coordenadas $x$ e $y$ da posição de cada objeto sonoro e posição de cada caixa de som para calcular e aplicar cada delay (atrasos) e intensidade de som do sinal de áudio para cada caixa de som da matriz. A figura 22 mostra os 12 módulos WFS, um para cada canal, desenvolvidos no protótipo em Pure Data para um objeto sonoro (uma entrada de áudio).

A saída de áudio multicanal recebe o áudio dos doze canais e os envia à saída de som

$5 \quad$ Esta ideia está em desenvolvimento e é descrita na seção 5.3 


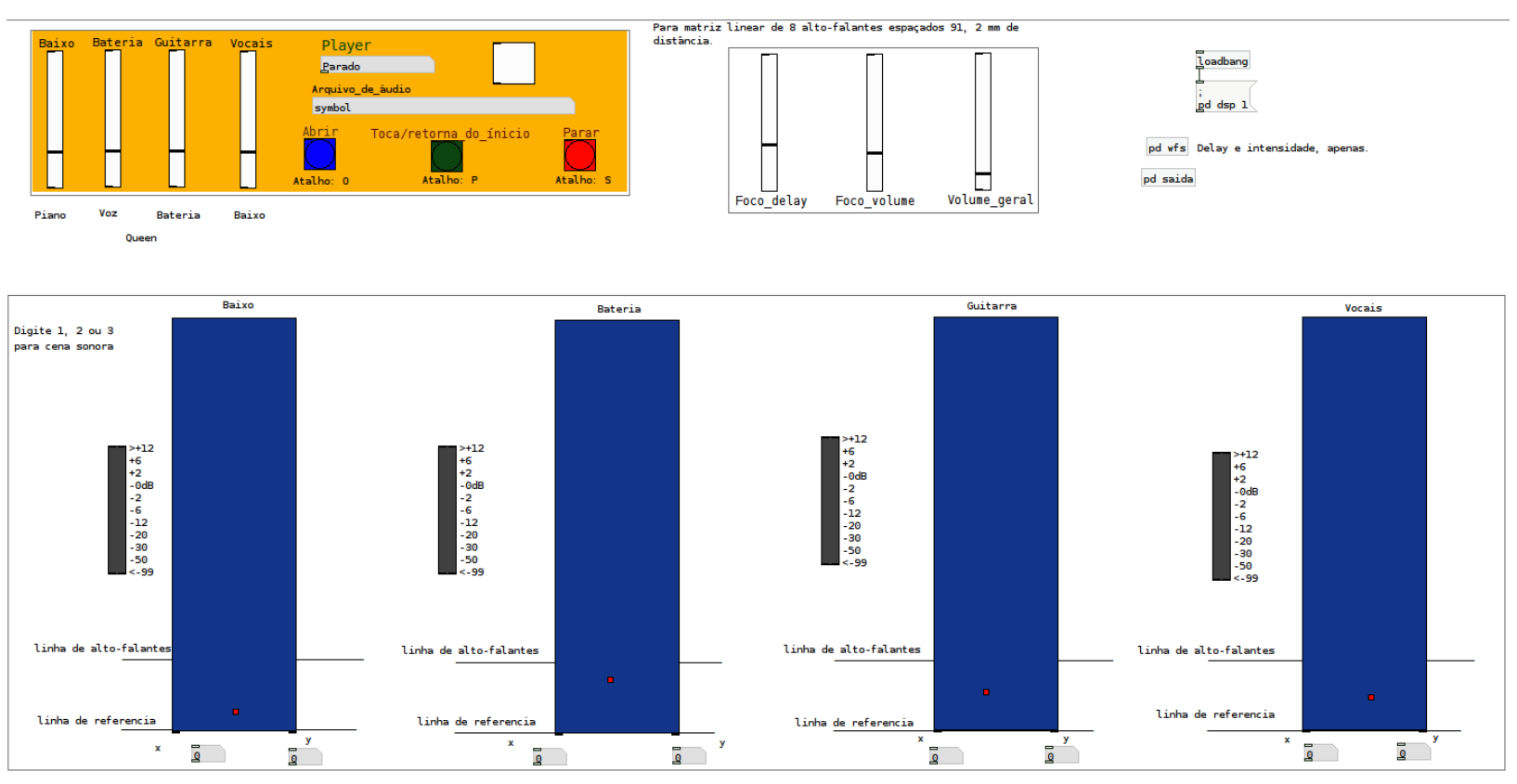

Figura 21 - GUI do protótipo inicial para WFS.

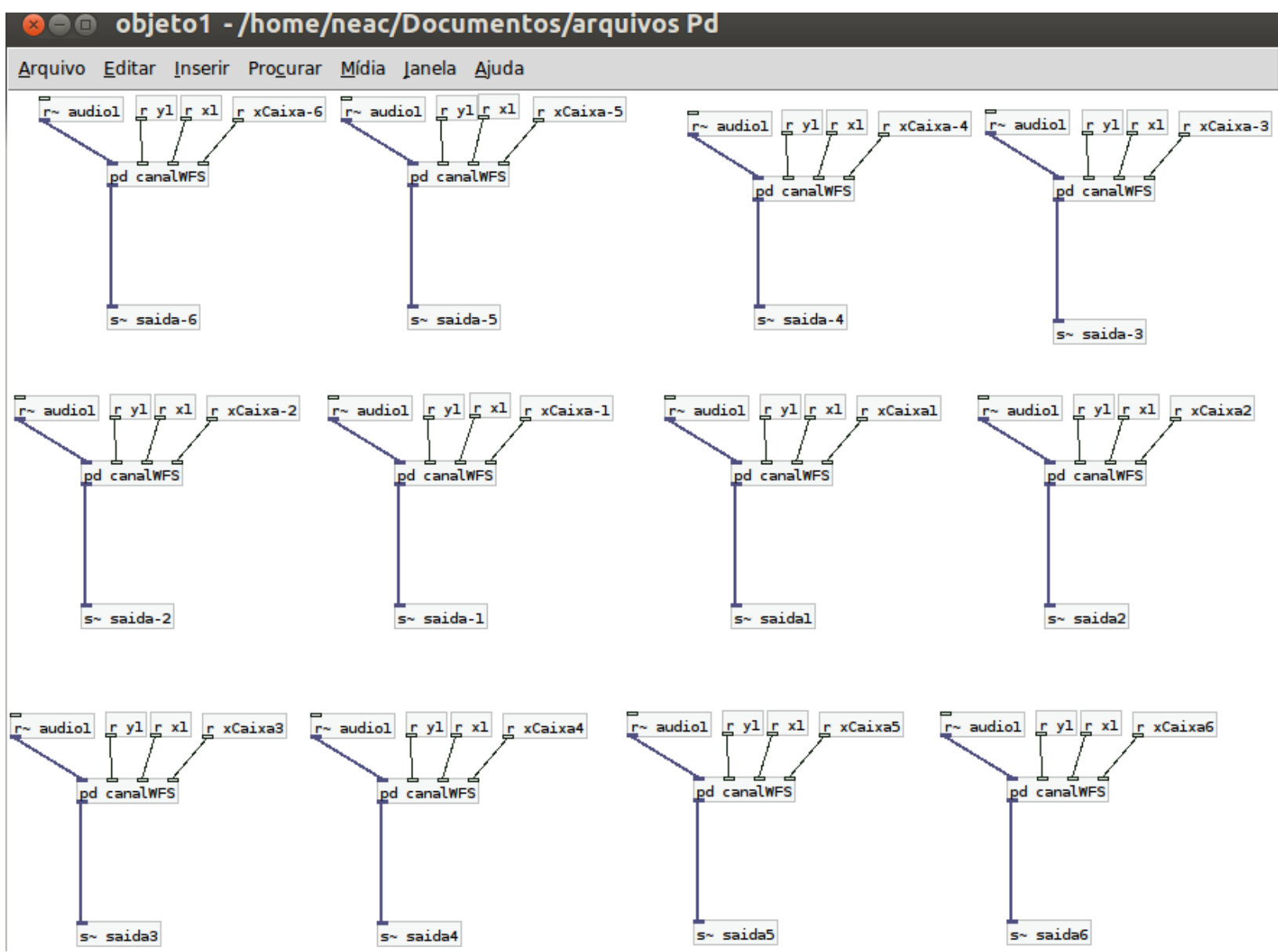

Figura 22 - Módulos para WFS. Parte do primeiro protótipo.

do computador. Na figura 23, como havia quatro objetos sonoros (quatro canais de entrada) aparecem 12 combinações de 4 sinais de áudio que estão ligadas aos 12 canais de saída do 
sistema (no retângulo onde está escrito $d a c^{\sim}$ ).

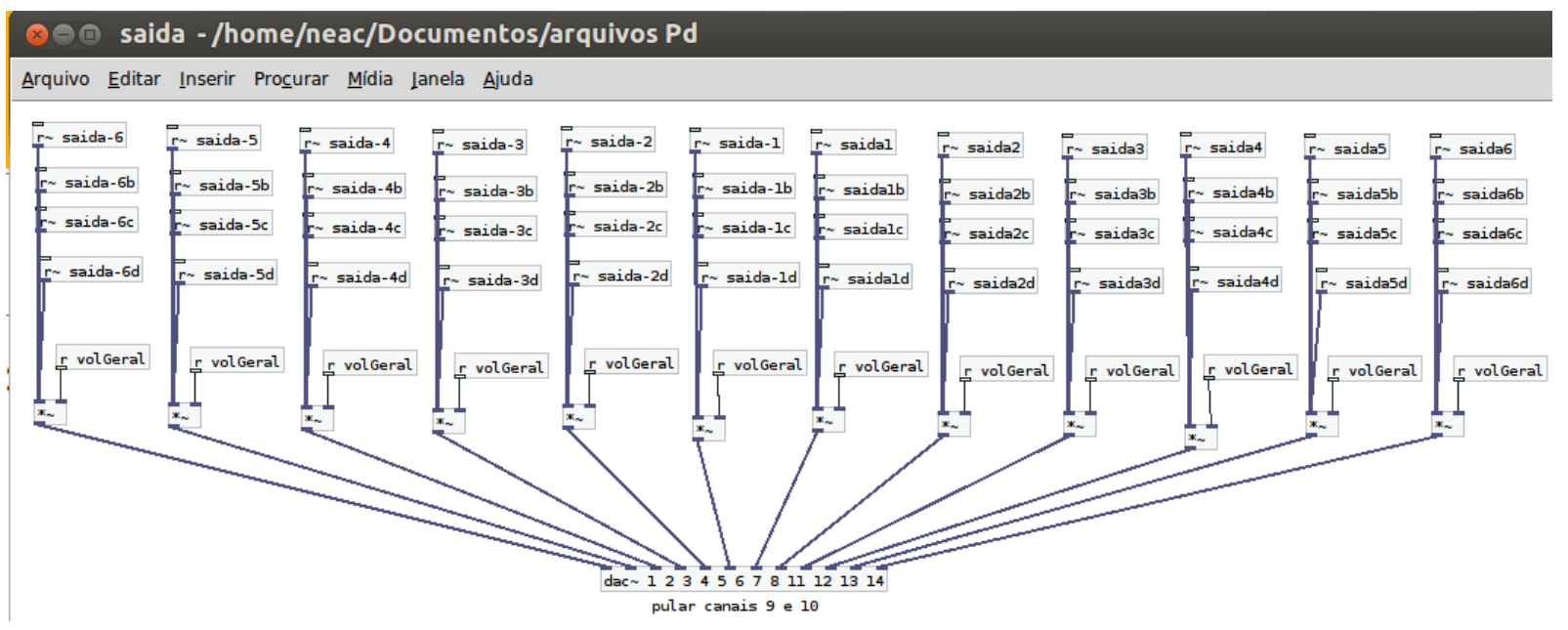

Figura 23 - Saída de aúdio do primeiro protótipo do sistema de WFS.

Nesta montagem inicial foram usadas 12 caixas de som que estão representadas sobre o eixo $x(y=0)$. No encontro entre a sexta e sétima caixas (exatamente no meio das 12 caixas), está a coordenada $(0,0)$. A linha de referência foi colocada a 1 metro da matriz de alto-falantes. Nos testes iniciais obteve-se uma noção razoável de profundidade (movimentação na direção do eixo $y$ ) enquanto a movimentação na direção do eixo $x$ não foi satisfatória. Descobriu-se, durante o desenvolvimento do protótipo, que a expressão para o operador WFS precisava das correções que acabaram sendo propostas na seção 4.1 .

\subsection{Avaliação básica do funcionamento do protótipo inicial}

Os módulos do protótipo inicial do sistema de WFS foram testados em laboratório com matriz de 12 alto-falantes para a avaliação básica do seu funcionamento e comparados em termos práticos ao SSR. Foi realizado um teste subjetivo com voluntários, que identificaram a localização de fontes sonoras, conforme sua percepção auditiva. Os testes de avaliação do sistema consistiram na correção da projeção sonora esperada para cenas sonoras simples, com objetos sonoros próximos ou um pouco afastados, visando verificar o funcionamento prático do protótipo inicial de WFS que seria integrado ao sistema AUDIENCE e buscando aperfeiçoar as estratégias que viriam a ser usadas nos testes finais. As medições foram simplificadas, tendo em vista a falta de condições acústicas adequadas para testes mais rigorosos.

As instalação dos itens necessários foi feita no computador MacBook Pro de 64 bits. A resolução de áudio para todos os programas foi ajustada para $44100 \mathrm{~Hz}$. As conexões entre eles, usados no teste para a WFS, foram feitas pelo servidor de áudio do $J A C K$, que interliga os programas usados para o uso de WFS e estes com as entradas e saídas do sistema. Trabalhou-se com 12 canais de saída, ligadas a 12 caixas de som ativas Lando amplificadas (ver item 4.2.1). Está configuração limitou o comprimento da matriz linear de alto-falantes em 1,092 m. 
A versão instalada do programa $S S R$ foi a 0.4.1. Como o arquivo disponibilizado era pré-compilado para o sistema operacional Mac OS X, esta instalação foi relativamente simples. Antes de rodar o $S S R$, sempre deve-se inicializar o servidor de áudio do JACK. A escolha da geometria final do sistema, com a definição do número e da posição dos alto-falantes e da orientação do espaço de audição foi feita alterando-se um arquivo de configuração, que está em linguagem xml. Detalhes da configuração do SSR estão detalhados no apêndice A.

Os testes objetivaram avaliar a percepção das fontes sonoras geradas em um espaço de audição $^{6}$, descrevendo como estes programas se comportariam como sistema de sonorização para aplicação prática da teoria de Wave Field Synthesis (WFS). Os sujeitos participantes do teste inicial tinham de 22 a 24 anos e profissão não relacionada a temática da pesquisa. A escolha de tais sujeitos foi feita de forma aleatória, através de um convite verbal, explicando qual a finalidade e quais as etapas compunham o teste.

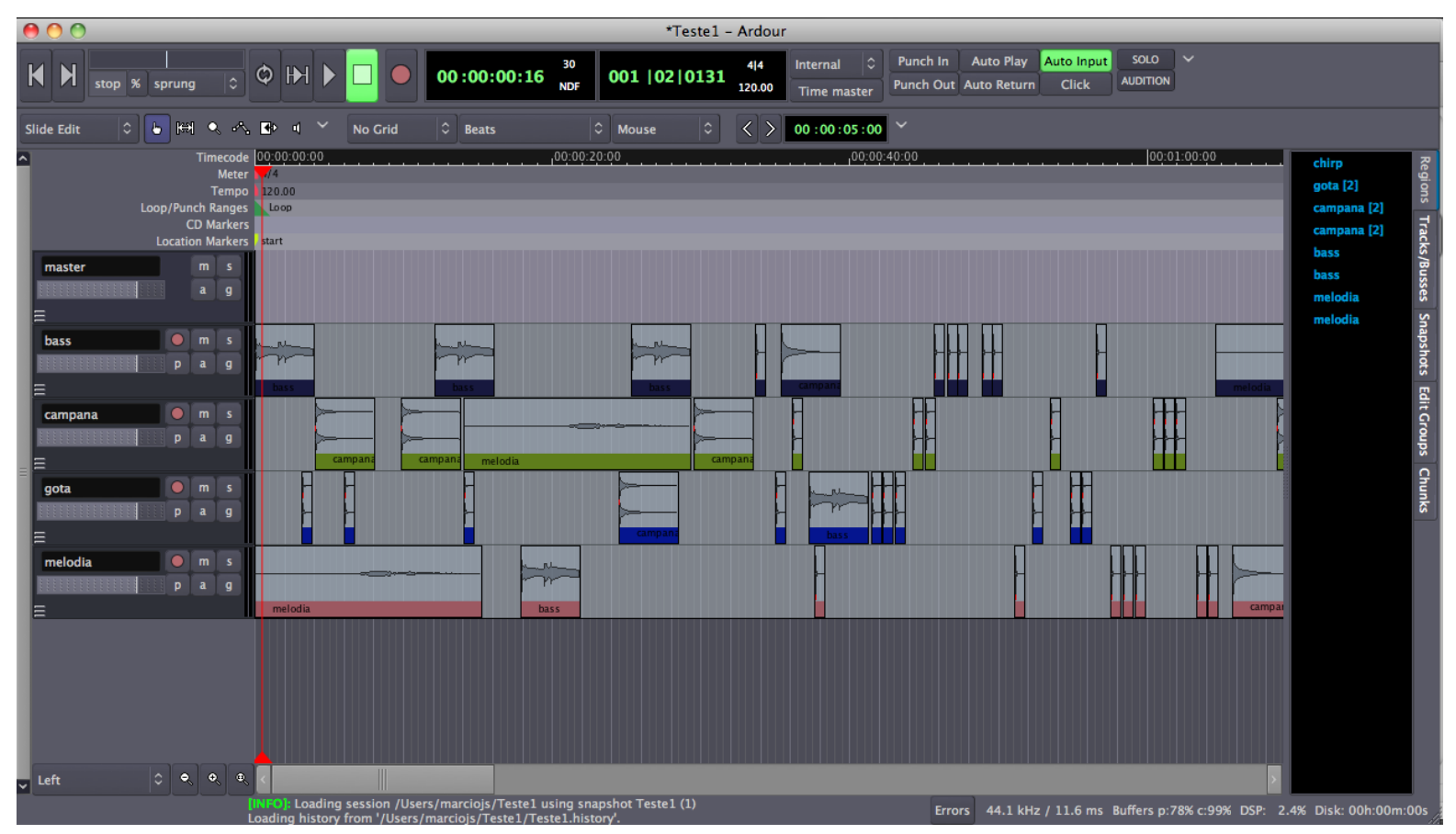

Figura 24 - O programa Ardour para a reprodução dos arquivos de áudio distribuídos em canais que foram controlados pelos sliders ilustrados à esquerda. Suas conexões de áudio são distribuídas ao protótipo em $P d$ e ao $S S R$ via $J A C K$.

A figura 24 mostra o programa Ardour, onde foram tocados os arquivos de áudio, usados pelo $S S R$ e pelo protótipo desenvolvido em $P d$, com os instrumentos organizados em pistas (tracks) diferentes e tocados repetidamente durante os testes. O uso deste recurso é útil quando quer-se ouvir uma fonte sonora por vez, ou selecionar algumas delas para audição, ou editar os momentos de execução em tempo real. Com a utilização deste programa foram distribuídos os canais para a execução das projeções sonoras. No início, os ouvintes foram expostos aos sons para que pudessem descrever as impressões causadas de acordo com a denominação dada pelo

6 Área com aproximadamente $8 \mathrm{~m}^{2}$, em sala simples, preparada com alguns painéis de absorvição de cabine audiométrica para reduzir as reflexões das paredes. 
pesquisador para facilitar a análise, pois os sons poderiam não aparecer numa mesma ordem da nomenclatura estabelecida. Depois, foi pedido para que, um de cada vez, ficassem sentados a cerca de 1,20 m das caixas de som. Foram colocadas 3 amostras de áudio (arquivos .wav) de resolução de áudio de $44100 \mathrm{~Hz}$. A seguir a descrição destes arquivos:

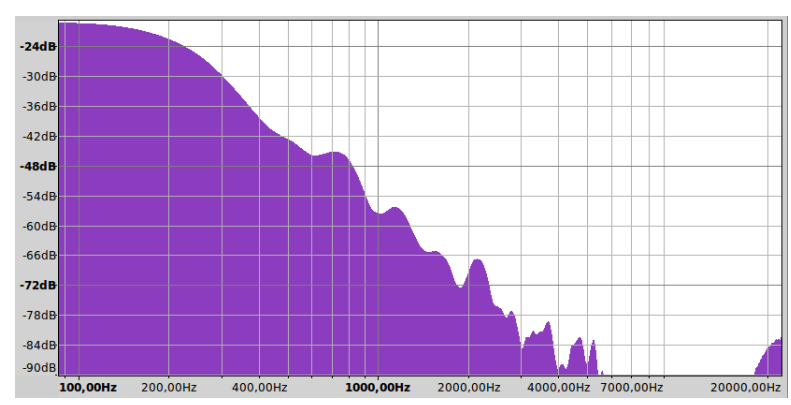

(a) Espectro de "bass.wav".

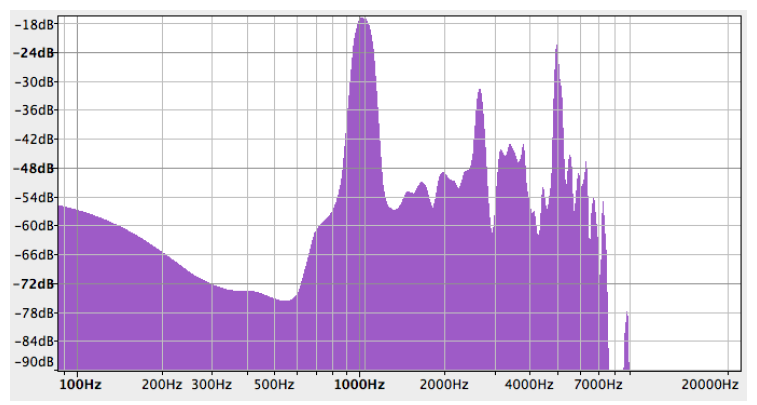

(b) Espectro de "campana.wav".

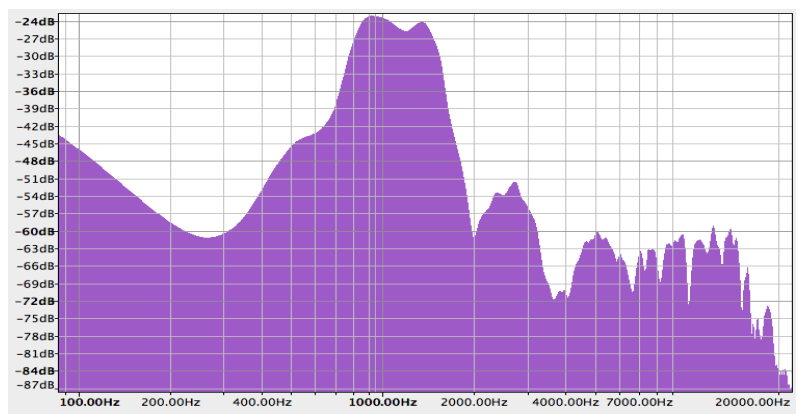

(c) Espectro de "gota.wav".

Figura 25 - Espectros de frequência dos sons usados no teste.

bass.wav gravação, com duração de 3,9 segundos, de um contra-baixo elétrico tocando uma frase musical numa região grave, com maior intensidade sonora para frequências inferiores a $300 \mathrm{~Hz}$, conforme mostra seu espectro de frequências, correspondente à soma de todos os sons deste arquivo de áudio, na figura 25a.

campana.wav gravação de um tom agudo de 2 segundos de uma campainha, com maior intensidade sonora para frequências em torno de $1000 \mathrm{~Hz}$ (pico de intensidade), $2500 \mathrm{~Hz}$ e $5000 \mathrm{~Hz}$ (esta última acima da frequência de aliasing), conforme mostra seu espectro de frequências na figura $25 b$.

gota.wav gravação, com duração de 0,05 segundo, de uma gota de água tocando uma superfície de água, com maior intensidade sonora para frequências com valores entre $900 \mathrm{~Hz}$ e 1500 $\mathrm{Hz}$, conforme mostra seu espectro de frequências na figura $25 \mathrm{c}$.

O Patchage $e^{7}$ é uma interface gráfica para realizar e visualizar as conexões feitas pelo servidor jack. Na figura 26 podem ser vistas todas as conexões feitas pelos programas usados no teste.

$\overline{7}$ Acesso ao programa pela página $<$ http://drobilla.net/software/patchage/ $>$ 


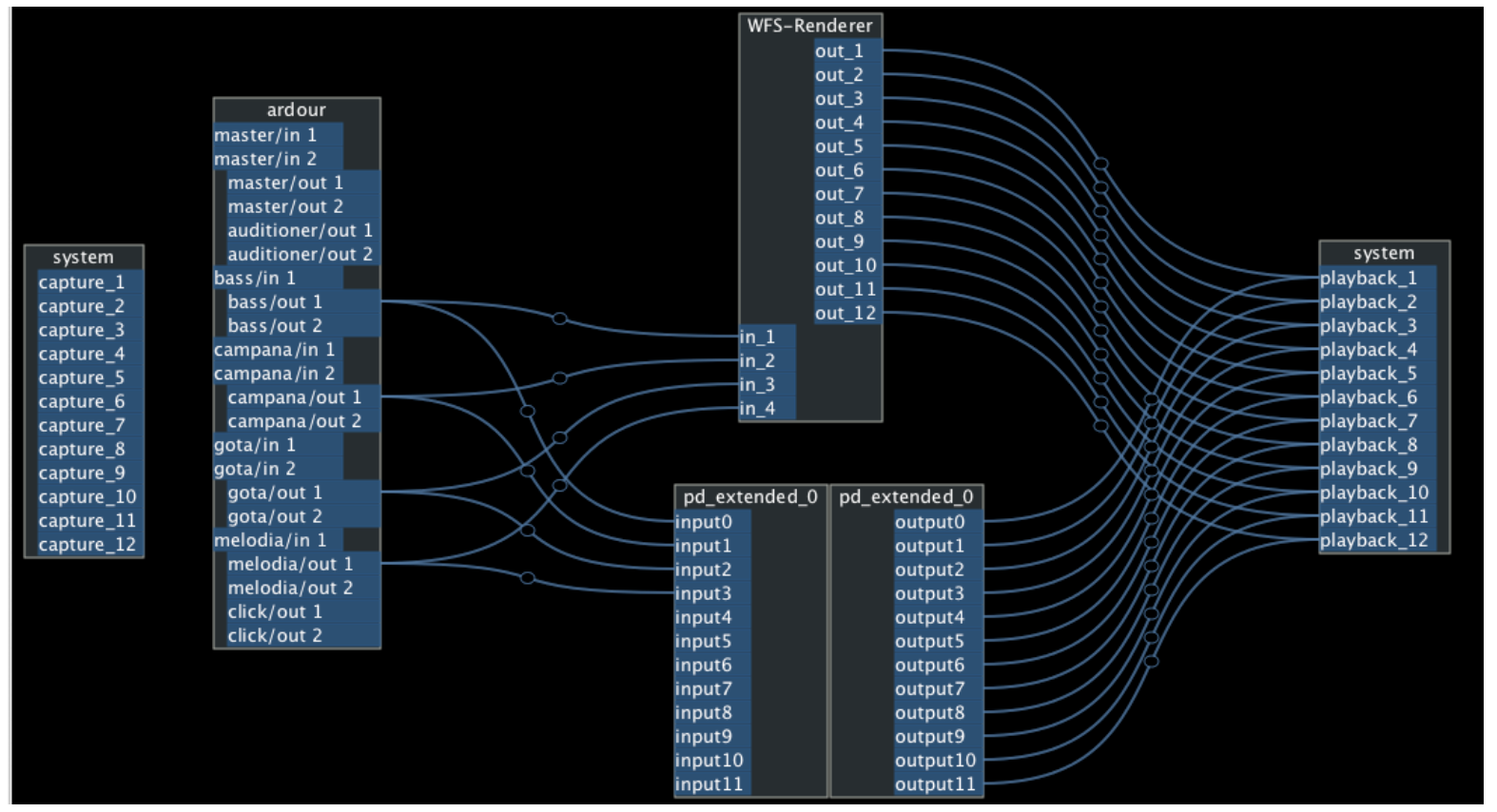

Figura 26 - Patchage: interface gráfica para realizar e visualizar as conexões feitas pelo JACK. As quatro saídas de áudio do Ardour são conectadas paralelamente às entradas dos dois programas testados, que por sua vez tem saídas de áudio conectadas à saída do sistema (interface de áudio).

Durante o teste propriamente dito, os sons foram passados dois a dois e os participantes deveriam localizá-los espacialmente na sala. Foram usadas fontes sonoras pontuais paradas atrás ou em frente aos alto-falantes, projetadas nos quatro quadrantes do plano cartesiano adotado, respeitando o limite de reprodução de 1,20 m imposto pela linha de referência (conforme explicado na seção 2.1), ou seja, fora do espaço de audição dos ouvintes.

As coordenadas das posições das fontes sonoras projetadas na cena sonora foram determinadas em metros, com o auxílio de uma trena. Tal teste foi aplicado, como dito anteriormente, comparando o protótipo inicial em $P d$ desenvolvido nesta pesquisa ao $S S R$. As projeções selecionadas por ambos os programas, tinham as seguintes coordenadas cartesianas: posição 1: $(-0.55 ; 1.13)$, posição $2:(-0.19 ;-0.88)$, posição $3:(0.25 ; 3.30)$ e posição $4:(0.49 ;-0.37)$. A interface gráfica do $S S R$, com configuração para o uso de WFS e com as posições das fontes sonoras, é mostrada na figura 27.

Os casos avaliados foram os seguintes:

Caso 1: avaliação da posição 1 (com som do contra-baixo) 1 e da posição 4 (com som de gota d'água).

Caso 2: avaliação da posição 2 (com som de gota d'água) e da posição 3 (com som de campana).

Caso 3: avaliação da posição 1 (com som de campana) e da posição 3 (com som do contra-baixo).

Caso 4: avaliação da posição 2 (gota d'água) e da posição 4 (com som do contra-baixo). 


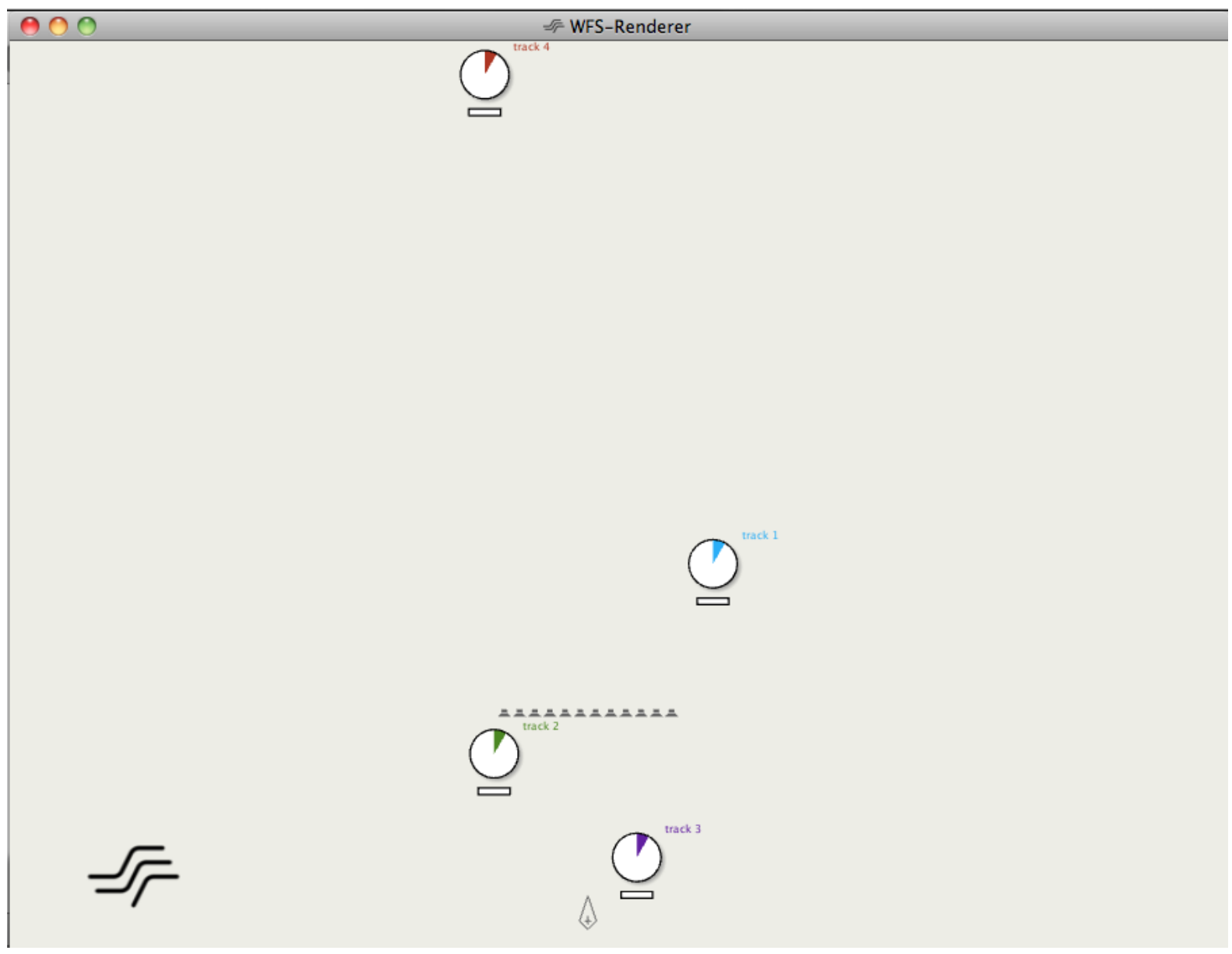

Figura 27 - Interface gráfica do SSR, configurada para WFS. A matriz de 12 alto-falantes é representada um pouco abaixo do centro da figura por 12 pequenos desenhos de alto-falantes alinhados na horizontal. As posições informadas pelos objetos (tracks) correspondem às posições das fontes sonoras.

As medidas, bem como a distância entre o ponto previsto e o ponto medido (erros calculados), para cada uma delas encontram-se na tabela 1. Com estes dados, calculou-se o erro médio da diferença entre a posição projetada e a percepção desta projeção, para o SSR é 1,14 m e do protótipo em Pure Data é 1,51 m. Nesta avaliação o programa $S S R$ teve melhor resultado, com $24,5 \%$ de rendimento superior aos acertos do protótipo inicial desenvolvido em Pure Data para o sistema OpenAUDIENCE.

\subsection{Protótipo final}

A implementação do sistema de WFS, e seus respectivos testes iniciais, motivou a busca por uma escolha ferramental que permitisse automatizar as configurações do programa, uma vez que a estrutura modular contando com um elevado número de canais implicava em um grande número de conexões a serem feitas. Além disso, um grande número de conexões a serem feitas manualmente aumentava a chance de erros na programação de patches. Os requisitos para esta escolha foram: 
Tabela 1 - Medidas das posições indicadas pelos ouvintes e, para cada uma delas, a distância entre o ponto previsto e o ponto medido (erros calculados) para a comparação entre os programas $S S R$ e o primeiro protótipo em Pure Data para o módulo de WFS do sistema OpenAUDIENCE. Todas as medidas em metros.

\begin{tabular}{|c|c|c|c|c|c|c|c|}
\hline \multicolumn{8}{|c|}{ SSR } \\
\hline & & \multicolumn{3}{|c|}{ Voluntário 1} & \multicolumn{3}{|c|}{ Voluntário 2} \\
\hline Caso 1 & Pos. projetada $(\mathrm{x}, \mathrm{y})$ & $\mathrm{x}$ & $\mathrm{y}$ & Erro & $\mathrm{x}$ & $\mathrm{y}$ & Erro \\
\hline contra-baixo & $(-0,55 ; 1,13)$ & $-0,43$ & 0,23 & 0,91 & $-0,42$ & $-0,16$ & 1,30 \\
\hline $\begin{array}{l}\text { gota d'água } \\
\text { Caso } 2\end{array}$ & $(0,49 ;-0,37)$ & 0,42 & $-0,27$ & 0,12 & 0,36 & $-0,28$ & 0,16 \\
\hline gota d'água & $(-0,19 ;-0,88)$ & $-0,05$ & $-0,78$ & 0,17 & 0,02 & $-0,46$ & 0,47 \\
\hline campainha & $(0,25 ; 0,3)$ & 0,23 & 0,56 & 2,74 & $-0,2$ & 0,6 & 2,74 \\
\hline $\begin{array}{c}\text { Caso } 3 \\
\text { campainha }\end{array}$ & $(-0.55 ; 1,13)$ & -0.09 & 0.31 & 0.94 & -0.26 & -0.47 & 163 \\
\hline contra-baixo & $(0,25 ; 0,3)$ & 0,12 & 0,56 & 2,95 & 0,43 & 0,86 & 2,45 \\
\hline Caso 4 & & & & & & & \\
\hline gota d'água & $(-0,19 ;-0,88)$ & $-0,09$ & $-0,55$ & 0,34 & $-0,24$ & $-0,51$ & 0,37 \\
\hline contra-baixo & $(0,49 ;-0,37)$ & 0,47 & 0,36 & 0,73 & 0,46 & $-0,14$ & 0,23 \\
\hline \multicolumn{8}{|c|}{ Pd } \\
\hline & & \multicolumn{3}{|c|}{ Voluntário 1} & \multicolumn{3}{|c|}{ Voluntário 2} \\
\hline Caso 1 & Pos. projetada $(\mathrm{x}, \mathrm{y})$ & $\mathrm{x}$ & $\mathrm{y}$ & Erro & $\mathrm{x}$ & $\mathrm{y}$ & Erro \\
\hline contra-baixo & $(-0,55 ; 1,13)$ & 0,22 & 0,36 & 1,09 & $-0,34$ & 0,36 & 0,80 \\
\hline gota d’água & $(0,49 ;-0,37)$ & $-0,19$ & 0,81 & 1,36 & 0,43 & 0,32 & 0,69 \\
\hline Caso 2 & & & & & & & \\
\hline gota d’água & $(-0,19 ;-0,88)$ & 0,06 & $-0,11$ & 0,81 & 0,16 & 0,27 & 1,20 \\
\hline campainha & $(0,25 ; 0,3)$ & 0,13 & 0,3 & 3,00 & 0,44 & 0,11 & 3,20 \\
\hline Caso 3 & & & & & & & \\
\hline campainha & $(-0,55 ; 1,13)$ & $-0,22$ & $-0,33$ & 1,61 & $-0,25$ & 0,22 & 0,96 \\
\hline contra-baixo & $(0,25 ; 0,3)$ & $-0,16$ & $-0,07$ & 3,05 & 0,17 & $-0,26$ & 3,56 \\
\hline Caso 4 & & & & & & & \\
\hline gota d'água & $(-0,19 ;-0,88)$ & $-0,14$ & $-0,43$ & 0,45 & 0,23 & $-0,13$ & 0,86 \\
\hline contra-baixo & $(0,49 ;-0,37)$ & 0,14 & 0,25 & 0,71 & $-0,08$ & 0,2 & 0,81 \\
\hline
\end{tabular}

- capacidade de configurar vários canais de entrada e saída,

- capacidade de alterar a posição de cada objeto durante a execução do algoritmo,

Tais exigências motivaram a busca de formas mais seguras e rápidas para se implementar o sistema de patches, principalmente motivada pelas razões descritas a seguir.

A baixa flexibilidade da implementação inicial pode ser notada pela quantidade de objetos e conexões necessários à implementação do sistema que inicialmente trabalha com apenas um objeto sonoro. Seguir tal linha de implementação implicaria replicar todos os objetos e conexões para tratar mais objetos sonoros. No caso mostrado, para cada novo canal de entrada teria que ser feita uma nova cópia destes 12 módulos e teriam que ser renomeados, de forma manual, vários objetos, a maioria deles não mostrados na figura 22 . $\mathrm{O}$ mesmo ocorreria caso 
fosse necessário alterar algum índice, nome ou equação. $\mathrm{O}$ mesmo raciocínio se aplica caso houvesse alteração do número de canais de saída, pois uma mudança na posição ou quantidade de caixas de som implicaria em uma refatoração completa da implementação.

\subsubsection{Aspectos gerais do projeto}

A figura 28 mostra um diagrama geral de entradas e saídas para o sistema de WFS, onde $F$ é o número total de canais de entrada (igual ao número de objetos sonoros em cena) e $N$ é o número total de canais de saída. $S_{f}$ e $C_{n}$ representam, respectivamente, cada sinal de entrada de áudio e cada canal de saída de áudio, $x_{n}$ corresponde à posição de cada caixa de som e $\left(x_{f}, y_{f}\right)$ são as coordenadas do objeto sonoro, em relação ao sistema de coordenadas. O sistema possui uma configuração relativamente complexa devido à quantidade de informações correspondentes às suas entradas e saídas.

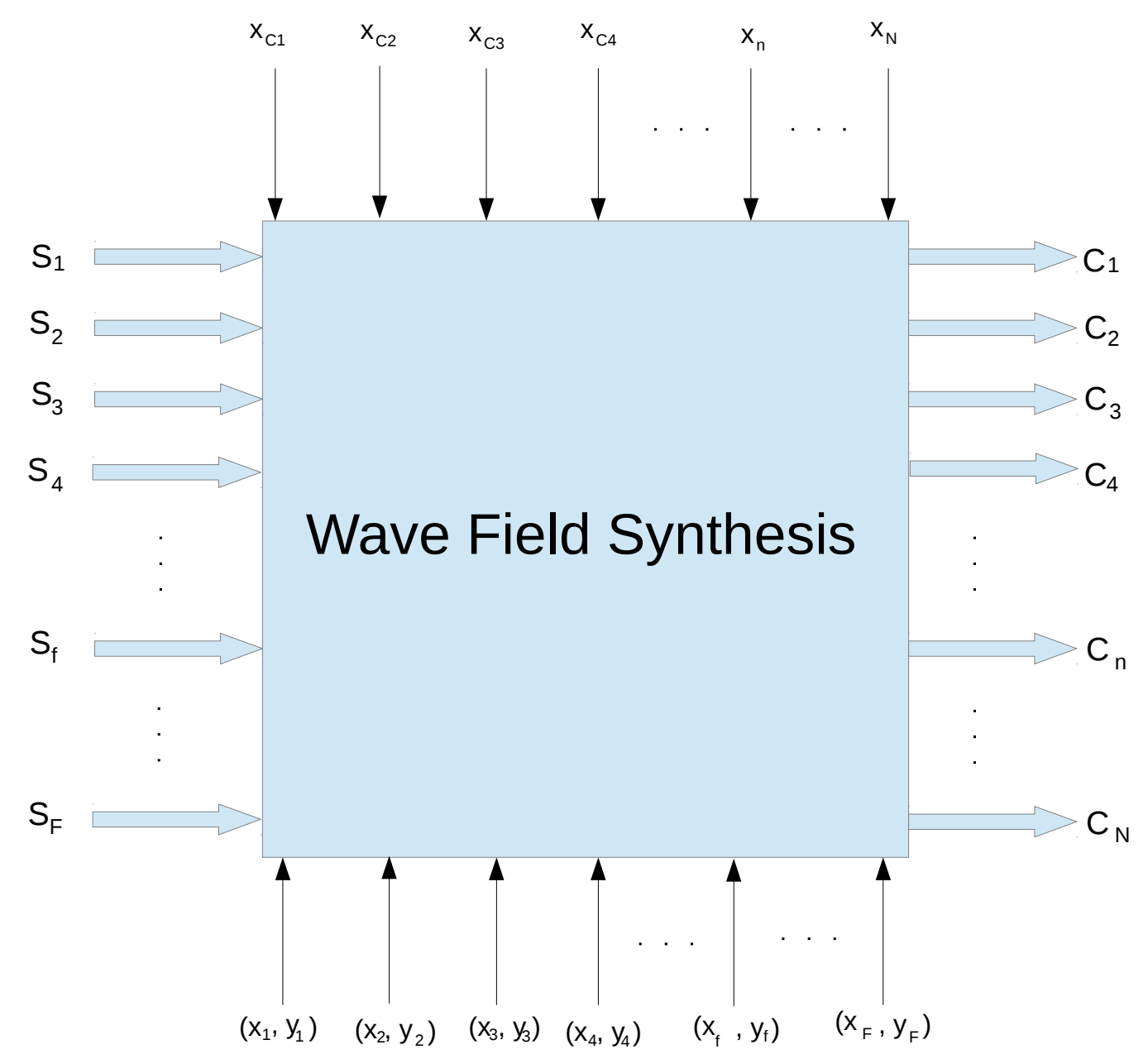

Figura 28 - Diagrama geral de entradas e saídas de uma matriz processada de WFS. $S_{f}, C_{n}, x_{n}$ e $\left(x_{f}, y_{f}\right)$ representam, respectivamente, cada sinal de entrada e saída de áudio, a posição de cada caixa de som e as coordenadas de cada objeto sonoro.

Durante o uso do sistema, as posições e a quantidade de caixas de som normalmente são fixas. Já o número de canais de entrada, usualmente, tanto pode ser fixo como pode ser alterado 
se, por exemplo, forem usados arquivos de áudio com número diferente de canais. Para uma dada configuração é necessário que o programa permita o uso de um número variável de canais de entrada e saída do sistema.

Para cada sinal $S_{f}$ de entrada é atribuída a posição $\left(x_{f}, y_{f}\right)$. Para cada canal de saída $C_{n}$ temos a configuração da posição da respectiva caixa acústica no eixo $x$. Vale notar que a posição das caixas de som no eixo $y$ é fixa.

A figura 29 mostra o diagrama geral para o sistema de WFS com uma divisão em blocos, aprofundando a visão mais geral mostrada na figura 28. Percebe-se que para cada canal de áudio (objeto sonoro) é feito o processamento em $N$ módulos de WFS, para que o sinal deste objeto sonoro seja distribuído nas $N$ caixas de som correspondentes a cada um destes módulos. É possível verificar que a posição de um objeto sonoro irá alterar o sinal em todos os canais de saída. Claramente nesta plataforma de programação orientada a patches, era necessária uma solução que empregasse mecanismos para automatizar a construção e conexão dos patches.

A implementação do primeiro protótipo em $P d$, apresentada na figura 22, mostrou-se eficaz para os objetivos do projeto, porém tal implementação com 12 módulos WFS desenvolvidos para um único objeto sonoro (uma entrada de áudio) demandou bastante tempo e se mostrou pouco flexível. Uma solução para construir um grande número de conexões, de modo flexível e em tempo real, é proposto na próxima seção.

\subsubsection{Implementação do módulo processador de WFS com programação dinâmica no $P d$}

Analisando-se as possíveis implementações para processamento em tempo real no ambiente Pure Data, foi apresentada uma solução para a geração automática de patches aplicados à sonorização de um sistema de espacialização baseado em WFS. Esta solução emprega patches dinâmicos e uma arquitetura modular, permitindo flexibilidade e manutenabilidade do código, com vantagens particularmente para lidar com um número elevado de fontes e alto-falantes.

A programação dinâmica é uma técnica computacional na qual o programa pode alterar seu próprio código em tempo de execução, permitindo assim que o mesmo se adeque dinamicamente a um problema específico (RITSCH, 2006). Esta técnica de programação é bastante similar à técnica computacional chamada reflexão (ZMöLNIG, 2009), por tratar do conhecimento que o código possui sobre si mesmo. Com isto, a abstração em si não traz apenas sua implementação, porém recria o subpatch toda vez em que é instanciado, baseando esta criação nos parâmetros informados. Em consequência disto, o número de canais pode ser alterado de forma simples e rápida. De acordo com Silva, Schiavoni e Faria (2014), usar programação dinâmica para flexibilizar a configuração e aliviar a replicação de código é bastante atraente para o caso específico de WFS em que os sistemas podem chegar a centenas de alto-falantes.

Como a experimentação do protótipo do sistema seria feita a partir de diferentes configurações com variações de parâmetros de entrada e saída, posição das fontes (ou objetos) sonoras 

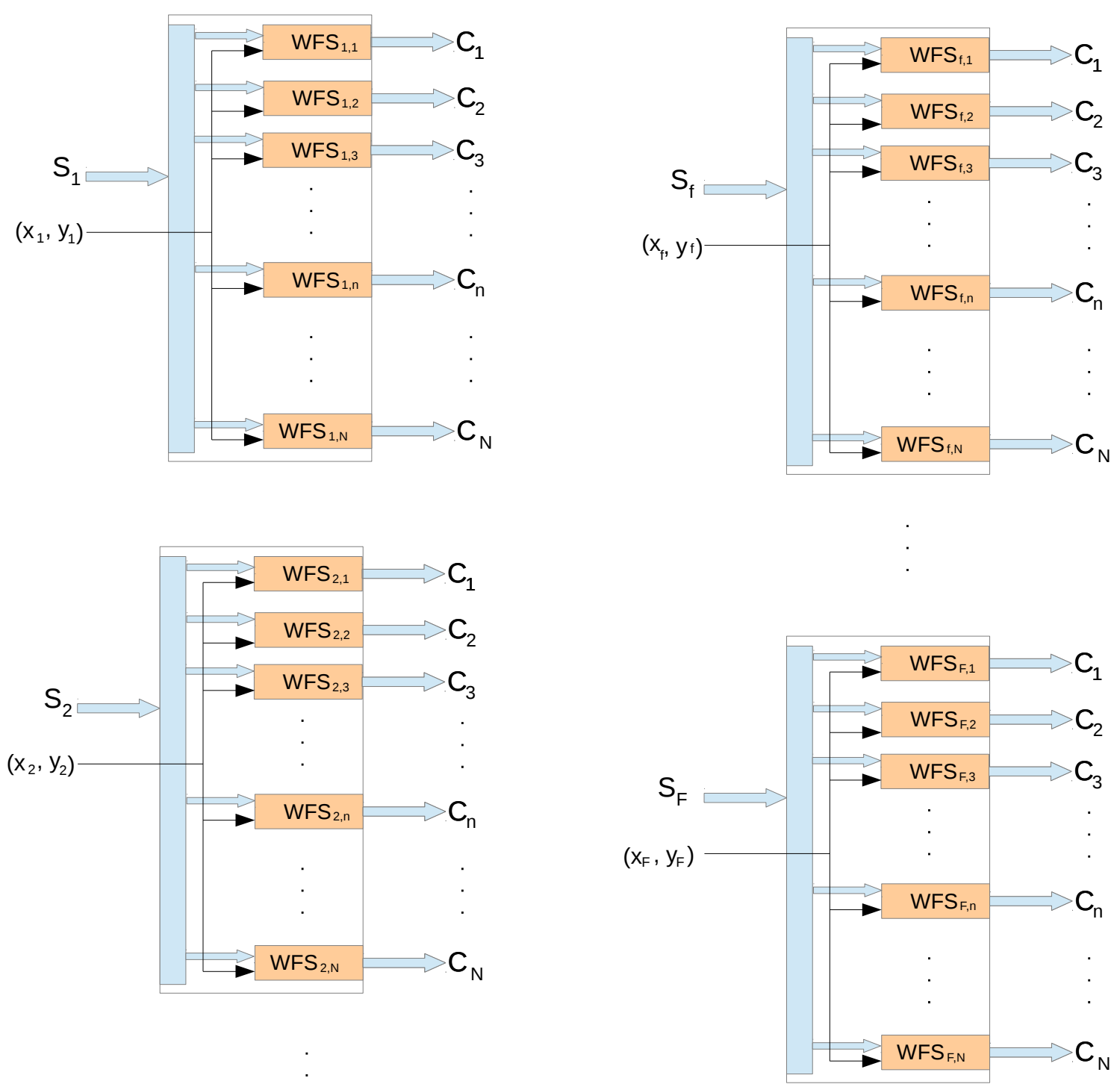

Figura 29 - Diagrama em blocos para o sistema de WFS. Para cada canal é feito o processamento em $N$ módulos de $W F S$ e finalmente enviado para as $N$ saídas de áudio.

e das caixas, foram adotadas algumas possibilidades para automatizar as configurações dos patches.

O formato de arquivo do $P d$ é bastante simples e padronizado e pode ser visto como um arquivo de texto. A figura 30 mostra um trecho de código que pode ser visto quando um arquivo .pd é aberto num editor de texto.

A primeira possibilidade de automatização da configuração que gerava um arquivo .pd foi desenvolvida em uma ferramenta na linguagem Java que, a partir dos parâmetros iniciais, gerava os patches já configurados. Esta solução otimizou a criação do patch de WFS, porém demandava a incorporação de uma ferramenta externa no processo de trabalho, o que nem sempre é desejável.

Outra possibilidade de automatização estudada foi criar em linguagem $\mathrm{C}$ um external para o $P d$ que poderia receber parâmetros em sua criação, como a quantidade de fontes sonoras 


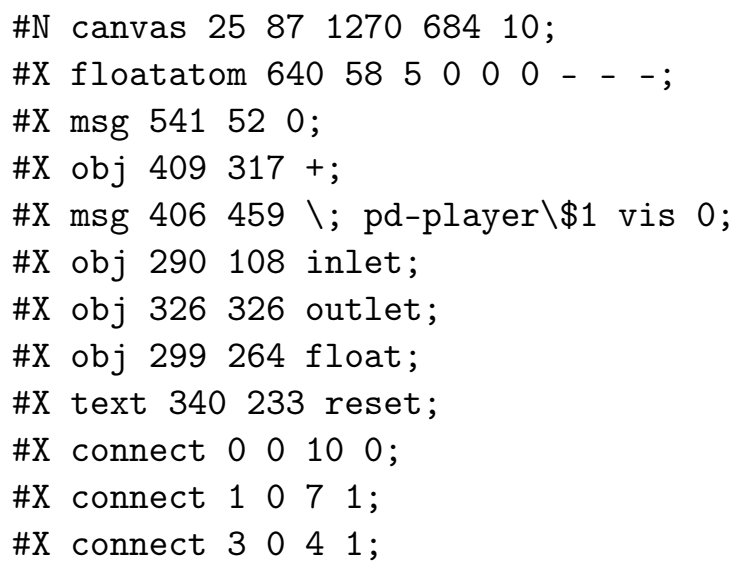

Figura 30 - Exemplo de arquivo do $P d$. Mostrando um trecho de código que pode ser visto quando um arquivo .pd é aberto num editor de texto.

e de canais, e se adequar dinamicamente a esta configuração de maneira transparente ao usuário. Tal solução, apesar de trazer benefícios como o processamento em $\mathrm{C}$ de algumas funcionalidades, mostra-se pouco portável, pois faria que tal external fosse compilado para cada sistema operacional onde o $P d$ fosse executado. Novamente, isto incluiria ao processo novas ferramentas, como o compilador $\mathrm{C}$, o que não é desejável. O protótipo inicial nos mostrou que os objetos necessários para a implementação já existiam e que construir um external não seria imprescindível.

O patch principal utiliza abstrações do $P d$ para criar patches independentes do primeiro ou subpatches dinamicamente a partir de argumentos. Tecnicamente, esta abstração não possui nada além de uma estrutura para criar a si mesma quando é instanciada. Isto quer dizer que, internamente, a abstração coleta o parâmetro da instanciação informada pelo usuário do programa e envia uma série de mensagens ao próprio patch para que ele se auto-construa de acordo com este parâmetro.

Como o Pure Data permite sua extensão também por meio de abstrações, tal solução foi considerada mais adequada que as anteriores pelas seguintes razões:

- não há necessidade de adicionar novas ferramentas ao processo de desenvolvimento;

- o resultado obtido é totalmente compatível com o ambiente $P d$ e independente de onde ele foi compilado;

- a modificação da abstração pode ser feita durante a sua execução simplificando os experimentos e testes da ferramenta.

\subsubsection{Integração ao sistema AUDIENCE}

Um dos requisitos para esta implementação foi torná-la compatível às diretrizes da arquitetura do sistema AUDIENCE (FARIA et al., 2005; FARIA, 2011a), que prevê a modularização funcional com operações claramente atreladas a uma das quatro camadas funcionais 
descritas nesta arquitetura. Desta forma, procurou-se projetar e agrupar as operações em camadas funcionais afins.

Cada uma das camadas da estrutura do sistema AUDIENCE é explicada a seguir. A aplicação dedicada de WFS com arquitetura modular desenvolvida neste projeto segue a lógica estrutural apresentada.

Camada 1/ Descrição da cena sonora: nesta camada determina-se a composição da cena acústica, com a descrição de como as fontes sonoras (instrumentos musicais) deverão ser posicionados no espaço de audição. Primariamente parâmetros do ambiente de escuta devem ser considerados.

Camada 2/ Simulação acústica da cena: na segunda camada faz-se a simulação acústica considerando-se o ambiente de escuta. Uma das ideias é que este módulo possa gerar metadados que parametrizem a codificação de frentes de ondas no módulo seguinte. As funções que são implementadas nesta camada visam algum tipo de simulação acústica ou gerar parâmetros para a síntese de frente de onda (sinais de saída).

Camada 3/ Codificação do áudio: a terceira camada é responsável pela codificação do áudio utilizando os metadados descritores da síntese da frente de onda. O módulo deverá converter o sinal para algum formato $W F S$.

Camada 4/ Decodificação do áudio e reprodução: a quarta camada determina qual configuração e disposição de caixas de som serão utilizados.

A construção de uma cena de áudio virtual imersiva passa pela descrição da cena sonora, pelo processamento de áudio e, finalmente, pela sonorização. Como o sistema possui uma divisão clara de funcionalidades, poderá ser modificado em partes, permitindo novas configurações e implementações em cada módulo.

\subsubsection{Construção do protótipo final}

A partir dos requisitos e especificações do projeto, a solução adotada para a construção de um sistema de auralização com WFS baseia-se num conjunto de abstrações dinamicamente construídos no $P d$. A implementação permitiu que o sistema fosse visualizado de maneira que cada funcionalidade fosse implementada em blocos de funções interconectáveis. A figura 31 mostra um diagrama de blocos proposto para o protótipo final.

O diagrama mostra os módulos constituintes do protótipo final, articulando os conceitos de programação dinâmica e atendimento aos requisitos da arquitetura AUDIENCE de referência. $\mathrm{Na}$ interface principal o usuário determina os parâmetros básicos do sistema WFS (interface controladora), como a disposição das fontes sonoras na cena (interface de cena) e o número de alto-falantes no array. Nesta interface está o núcleo do módulo WFS, dividido funcionalmente em 3 tipos de subpatches: 


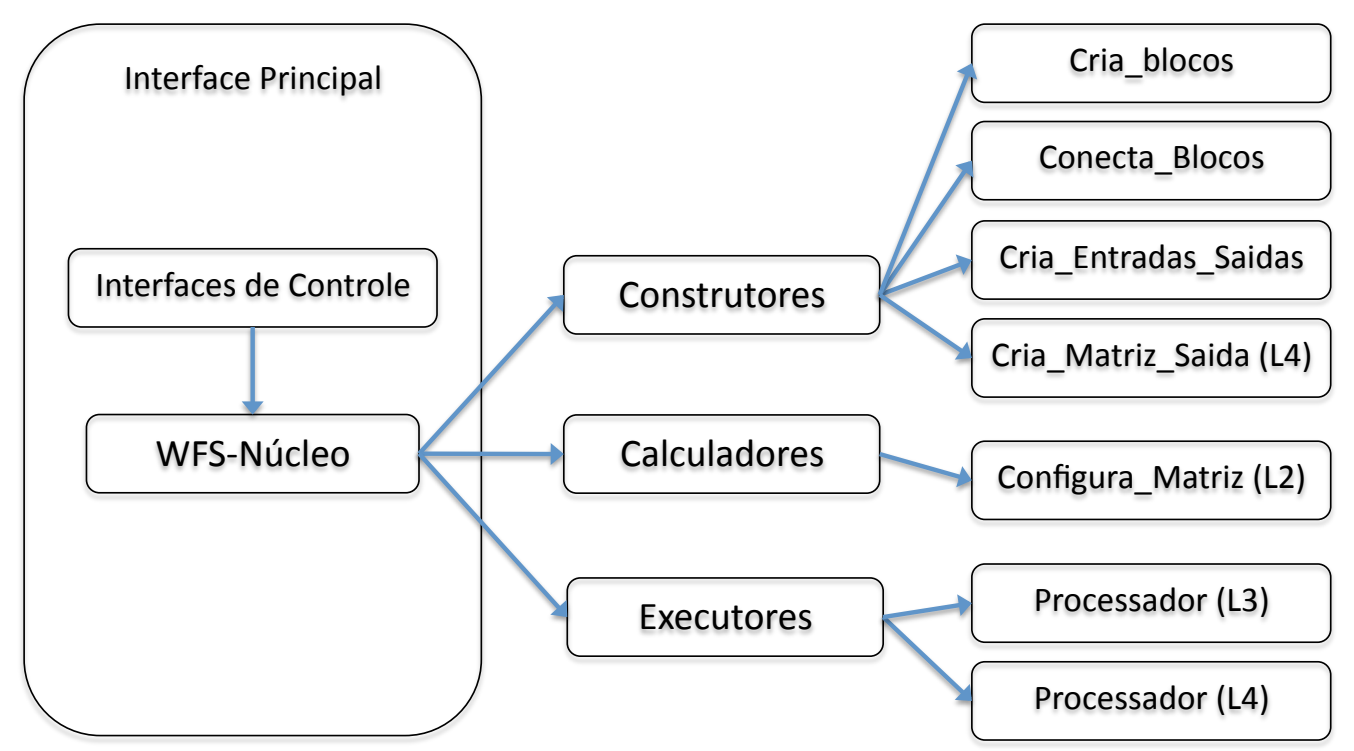

Figura 31 - Diagrama de blocos conceitual para o protótipo final, mostrando os tipos de patches projetados e suas respectivas funções.

- construtores (responsável pela construção dinâmica dos patches processadores, das conexões de entrada e saída, do patch das matrizes de alto-falantes, e das conexões entre os blocos);

- calculadores (responsável pelos cálculos dos atrasos e ponderações de amplitude que serão aplicadas a cada alto-falante do sistema);

- executores (onde são construídos e conectados os patches processadores de áudio).

A figura ainda mostra a que camada funcional do AUDIENCE estão associados cada bloco.

Na presente versão, L1 se refere a um objeto pertencente à camada funcional 1, conforme a arquitetura AUDIENCE. L2, L3 e L4, igualmente, se referem às camadas 2, 3 e 4, respectivamente. São as seguinte abstrações (módulos ou blocos funcionais) mais relevantes e suas respectivas funções no fluxo de processos:

Módulos de entradas (L1) e saídas (L4): recebem as informações de posição dos objetos sonoros, seus respectivos sinais de áudio e as posições das caixas de som usadas pelo sistema.

Módulos de cálculo para WFS (L2): recebem as configurações de entrada e calculam, conforme as equações descritas nas início do capítulo 4.1, os fatores de amplitude (equação 4.1) e atrasos (equação 4.2) que serão aplicados aos sinais de áudio.

Módulos de processamento de áudio (L3): aplicam, nos sinais de áudio, os atrasos e as relações de amplitude correspondentes à técnica de WFS. 


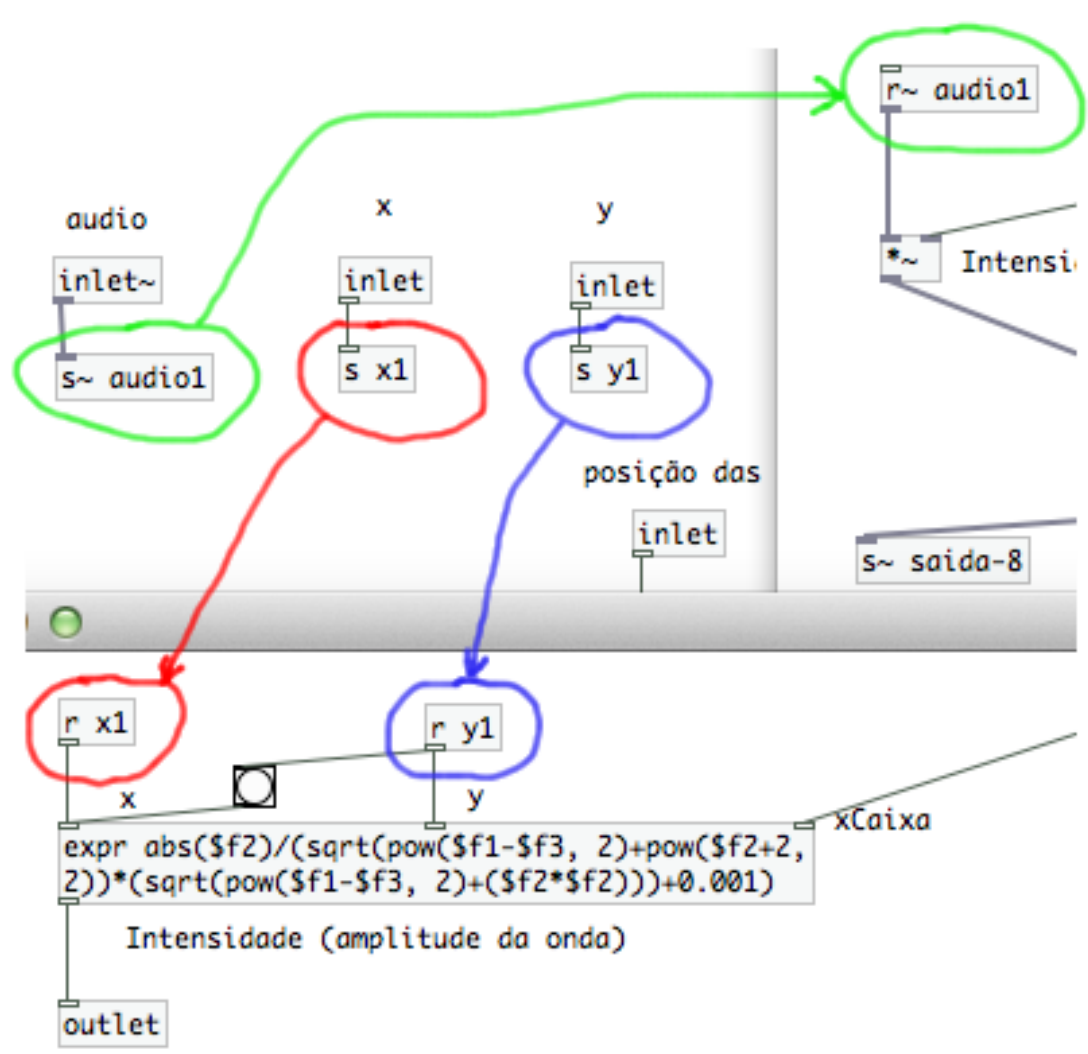

Figura 32 - Conexões em feitas no Pure Data com o uso de send e receive.

A divisão das funções do programa em módulos se aproxima da proposta de arquitetura sugerida pelo sistema AUDIENCE (FARIA, 2011a). Os módulos descritos podem ser associados às camadas específicas deste sistema. Uma vez feita a divisão de responsabilidades do sistema, o próximo passo foi definir como seriam feitas as conexões entre os módulos.

A solução encontrada para permitir flexibilidade para as conexões de áudio e de controle foi construí-las utilizando os objetos básicos do Pure Data, send e receive. Desta forma, foi possível que tais conexões funcionassem de maneira transparente para o usuário que, por sua vez, não precisaria criar cada conexão individualmente.

Conforme ilustrado na figura 32, por meio de objetos send são feitas as conexões dos sinais de áudio, no exemplo [send $\sim$ audio1] (ou [s audio1]), e enviadas as coordenadas de uma fonte sonora, no exemplo [send x1] (ou [s x1]) e [send y1] (ou [s y1]). Qualquer outro objeto no patch que precisar receber tal informação pode acessá-la por meio de um objeto receive, por exemplo [receive $\sim$ audio1] (ou [r $\sim$ audio1]). Com esta solução não há mais a necessidade de conectar estes objetos explicitamente. Tal abordagem de implementação exigiu a definição de nomes para envio e recebimento de mensagens e a formalização na comunicação entre os módulos. Além disso, isto permite que os módulos sejam trocados e que exista mais de uma implementação para cada um deles. 


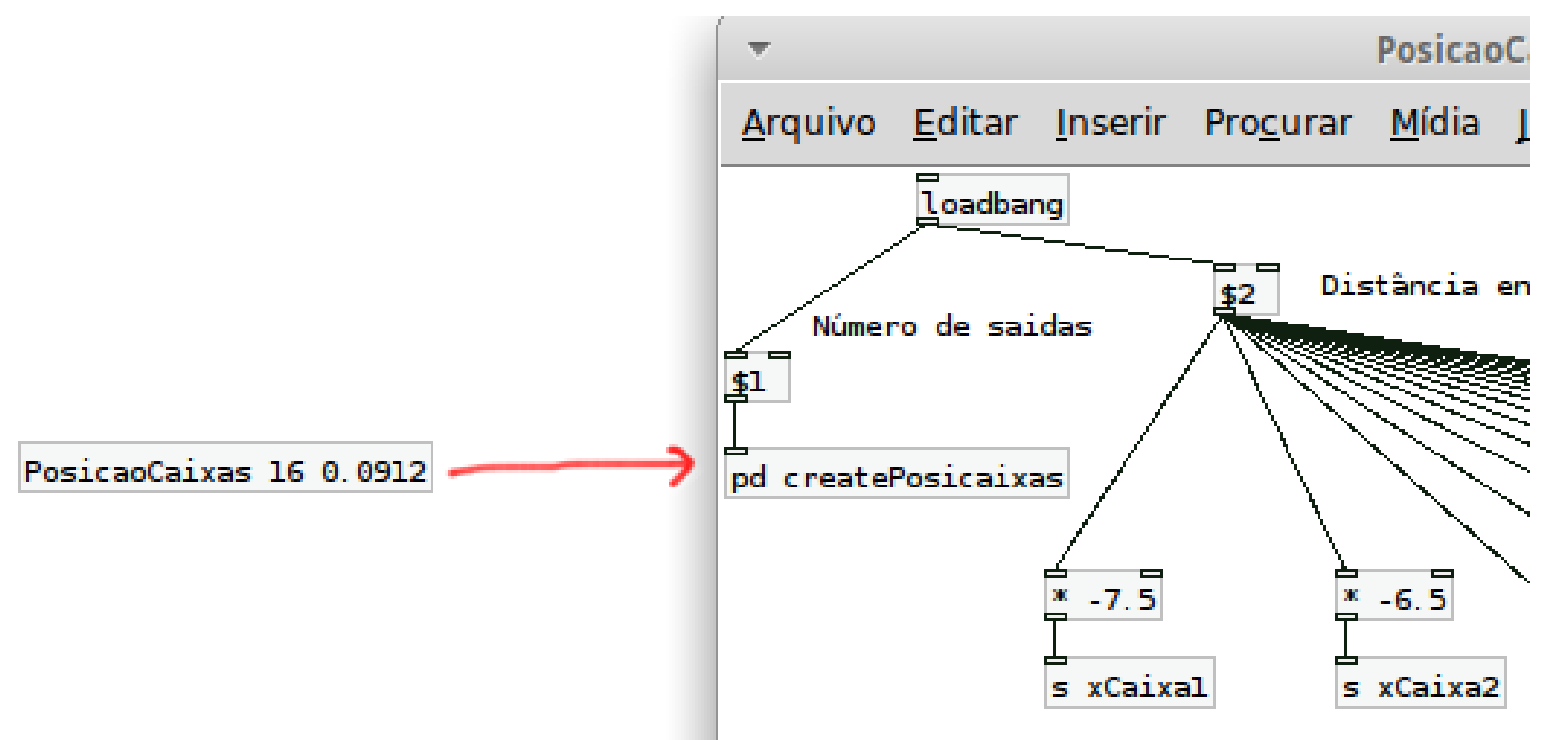

Figura 33 - Exemplo de reflexão computacional. Quando foi criada a abstração PosicaoCaixas recebeu os parâmetros 16, correspondente ao número de canais de saída, e 0.0912, correspondente à distância entre as caixas de som.

A segunda parte da solução está na criação destes módulos como abstrações que utilizam programação dinâmica para a configuração do sistema. Através da passagem de parâmetros é possível informar a quantidade de canais de entrada e saída ou, também conforme ilustrado na figura 33, a distância entre as caixas de som em sua criação. A estrutura do protótipo final, isto é, como os patches e subpatches foram construídos e concatenados, é mostrada na figura 34.

A GUI do Patch principal desenvolvido em $P d$ para testes do sistema de WFS é mostrada na figura 35. Nela pode ser vista a sala virtual, onde a coordenada $x$ pode variar de $-1 \mathrm{~m}$ até $1 \mathrm{~m}$ e a coordenada $y$ pode variar de $-1.2 \mathrm{~m}$ (linha de referência) até $4 \mathrm{~m}$. Neste exemplo, é mostrada uma configuração para 5 fontes sonoras, que podem ter suas posições monitoradas pelas caixas de número que estão no canto superior esquerdo. Dentro do subpatch "pd WFS" estão as conexões de áudio de entrada e saída e abstrações para o Pure Data, onde são informados os dados de configuração (quantidade de entradas, quantidade de saídas, posição dos alto-falantes e linha de referência), feitos os cálculos e realizado o processamento. A entrada de áudio que envia o sinal que pode ser de um arquivo de áudio do computador, da entrada de som externa (via placa de som) ou um som sintetizado no próprio patch. Opcionalmente pode ser utilizado o player, que está no canto inferior esquerdo, para onde podem ser importados arquivos de áudio e suas saídas monitoradas pelos sliders e controles de volume que são mostrados à direita.

A implementação do sistema na forma de abstrações e subpatches que utilizam programação dinâmica para se instanciarem garante uma simplicidade grande de manutenção do sistema, conforme mostra a figura 36. Tal solução também se mostrou eficaz devido à portabilidade e à facilidade de integração com outros sistemas ou outros patches.

A posição de cada objeto sonoro poderá ser informada por dispositivos externos (como 


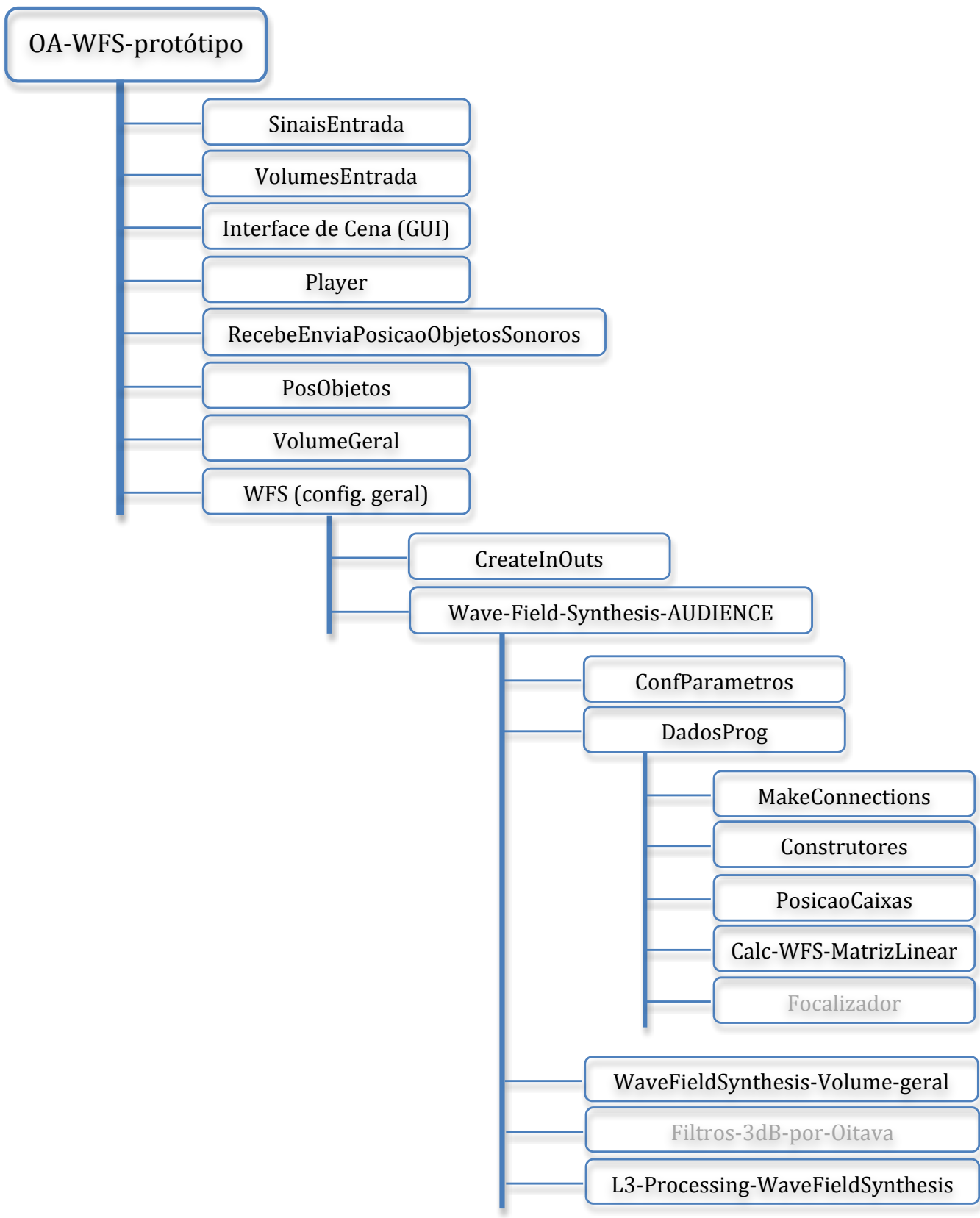

Figura 34 - Organização do patch do protótipo de WFS para o sistema OpenAUDIENCE e seus respectivos subpatches. Os subpatches em cinza não foram utilizados no teste final. 




Figura 35 - GUI do Patch principal desenvolvido em $P d$ para testes do sistema de WFS do OpenAUDIENCE.

sensores), por interfaces do AUDIENCE ou mesmo por outros programas, podendo substituir ou trabalhar conjuntamente com a interface de controle já implementada para o protótipo desenvolvido, conforme ilustrado na figura 37. Instrumentos eletrônicos, como os teclados controladores e os mais modernos computadores, também podem controlar os sons no espaço de audição em tempo real ou de forma programada, permitindo que, como exemplo de aplicação, sejam colocados sensores adaptados a instrumentos musicais que variam suas coordenadas conforme mudam suas localizações num dado referencial.

\subsection{Testes de funcionamento realizados no protótipo final}

O protótipo final do sistema de WFS para o sistema OpenAUDIENCE foi testado em laboratório com matriz de 16 alto-falantes. Foi realizado um teste subjetivo 10 voluntários com idades entre 20 e 60 anos e profissão não relacionada a temática da pesquisa, que identificaram a localização de fontes sonoras, conforme sua percepção auditiva. A escolha de tais voluntários foi 


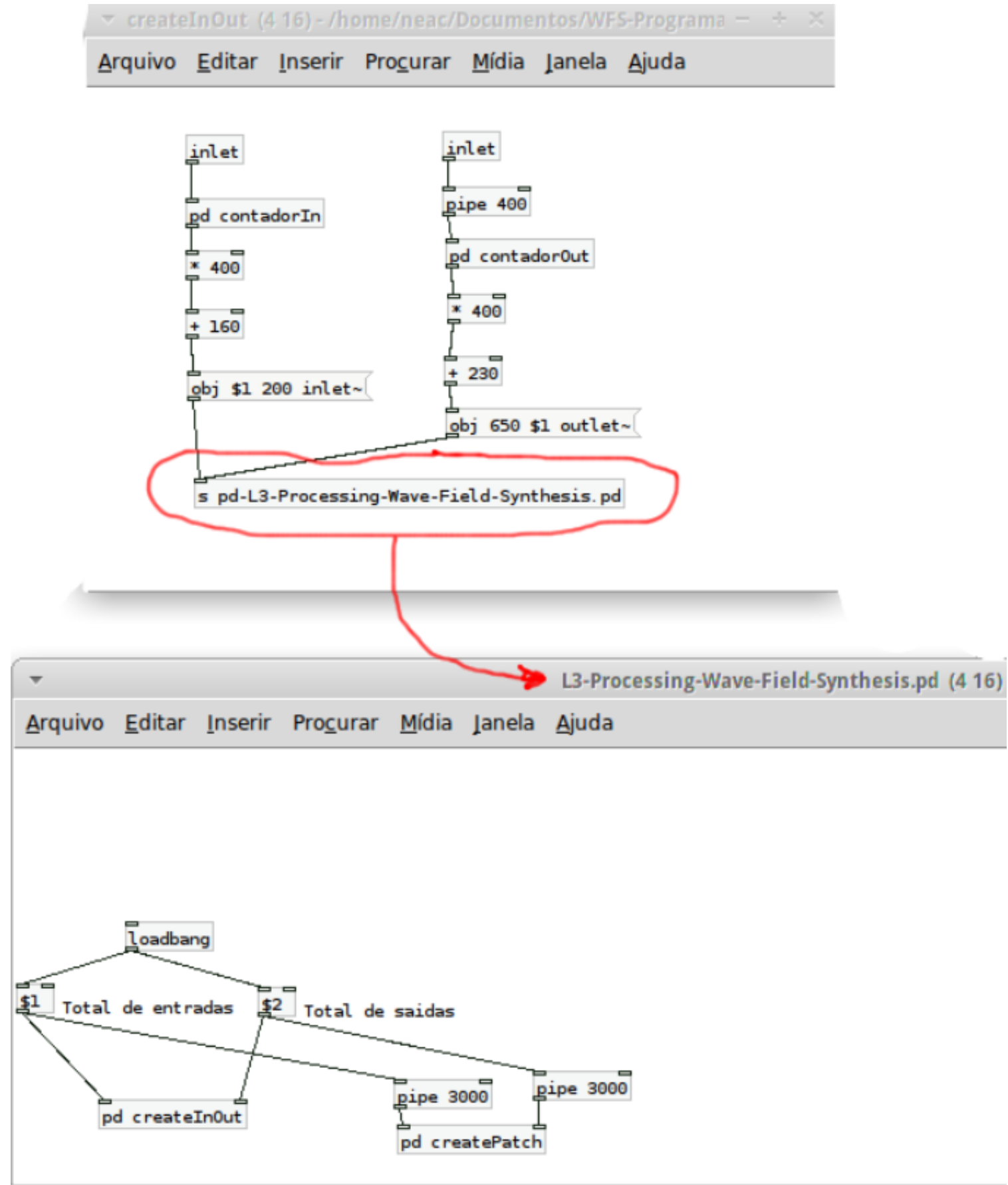

Figura 36 - Exemplo de código de abstração funcional gerativa do sistema (criação dinâmica de objetos em patch).

feita de forma aleatória, através de um convite verbal, explicando qual a finalidade e quais as etapas compunham o teste.

Foi construído dinamicamente um patch com 16 canais de saída, sendo suas conexões de áudio de entrada e saída roteados via $J A C K$. Da mesma forma que na seção 4.4, foi usado o programa Ardour para distribuir os canais para a execução dos arquivos de áudio que são enviados para o $P d$, com os instrumentos organizados em pistas (tracks) diferentes e tocados repetidamente durante os testes. As saídas de áudio do Ardour foram conectadas às entradas 


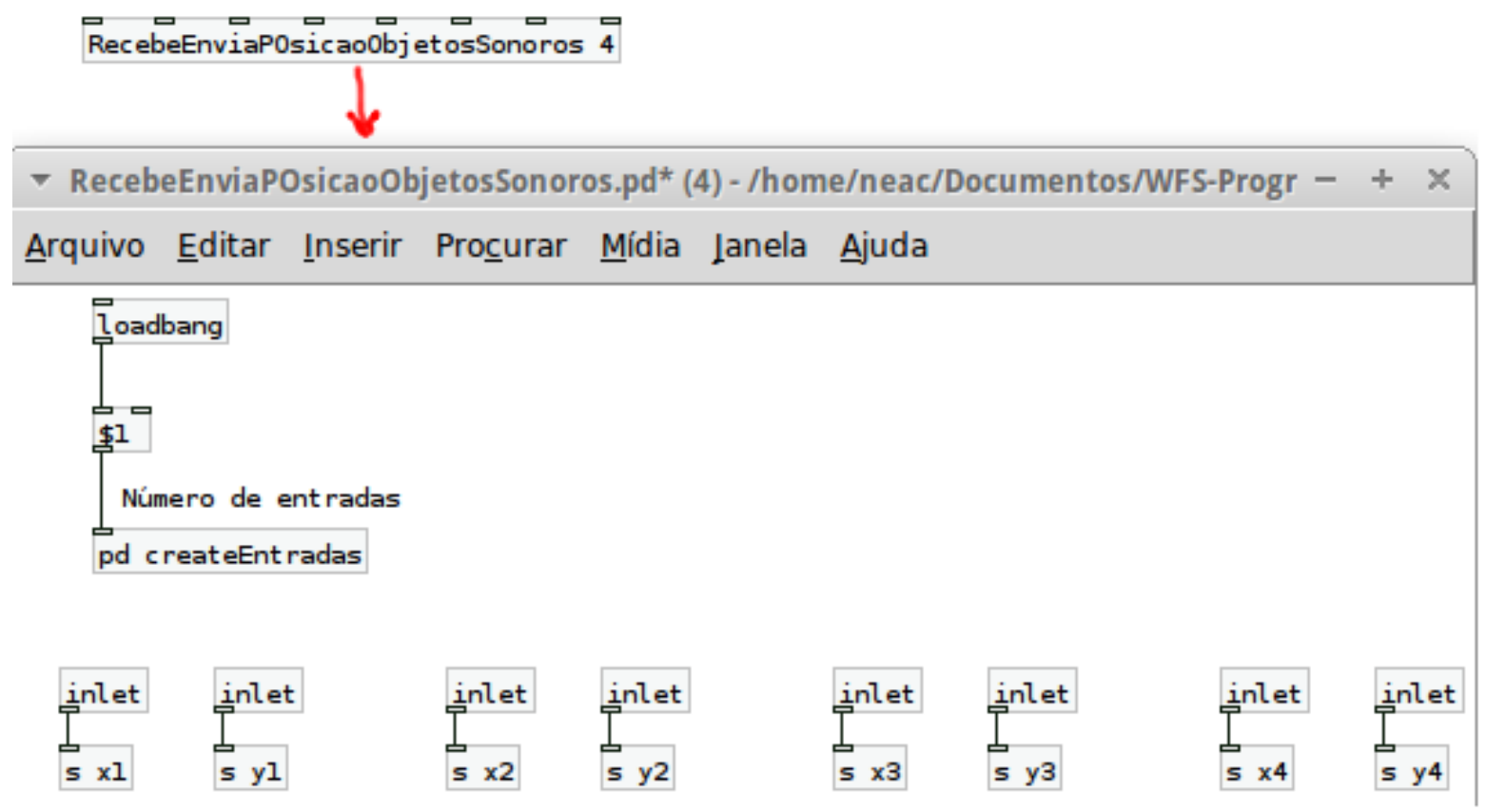

Figura 37 - Qualquer dispositivo que envie as coordenadas $x$ e $y$ para as entradas da abstração RecebeEnviaPOsicaoObjetosSonoros altera a posição da fonte sonora no Pd.

do programa para WFS, que por sua vez tem saídas de áudio conectadas à saída do sistema (interface de áudio), conforme pode ilustrado pela figura 38. Foram colocadas 4 amostras de áudio (arquivos .wav) com resolução de $44100 \mathrm{~Hz}$. A seguir a descrição destes arquivos:



Figura 38 - Na interface gráfica Patchage podem ser visualizadas as conexões feitas pelo JACK. As saídas de áudio do Ardour foram conectadas às entradas do programa para WFS do OpenAUDIENCE, que por sua vez tem saídas de áudio conectadas à saída do sistema.

gota.wav gravação, com duração de 0,05 segundo, de uma gota de água tocando uma superfície de água, com maior intensidade sonora para frequências com valores entre $900 \mathrm{~Hz}$ e $1500 \mathrm{~Hz}$, conforme mostra seu espectro de frequências na figura 25c. 


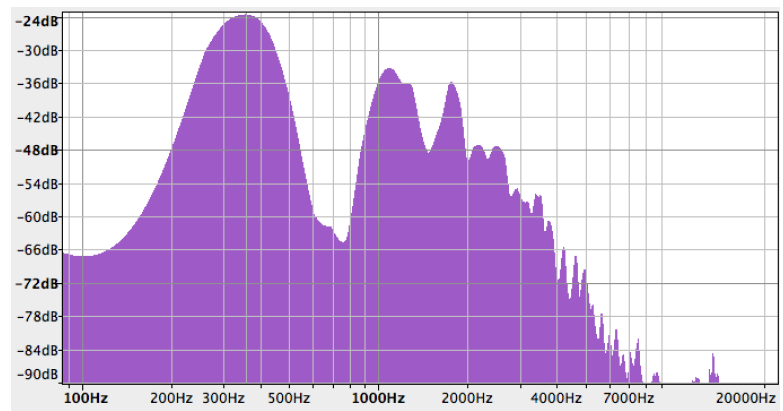

(a) Espectro de "Cl.wav".

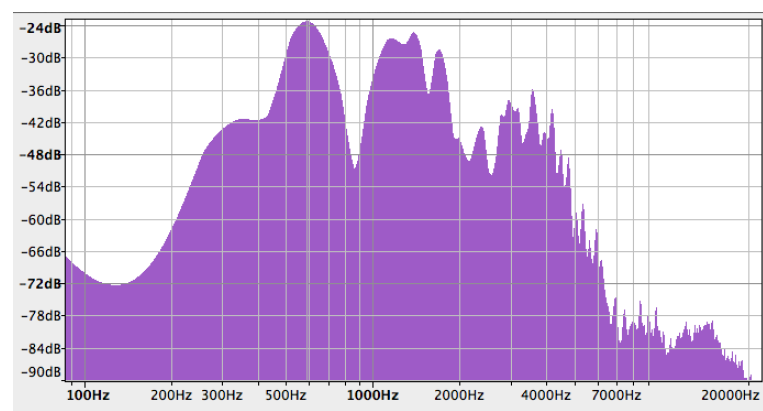

(b) Espectro de "Ob.wav".

Figura 39 - Espectros de frequências dos sons usados no teste.

campana.wav gravação de um tom agudo de 2 segundos de uma campainha percurtida, com maior intensidade sonora para frequências em torno de $1000 \mathrm{~Hz}$ (pico de intensidade), $2500 \mathrm{~Hz}$ e $5000 \mathrm{~Hz}$ (acima da frequência de aliasing), conforme mostra seu espectro de frequências na figura $25 \mathrm{~b}$.

Cl.wav execução de uma frase musical com 4 segundos de duração tocada por uma clarineta, com maior intensidade sonora para frequências nas faixas de 250 a $490 \mathrm{~Hz}$ (picos de intensidade), 1000 a $1300 \mathrm{~Hz}$ e em torno de $1700 \mathrm{~Hz}$, conforme mostra seu espectro de frequências, correspondente à soma de todos os sons deste arquivo de áudio, na figura 39a.

Ob.wav execução de uma frase musical com 4 segundos de duração tocada por um oboé, com maior intensidade sonora para frequências nas faixas de 530 a $650 \mathrm{~Hz}$ (picos de intensidade), 1100 a $1300 \mathrm{~Hz}$ (com valor próximo ao da faixa anterior) e em torno de 3500 $\mathrm{Hz}$, conforme mostra seu espectro de frequências, correspondente à soma de todos os sons deste arquivo de áudio, na figura $39 b$.

As frases musicais executadas pela clarineta e pelo oboé fazem parte da peça The Unanswered Question, composta em 1908 por Charles Ives, e a partitura deste trecho é mostrado na figura 40.

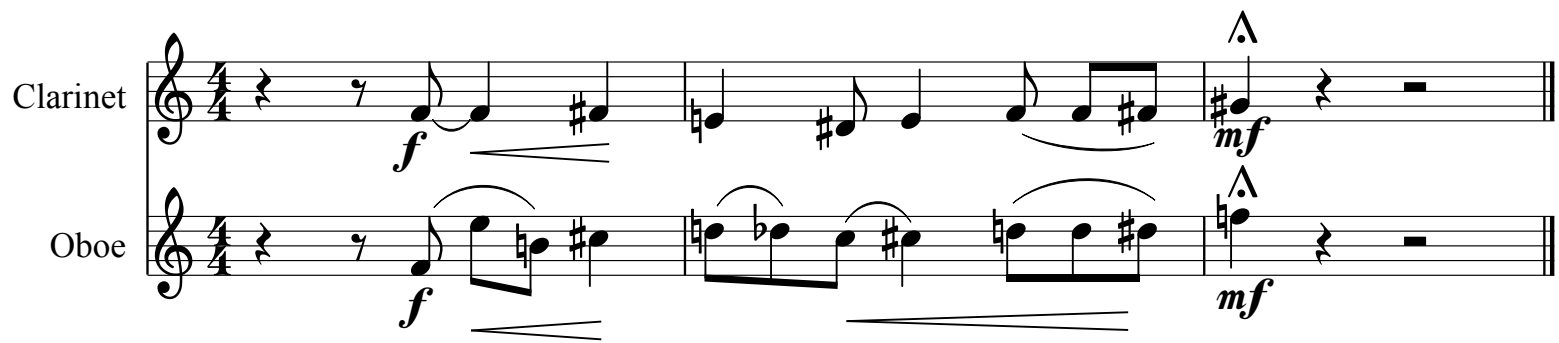

Figura 40 - Partitura do trecho da peça The Unanswered Question, composta por Charles Ives, executado pela clarineta e pelo oboé para o teste do protótipo final.

Inspirado na experiência descrita por Montag (2011, pg. 67-73), foi montado um setup para os testes no qual uma cortina preta ortofônica que escondia os alto-falantes foi colocada a 
$0,18 \mathrm{~m}$, a frente da matriz linear de alto-falantes, com uma régua em sua base, sobre o mesmo eixo (de ordenada $y=-0,18 \mathrm{~m}$ ). A linha de referência foi fixada na posição $\mathrm{y}=-1,2 \mathrm{~m}$, o limite para as projeções virtuais foi limitado a $4 \mathrm{~m}$ atrás da matriz de alto-falantes e foram deixados 2,3 $\mathrm{m}$ depois da linha de referência para o posicionamento dos ouvintes. A descrição deste ambiente pode ser vista na figura 41.

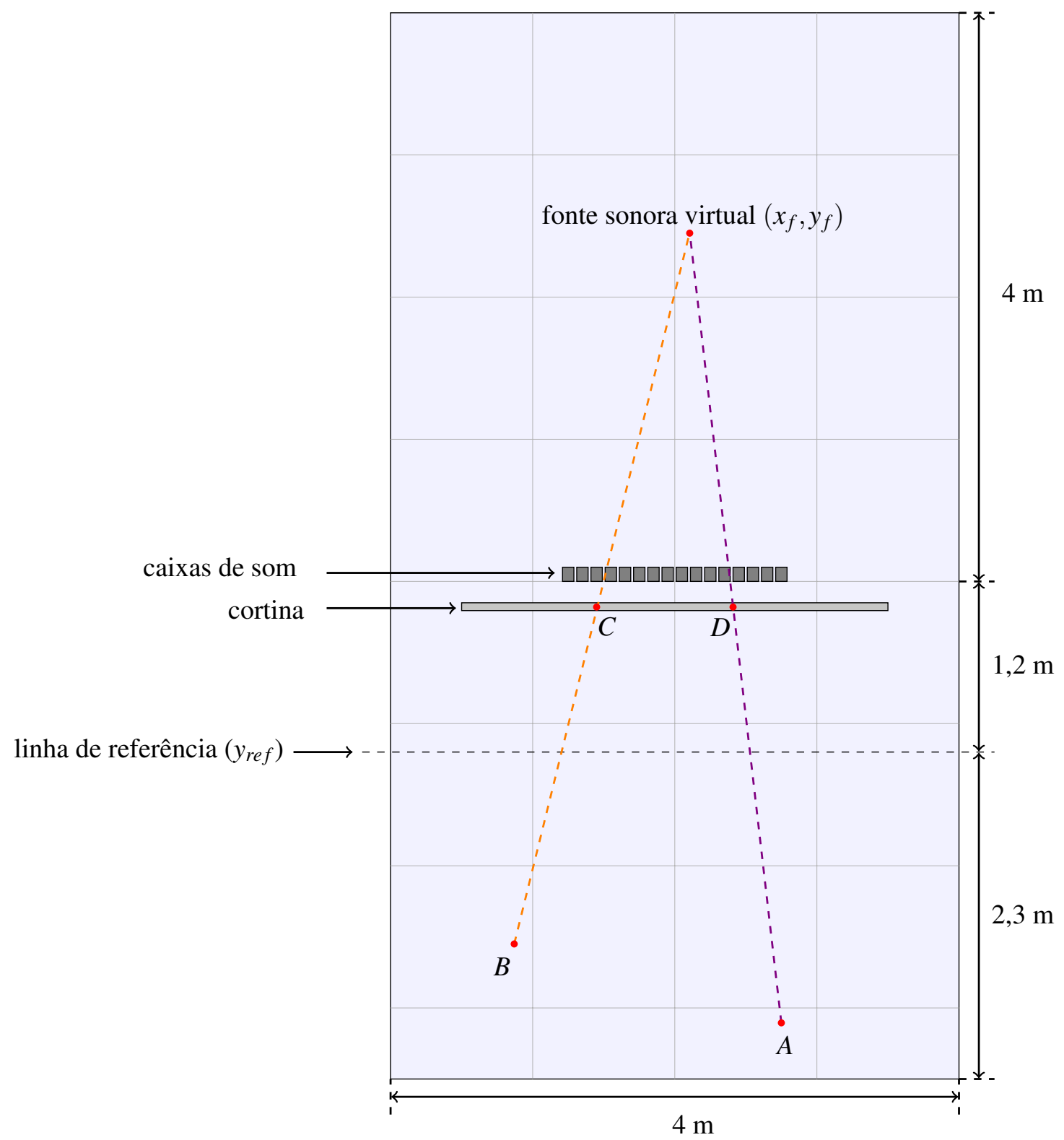

Figura 41 - Configuração da sala para os testes com WFS. A cortina está a $0,18 \mathrm{~m}$ da matriz de alto-falantes. Cada ouvinte fez duas audições: uma na posição representada pelo ponto $\mathrm{A}$, que tem coordenadas $\mathrm{x}=0,725$ $\mathrm{m}$ e $\mathrm{y}=-3,105 \mathrm{~m}$, e outra audição na posição representada pelo ponto $\mathrm{B}$, que tem coordenadas $\mathrm{x}=-1,13 \mathrm{~m}$ e $\mathrm{y}=-2,505 \mathrm{~m}$.

Os testes de avaliação do sistema consistiram no quanto os ouvintes poderiam indicar a projeção sonora esperada para cenas sonoras simples. Os sons das 4 fontes sonoras testadas foram calibrados em volume tentando-se ajustar à percepção real da escuta destes tipos sonoros, considerando-se as posições em que ficariam os ouvintes. No início, os sons que seriam usados 
no teste foram expostos aos ouvintes para que estes pudessem entender melhor as instruções passadas pelo pesquisador. Foram usadas fontes sonoras pontuais paradas atrás e em frente aos alto-falantes, projetadas nos quatro quadrantes do plano cartesiano. Para cada posição foram realizadas 4 audições, totalizando 8 audições por ouvinte. As fontes sonoras objeto 1 (gota) e objeto 2 (campana) foram escutadas separadamente; as fontes instrumentais objeto 3 (clarineta) e objeto 4 (oboé) foram escutadas simultaneamente. Os ouvintes deveriam ficar em duas posições previamente definidas: o ponto A que tinha coordenadas $(0,725 ;-3,105)$ e o ponto B com coordenadas $(-1,13 ;-2,505)$, no referencial adotado para a experiência.

Durante o teste, os participantes, um por vez, deveriam apontar um feixe de laser na direção em que a fonte sonora era percebida, gerando um ponto iluminado na cortina do qual era medida na régua a coordenada $x$, o valor da coordenada $y$ já era conhecido $(\mathrm{y}=-0,18 \mathrm{~m})$. A partir do teste feito com o ouvinte sobre o ponto A media-se o ponto $\mathrm{D}$ e partir do teste feito com o ouvinte sobre o ponto $\mathrm{B}$ media-se o ponto $\mathrm{C}$. A intersecção das retas $\mathrm{AD}$ (que passa pelos pontos A e D) e BC (que passa pelos pontos B e C) é o ponto no qual o ouvinte percebeu o objeto. Uma explicação detalhada sobre o método para o cálculo da posição da fonte sonora é descrito no apêndice B que mostra como as medidas coletadas produziram as medidas estimadas de posição de cada fonte sonora no espaço de audição criado.

As projeções selecionadas tinham as seguintes coordenadas cartesianas (em metros). Estas posições correspondem às mostradas na figura 35 (a quinta fonte sonora não foi usada), a interface gráfica de usuário do Patch principal desenvolvido em $P d$ para o sistema de WFS do OpenAUDIENCE. Os casos avaliados foram os seguintes:

Caso 1: avaliação da posição do objeto $1(0,61 ; 1,20)$, som de choque de gota d'água com água.

Caso 2: avaliação da posição do objeto $2(-0,50 ;-0,61)$, som de tom de campainha (campana).

Caso 3: avaliação da posição do objeto $3(0,56 ;-0,21)$ e posição do objeto $4(-0,60 ; 0,93)$, tocados simultaneamente, respectivamente o som de uma passagem tocada por uma clarineta e um oboé, cujas partes são mostradas na figura 40, de aproximadamente 4 segundos.

\subsubsection{Apresentação dos resultados do teste subjetivo}

A tabela 2 resume algumas estatísticas dos resultados obtidos no teste subjetivo onde são mostrados as distâncias (em metros, chamadas de erros) entre cada posição de fonte sonora projetada pelo protótipo de WFS para o OpenAUDIENCE e a posição calculada baseada nas estimativas dadas por cada ouvinte. O erro médio obtido entre todos os ouvintes e para todas as fontes sonoras foi $0,84 \mathrm{~m}$, com um desvio padrão de $0,21 \mathrm{~m}$, portanto o erro poderia chegar a $1,05 \mathrm{~m}$. A fonte sonora que apresentou menor erro médio foi o objeto 3 (clarineta) de 0,42 m, com um desvio padrão de $0,25 \mathrm{~m}$, e a que apresentou maior erro médio foi o oboé (objeto 4), de 
1,32 m, com um desvio padrão de 0,33 m. Considerando o quanto os valores máximos que cada erro pode alcançar, teremos estimativa máxima de erro para o objeto 1 (gota) de 1,54 m, para o objeto 2 (campana) de $0,94 \mathrm{~m}$, para o objeto 3 (clarineta) de $0,67 \mathrm{~m}$ e para o objeto 4 (oboé) de $1,65 \mathrm{~m}$.

A figura 42 mostra os diagramas de dispersão obtidos para cada uma das 4 fontes sonoras. As posições das projeções feitas pelo protótipo das fontes sonoras no espaço de audição são indicadas pelo círculo (um dos dois pontos maiores) e pelos pontos menores para formar os diagramas de dispersão das estimativas de posições levantadas no teste subjetivo. A média das estimativas é indicada com a marca quadrada e nela estão indicados seus respectivos desvios padrão, por meio das barras de incerteza. A escala está em metros. Conforme observado nesta figura, apenas o valor esperado pelo objeto 3 (clarineta) está de acordo com o valor estimado pelo experimento, pois se encontra dentro dos limites estabelecidos pelas barras de incerteza. $\mathrm{O}$ valor estimado mais discrepante com relação ao valor esperado foi o do objeto 4 (oboé), passando $0,86 \mathrm{~m}$ do limite estabelecido pela barra de incerteza relativa ao eixo $y$.

Tabela 2 - Resultados do teste subjetivo para o protótipo final de WFS para o OpenAUDIENCE. As medidas estão em metros e descrevem a diferença da posição (erros) entre o valor esperado e os valores estimados pelos ouvintes.

média erros do ouvinte Erro obj1 Erro obj2 Erro obj3 Erro obj4 média erros

$\begin{array}{llllll}\text { ouvinte 1 } & 1,21 & 0,44 & 0,22 & 1,12 & 0,75 \\ \text { ouvinte 2 } & 1,94 & 0,25 & 0,61 & 1,64 & 1,11 \\ \text { ouvinte 3 } & 1,29 & 1,03 & 0,96 & 1,97 & 1,31 \\ \text { ouvinte 4 } & 1,50 & 1,03 & 0,14 & 0,89 & 0,89 \\ \text { ouvinte 5 } & 0,28 & 0,56 & 0,43 & 1,55 & 0,70 \\ \text { ouvinte 6 } & 0,49 & 0,72 & 0,38 & 1,45 & 0,76 \\ \text { ouvinte 7 } & 1,25 & 0,37 & 0,27 & 1,12 & 0,75 \\ \text { ouvinte 8 } & 0,56 & 0,85 & 0,26 & 1,01 & 0,67 \\ \text { ouvinte 9 } & 0,19 & 0,71 & 0,66 & 1,32 & 0,72 \\ \text { ouvinte 10 } & 1,01 & 0,69 & 0,31 & 1,10 & 0,78 \\ \text { Media geral } & 0,97 & 0,67 & 0,42 & 1,32 & 0,84 \\ \text { Desvio padrão } & 0,57 & 0,27 & 0,25 & 0,33 & 0,21\end{array}$




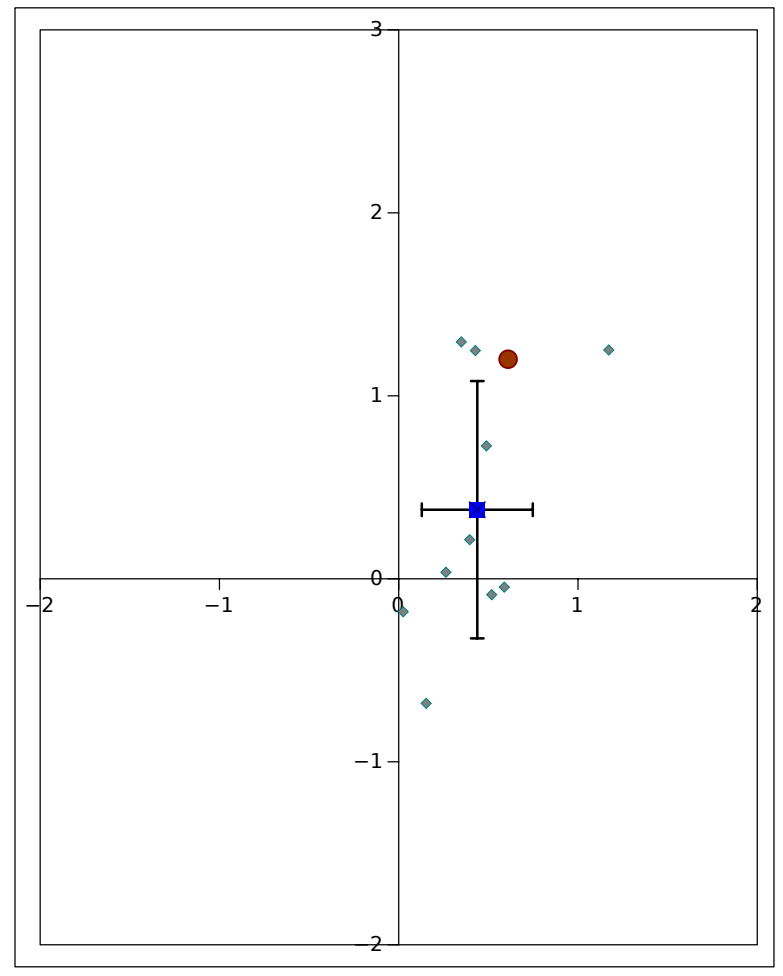

(a) Resultados para o objeto 1 (gota).

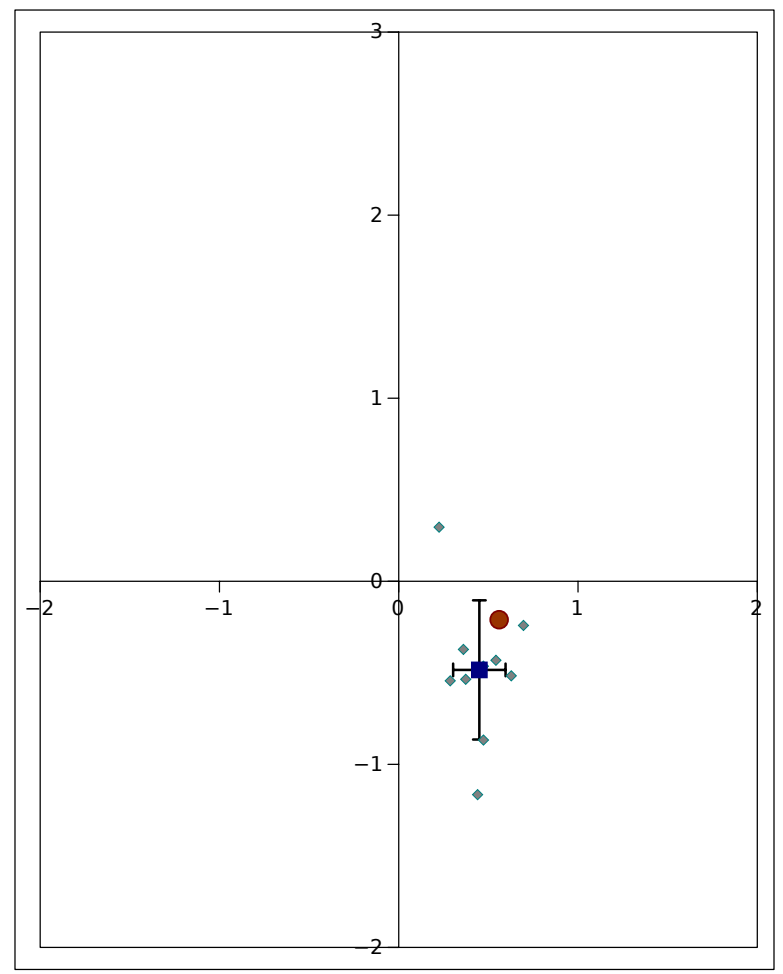

(c) Resultados para o objeto 3 (clarineta).



(b) Resultados para o objeto 2 (campana).

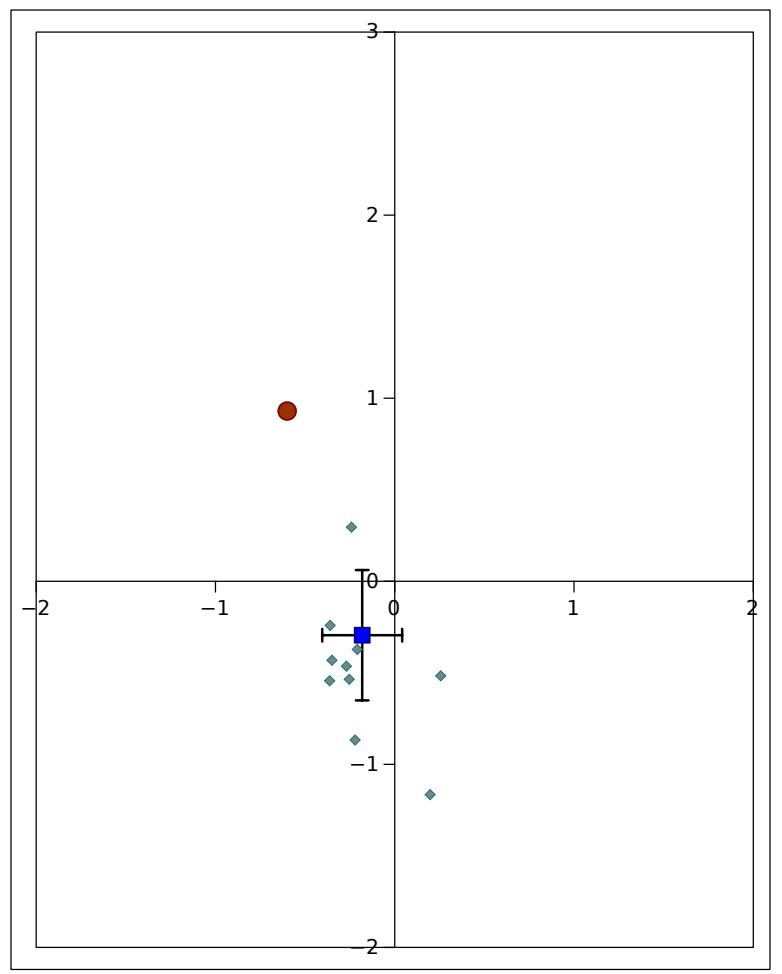

(d) Resultados para o objeto 4 (oboé).

Figura 42 - Posições das projeções das fontes sonoras no espaço de audição (círculo maior) e pontos menores para formar os diagramas de dispersão das estimativas de posições levantadas no teste subjetivo feitas pelo protótipo de WFS para o sistema OpenAUDIENCE. A média das estimativas é indicada com a marca quadrada e nela estão indicados seus respectivos desvios padrão, por meio das barras de incerteza. A escala está em metros. 


\section{CONCLUSÕES}

Esta pesquisa abre um promissor campo de trabalho para a realização prática de aplicações de WFS no universo musical e em áreas como realidade virtual e realidade aumentada, espacialização sonora, sonorização de ambientes, museus e instalações sonoras, cinema e auditórios. Desperta interesse a relativa facilidade do uso desta técnica para a modelagem de fontes sonoras instrumentais, a possibilidade de conectar o algoritmo de WFS a algoritmos de simulação acústica, e a possibilidade de usufruir da estabilidade da imagem sonora produzida em vários pontos de escuta simultaneamente, diferentemente do que ocorre nos formatos limitados a hot-spots, como Ambisonics.

Muitos problemas de configuração ocorreram, tomando muito tempo e mostrando quais caminhos seriam proibitivos e quais seriam viáveis para se implementar e testar os programas para WFS com o hardware disponível.

O patch desenvolvido para o sistema OpenAUDIENCE pode ser utilizado em aplicações de espacialização sonora com número de canais (alto falantes) e fontes sonoras variáveis, podendo acomodar matrizes de dezenas de alto-falantes em um sistema de interfaces multicanal, ficando limitado à disponibilidade de interfaces e poder de processamento do computador.

As avaliações feitas nas dependências do NEAC, em dois computadores com sistemas operacionais diferentes (Mac Os X e Linux Ubuntu Studio), indicam que o programa desenvolvido para WFS pode ser utilizado por qualquer usuário que tiver um uma matriz linear de alto-falantes e é de mais fácil operação do que os outros programas testados.

A divisão do programa desenvolvido neste projeto em uma implementação computacional modular como um patch do Pure Data, permite que o sinal enviado possa ser de um arquivo de áudio do computador, da entrada de som externa (via placa de som) ou um som sintetizado no próprio patch.

A matriz básica de 16 canais implementada tem uma frente de projeção de 1,456 m. As caixas foram dispostas lado-a-lado com distância entre drivers de aproximadamente $0,091 \mathrm{~m}$. Esta matriz mostrou-se viável para escalamento do sistema para um número maior de alto-falantes cobrindo uma área de projeção de frente de onda maior.

\subsection{Discussão dos resultados}

Analisando-se os resultados apresentados na seção 4.6, buscou-se entender as razões pelas quais a variação foi maior para o objeto 4 (oboé). A divergência maior apontada entre a posição projetada do oboé e as medidas coletadas no teste, levam a hipótese de que existe maior dificuldade dos ouvintes em discernir dois instrumentos de sopro tocando simultaneamente. 
Desta forma, deve-se levar em consideração que os ouvintes provavelmente confundiram o som do oboé com o som da clarineta, em uma passagem relativamente mais longa de 4 segundos.

Com relação ao teste realizado com o som do objeto 1 (gota), foi calibrado em volume - como os demais - para corresponder ao volume natural deste tipo de som escutado a certa distância do ouvinte, de forma que foi o som de menor volume entre todos. Provavelmente a atenuação esperada no seu volume devido ao seu posicionamento mais distante no espaço virtual contribuiu para dificultar sua localização.

O melhor sistema seria aquele em que as distâncias entre a posição projetada (círculos que marcam as fontes sonoras) e a posição média das medidas estimadas das posições das fontes (quadrados) fosse mínima. Por essa métrica observamos que o objeto 4 (oboé) teve o pior resultado $(1,29 \mathrm{~m})$ e o objeto 3 (clarineta) o melhor resultado $(0,30 \mathrm{~m})$.

Também observamos que a grande maioria das posições estimadas no teste subjetivo (95\%) caíram dentro do raio de cobertura do array de alto-falantes, mesmo tendo sido posicionadas as fontes em locais limítrofes e desafiadores para o tamanho do array usado. Isto sugere que com um número maior de alto-falantes os acertos de posição poderiam ser maiores.

Os resultados preliminares foram promissores, já que foi possível aos ouvintes acertar o quadrante da projeção do objeto, ressaltando-se que o ambiente de aplicação não estava completamente adaptado para tal atividade, sugerindo que condições acústicas devem ter influenciado os resultados. Idealmente a salas para estes testes devem ser anecóicas. Segundo Belloch et al. (2013), um dos problemas práticos de WFS é que sala de escuta introduz novos ecos que não estão incluídos no sinal a ser reproduzido pela matriz de alto-falantes, alterando, assim, o campo de som sintetizado e reduzindo o efeito espacial. Para testes futuros, condições acústicas adequadas serão importantes para testes mais rigorosos, pois não foi possível estimar a influência da acústica local sobre os resultados obtidos. Além disso, mesmo que esta influência seja estimada, o aprimoramento destes estudos deve levar em consideração toda a complexidade da escuta, ou seja, os estudos psicoacústicos que tratam da percepção humana de localização de sons no espaço.

\subsection{Principais contribuições deste trabalho}

Além de apresentar algumas das formulações mais relevantes propostas na literatura para o operador WFS, podemos ainda citar como contribuições importantes deste trabalho:

- a análise de algumas implementações da técnica em programas de referência disponíveis, o que propiciou um mapeamento das principais funções a serem implementadas e integradas num sistema de auralização por WFS;

- a modelagem e construção de um protótipo em linguagem de patches numa implementação aberta e compatível com a arquitetura de auralização modular AUDIENCE; 
- a implementação automatizada dos patch e subpatches do protótipo, empregando-se uma estratégia de programação dinâmica de patches (construção dinâmica e em tempo real dos fluxos de processamento).

O módulo de sonorização desenvolvido para o sistema OpenAUDIENCE pode ser utilizado na criação de cenas sonoras virtuais espaciais e modelar a sensação de localização de cada fonte sonora no espaço de audição, podendo assim ser útil em aplicações de espacialização sonora, como o desenvolvimento de instrumentos espaciais virtuais e modelagem física de espaços de audição.

O patch de WFS para o sistema OpenAUDIENCE é um protótipo extensível. A simplicidade de seu uso, com módulos independentes e reconfiguráveis, possibilita conectar o algoritmo de WFS a outros algoritmos de simulação acústica, podendo vir a se tornar uma alternativa aos aplicativos que executam esta função. O maior desafio na continuidade deste projeto é conceber uma forma de codificação que permita a escolha da geometria final do sistema de alto-falantes, deixado para o futuro. De qualquer modo, na presente arquitetura, isto implicaria num novo código de cálculo de parâmetros na camada 2 (L2), não interferindo nos códigos de outras camadas.

O protótipo de WFS para o sistema OpenAUDIENCE é reconfigurável dinamicamente e se mostrou bastante flexível e versátil, permitindo a diminuição do esforço necessário para a configuração do sistema. Além disso, trouxe facilidade de integração com os diversos recursos do Pd, principalmente com outros patches e entradas e saídas de programas no universo do áudio e da música, facilitando o uso desta técnica de sonorização em trabalhos de composição, gravações, apresentações, colaborações musicais interativas e aplicações que preconizem efeitos de espacialização sonora, alargando as possibilidades de auralização com instrumentações musicais. O uso do módulo WFS no sistema AUDIENCE permite sua integração, de modo flexível, a outras técnicas de auralização já nele implementadas e de forma extensiva a qualquer programa implementado no $P d$.

Neste trabalho foi desenvolvida uma matriz básica com 16 canais, que poderá servir de base para implementações futuras, podendo atingir, por exemplo, 64 alto-falantes que era a meta prevista no escopo do projeto temático MOBILE ${ }^{1}$, um dos pontos de partida deste projeto. Desta forma os resultados esperados deste projeto de mestrado serão matrizes perfeitamente utilizáveis num projeto de WFS maior.

\subsection{Trabalhos futuros}

Como desdobramentos a curto prazo, deseja-se realizar experimento no qual se utilize objetos sonoros que apresentam propriedades espectrais semelhantes como, por exemplo, ins-

1 MOBILE: Processos Musicais Interativos. Acesso ao site em <http://www.eca.usp.br/mobile/portal/> 
trumentos de uma mesma família (como violinos e violas) para isolar as possíveis variações induzíveis na percepção espacial de objetos de diferentes assinaturas espectrais e, além disso, levar em consideração o padrão de irradiação da fonte sonora na sua especificação, para testar condições mais realistas de auralização. Deve-se explorar as diferenças de sons com ataque bem pronunciado, nos quais predominam seus transientes (como sons percussivos), sons quase sem transientes (como violas e violinos) ou sons preponderantemente estacionários e avaliar como funciona o sistema com vozes humanas (fala e canto). Também considera-se fazer experimentações com instrumental virtual espacial, explorando a capacidade do sistema em produzir ilusões holográficas geradas pela criação e manipulação de fontes pontuais.

De acordo com Belloch et al. (2013), o princípio de Huygens pode ser usado para sintetizar as frentes de onda acústicas de uma forma arbitrária. Uma das ideias em vista, batizada como controle de foco, é citada inicialmente no item 4.3. Quando manipulados, sliders destinados a esta função enviam, de forma independente, a um bloco chamado de focalizador, o valor dos fatores que serão aplicados aos cálculos de atrasos nos sinal de áudio e de intensidade sonora de cada canal de áudio, mudando a contribuição do som gerado por cada alto-falante na frente de onda sintetizada. Em uma primeira implementação do recurso de foco espera-se avaliar, com a alteração destes parâmetros, como seriam as possíveis deformações da forma circular da frente de onda gerada por WFS.

Como desdobramentos a médio e longo prazo, espera-se construir uma matriz com maior cobertura espacial, de 32, 64 e mais alto-falantes, e que sejam adaptáveis a um sistema de suporte e sustentação dos alto-falantes, que seja adaptável a diferentes configurações geométricas e alturas. Além disso, sugere-se um estudo de simulação para visualização das frentes de onda geradas de forma a mapear as formas e evolução. Do ponto de vista da percepção auditiva das trajetórias de fontes em movimento, sugere-se um estudo para mapear a variação do perfil de loudness (volume) ao longo do espaço de escuta, principalmente para verificar-se variações indesejadas nas proximidades das caixas e ao atravessar do espaço virtual ao real.

Neste trabalho foi dada uma ênfase muito maior à tarefa de modelagem e prototipagem do módulo de auralização por WFS, à concepção de uma estratégia de programação dinâmica, e à sua sua integração com a arquitetura de referência de auralização (AUDIENCE), sendo deixada para trabalhos futuros a validação formal e operacional do sistema. Esta exigiria uma instalação de hardware (computadores, interfaces e distribuição de áudio) e configuração do software operacional em um ambiente acusticamente tratado para a realização de testes sistêmicos, objetivando validar a operação (funcionamento como esperado) do sistema como um todo.

Para um resultado menos suscetível a interferências com a acústica local, estes testes deveriam ser realizados em um ambiente (sala) preferencialmente seca (baixo RT60). Além disto, para atestar a qualidade e precisão das imagens sonoras produzidas deveria ser usada uma matriz de alto-falantes com dimensões da mesma ordem das dimensões físicas da sala de audição, exigindo-se, portanto, um número maior de alto-falantes, que não tínhamos disponível para este 
projeto.

Espera-se explorar a técnica de WFS, considerando suas limitações, principalmente aquelas relacionadas ao seu setup de sonorização, como o aliasing espacial, buscando-se estender os resultados práticos para as variações das distâncias entre as caixas de som, pesquisando-se as alternativas técnicas a estas limitações.

Dentro das perspectivas modernas de comunicação e tecnologia, espera-se que haja interatividade dos sons e imagens gerados para a criação de cenas virtuais com movimentos e gestos humanos, sugerindo que a execução, a escuta e a composição de novas peças musicais poderão lançar mão da utilização de imagens sonoras móveis formadas no espaço de audição, abrindo perspectivas para a realidade musical aumentada, combinando instrumentos reais e virtuais, isto é, que possam ter a sua percepção virtualizada.

O módulo de auralização para WFS e seu respectivo código serão disponibilizados posteriormente junto à distribuição da bilbioteca OpenAUDIENCE no site do NEAC em <www. 1si.usp.br/audience>. Esta solução é aberta, permitindo que outros pesquisadores utilizem-na em seus estudos. 


\section{Referências}

AHRENS, J.; GEIER, M.; SPORS, S. Introduction to the SoundScape Renderer (SSR). Quality and Usability Lab Deutsche Telekom Laboratories Technische Universität Berlin, 2012. Disponível em https://dev.qu.tu-berlin.de/projects/ssr/files.

BAALMAN, M. A. J. On wave field synthesis and the electro-acoustic music: State of the art 2007. In: Proceedings of the International Computer Music Conference 2007. [S.1.: s.n.], 2007.

BAALMAN, M. A. J. On Wave Field Synthesis and Electro-acoustic Music: With a Particular Focus on the Reproduction of Arbitrarily Shaped Sound Sources. Tese (Doutorado) Technischen Universität Berlin, 2008.

BAALMAN, M. A. J. et al. Renewed architeture of the $s W O N D E R$ software for wave field synthesis on large scale systems. In: Linux Audio Conference 2007. [S.1.: s.n.], TU Berlin, 2007. p. 76-83.

BELLOCH, J. A. et al. Gpu-based wfs systems with mobile virtual sound sources and room compensation. 52nd International AES Conference: Sound Field Control-Engineering and Perception, 2013.

BERKHOUT, A. J.; VRIES, D. de; VOGEL, P. Acoustic control by wave field synthesis. The Journal of the Acoustical Society of America, Acoustical Society of America, v. 93, n. 5, p. 2764-2778, 1993.

BRANDENBURG, K.; BRIX, S.; SPORER, T. Wave field synthesis: From research to applications. In: Proceedings of the European Signal Processing Conference. Vienna, Austria. [S.l.: s.n.], 2004.

BRAUN, H. J. Music and technology in the twentieth century. [S.1.]: The John Hopkins University Press, Baltimore, 2000.

CHION, M. Músicas, media e tecnologias. Lisboa: Instituto Piaget, 1994.

FARIA, R.; ZUFFO, J. An auralization engine adapting a 3d image source acoustic model to an ambisonics coder for immersive virtual reality. In: AUDIO ENGINEERING SOCIETY. 28th International AES Conference: The Future of Audio Technology-Surround and Beyond. [S.1.], 2006.

FARIA, R. R. A. Auralização em ambientes audiovisuais imersivos. Tese (Doutorado) Universidade de São Paulo, 2005.

FARIA, R. R. A. Audience for pd, a scene-oriented library for spatial audio. Proceedings of Pure Data Convention, Weimar - Berlin, Germany, 2011.

FARIA, R. R. A. The tempered space on the design of spatial musical instruments. Anais do 18th International Congress on Sound and Vibration, International Institute of Acoustics and Vibration, Rio de Janeiro, 2011.

FARIA, R. R. A. et al. Audience-audio immersion experiences in the caverna digital. In:

Proceedings of the 10th Brazilian Symposium on Computer Music, Belo Horizonte. [S.1.: s.n.], 2005. p. 106-117. 
FARIA, R. R. A.; ZUFFO, M. K.; ZUFFO, J. A. Improving spatial perception through sound field simulation in vr. In: IEEE. Virtual Environments, Human-Computer Interfaces and Measurement Systems, 2005. VECIMS 2005. Proceedings of the 2005 IEEE International Conference on. [S.1.], 2005. p. 6-pp.

GEIER, M.; AHRENS, J.; SPORS, S. The soundscape renderer: A unified spatial audio reproduction framework for arbitrary rendering methods. In: AUDIO ENGINEERING SOCIETY. 124th AES Convention. [S.1.], 2008.

HULSEBOS, E. M. Auralization using Wave Field Synthesis. Tese (Doutorado) - Delft University of Technology. Delft, Holanda, 2004.

IAZZETTA, F. A música, o corpo e as máquinas. Revista Opus, v. 4, n. 4, p. 27-44, 1997.

LOPEZ, J. J. et al. Wave field synthesis for next generation videoconferencing. In:

Communications, Control and Signal Processing (ISCCSP), 2010 4th International Symposium on. [S.1.: s.n.], 2010. p. 1-4.

MELCHIOR, F. Investigations on spatial sound design based on measured room impulse responses. Tese (Doutorado) — Tecnische Universiteit Delft, 2011.

MENZIES, D. Quasi wave field synthesis: Efficient driving functions for improved $2.5 \mathrm{~d}$ sound field reproduction. In: AUDIO ENGINEERING SOCIETY. 52nd International AES Conference: Sound Field Control-Engineering and Perception. [S.1.], 2013.

MONTAG, M. N. Wave Field Synthesis In Three Dimensions By Multiple Line Arrays. Dissertação (Mestrado) — University of Miami, Miami, 2011.

PUCKETTE, M. et al. Pure data: another integrated computer music environment. Proceedings of the Second Intercollege Computer Music Concerts, Citeseer, p. 37-41, 1996.

RANJAN, R.; GAN, W.-S. On the use of dynamically varied loudspeaker spacing in wave field synthesis. In: AUDIO ENGINEERING SOCIETY. 133rd AES Convention. [S.1.], 2012.

RANJAN, R.; GAN, W.-S. Wave field synthesis: The future of spatial audio. Potentials, IEEE, v. 32, n. 2, p. 17-23, 2013. ISSN 0278-6648.

RITSCH, W. Does pure data dream of electric violins? In: Bang: Pure Data - Wolke Verlagsges. Mbh, Graz, Austria, 2006.

SALVADOR, C. D. Discrete driving functions for horizontal reproduction using wave field synthesis and higher order ambisonics. 129th AES Convention, 2010.

SCHAFER, R. M. A afinação do mundo. São Paulo: Fundação Editora da UNESP, 2001.

SILVA, M. J.; FARIA, R. R. A. Aplicação de Wave Field Synthesis para auralização na música. In: AUDIO ENGINEERING SOCIETY. Anais do 11.o Congresso de Engenharia de Áudio. [S.1.], 2013.

SILVA, M. J.; SCHIAVONI, F. L.; FARIA, R. R. A. Programação dinâmica em Pure Data aplicada à Wave Field Synthesis. In: AUDIO ENGINEERING SOCIETY. Anais do 12.o Congresso de Engenharia de Áudio. [S.1.], 2014.

SPORS, S.; RABENSTEIN, R.; AHRENS, J. The theory of wave field synthesis revisited. In: 124th AES Convention. [S.1.: s.n.], 2008. p. 17-20. 
THOMAZ, L. F. Aplicação à música de um sistema de espacialização sonora baseado em Ambisonics. Dissertação (Mestrado) — Escola Politécnica da Universidade de São Paulo, 2007.

THOMAZ, L. F. et al. Orchestra spatialization using the audience engine. In: Proceedings of the ICMC. [S.1.: s.n.], 2006.

VALBOM, L.; MARCOS, A. Wave: Sound and music in an immersive environment. Computers \& Graphics, v. 29, n. 6, p. 871 - 881, 2005. ISSN 0097-8493. Disponível em: $<$ http://www.sciencedirect.com/science/article/pii/S0097849305001585>.

VERHEIJEN, E. N. G. Sound reproduction by wave field synthesis. Tese (Doutorado) Technische Universiteit Delft, 1998.

VRIES, D. de. Wave Field Synthesis - AES Monograph. New York: Audio Engineering Society Inc, 2009.

WITTEK, H. Perceptual differences between wavefield synthesis and stereophony. Tese (Doutorado) - University of Surrey, 2007.

ZMöLNIG, I. Reflection in pure data. Proceedings of the Linux Audio Conference, Parma, Itália, 2009. Disponível em http://lac.linuxaudio.org/2009/cdm/Saturday/18_Zmoelnig/18.pdf. 


\section{APÊNDICE A - Configurações do SSR}

Neste anexo é mostrado o conteúdo do arquivo de configuração $x m l$ utilizado pelo programa SoundScape Renderer (SSR) na seção 4.4, junto de algumas instruções para melhor entendimento.

A posição do ouvinte é a origem do sistema de coordenadas. A configuração da matriz é linear com 12 alto-falantes. Como a distância das caixas é regular, basta informar as coordenadas de duas das caixas de som da matriz (array) de reprodução. A primeira caixa tem coordenadas $x=" 1.25$ " e $y=" 0.319 "$ e a segunda $x=" 1.25$ " e $y=" 0.228 "$. Assim, a distância do ouvinte para a matriz de alto-falantes é $1,25 \mathrm{~m}$. E os centros dos alto-falantes de cada caixa estão a 0,091 m de distância entre si. Para que as caixas apareçam na GUI, da esquerda para a direita, na mesma ordem do que aparece na matriz de alto-falantes, deve ser colocado <orientation azimuth="180"/>.

Na sequência o conteúdo completo deste arquivo:

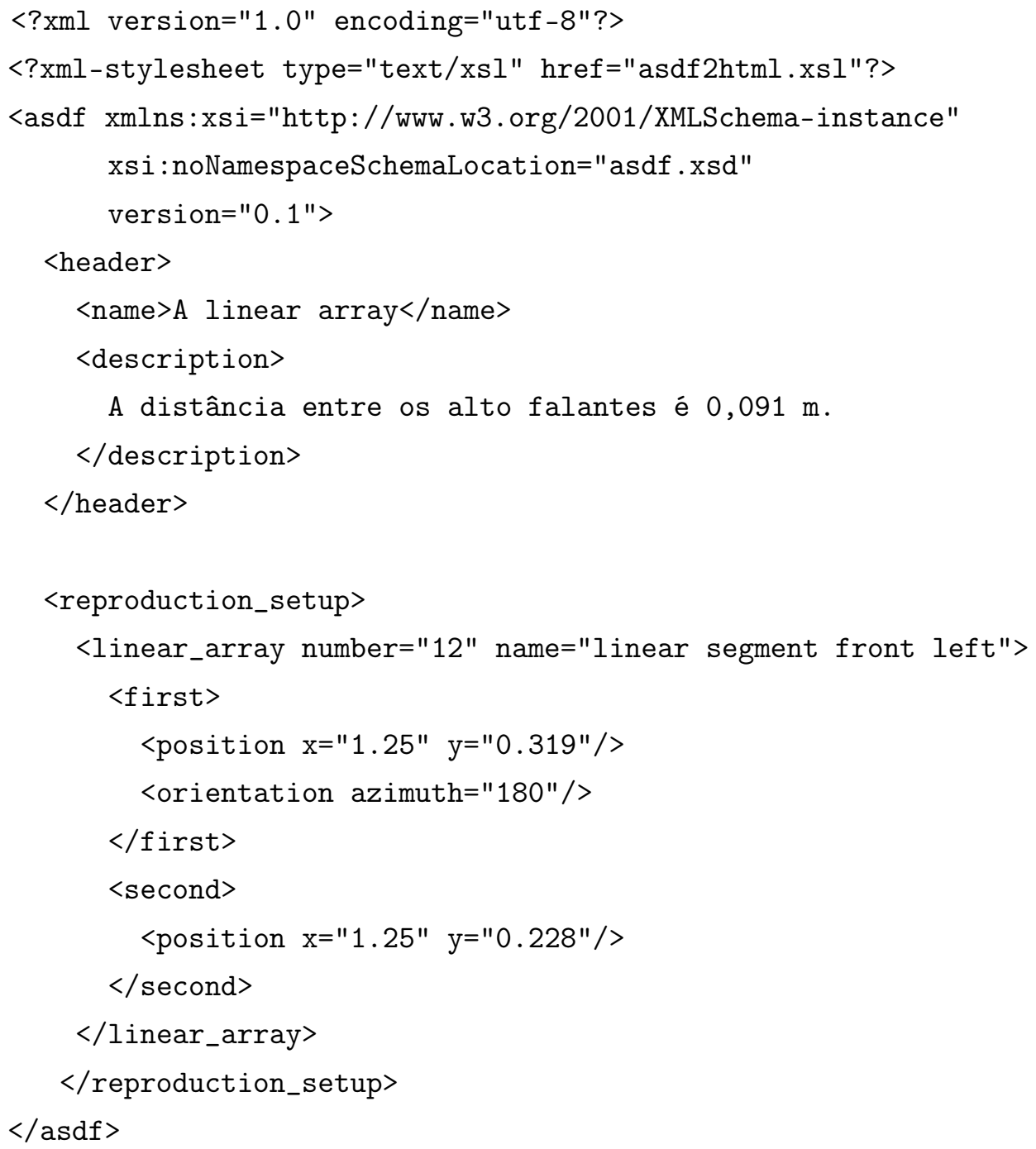




\section{APÊNDICE B - Método para o cálculo da posição da fonte sonora}

No teste subjetivo final, a linha de alto-falantes foi escondida dos ouvintes por uma cortina negra ortofônica, de modo que as posições das fontes sonoras foram estimadas por meio de 2 indicações da posição percebida do som indicadas sobre esta cortina usando-se um apontador laser. O método usado para o cálculo da posição da fonte sonora é mostrado a seguir. Dadas as coordenadas das duas posições (pontos A e B) nas quais o ouvinte se encontrava e dadas as duas coordenadas medidas pela apontamento da direção da fonte sonora pelo ouvinte (pontos C e D) obtém-se a intersecção de duas retas (reta $\mathrm{AD}$ e reta $\mathrm{BC}$ ), ou seja, a posição da fonte sonora $\left(x_{f}, y_{f}\right)$.

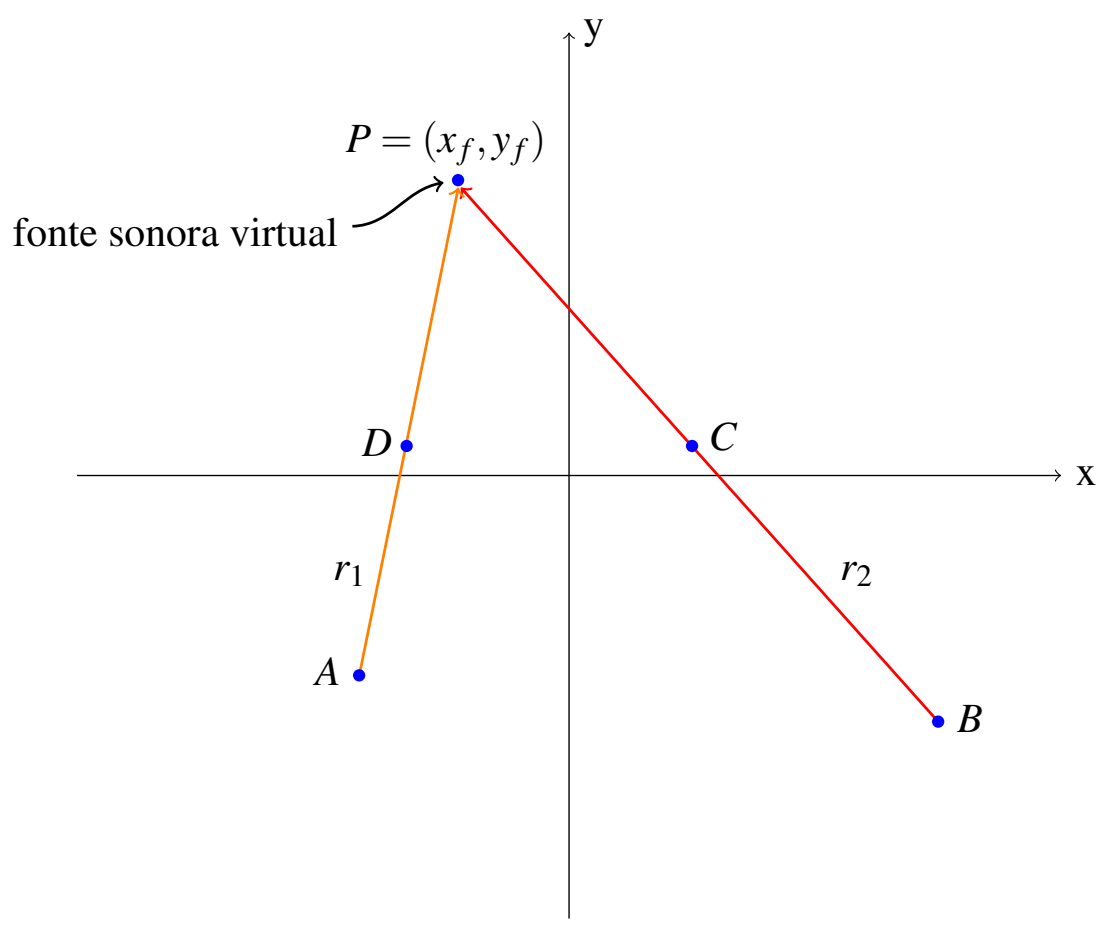

$A=\left(x_{A}, y_{A}\right)$ e $B=\left(x_{B}, y_{B}\right)$ são as duas posições em que o ouvinte escuta cada fonte sonora e $C=\left(x_{C}, y_{C}\right)$ e $D=\left(x_{D}, y_{D}\right)$ são as medidas no anteparo usadas para determinar a posição de $P$.

As equações das retas $r_{1}$ e $r_{2}$ são $y=a_{1} x+b_{1}$ e $y=a_{2} x+b_{2}$, respectivamente.

Para $r_{1}$ tem-se o seguinte sistema de equações:

$$
\left\{\begin{array}{l}
y_{A}=a_{1} x_{A}+b_{1} \\
y_{D}=a_{1} x_{D}+b_{1}
\end{array} \Rightarrow a_{1}=\frac{y_{A}-y_{D}}{x_{A}-x_{D}} \text { e } b_{1}=\frac{y_{D} x_{A}-y_{A} x_{D}}{x_{A}-x_{D}}\right.
$$

Para $r_{2}$ :

$$
\left\{\begin{array}{l}
y_{B}=a_{2} x_{B}+b_{2} \\
y_{C}=a_{2} x_{C}+b_{2}
\end{array} \Rightarrow a_{2}=\frac{y_{B}-y_{C}}{x_{B}-x_{C}} \text { e } b_{2}=\frac{y_{C} x_{B}-y_{B} x_{C}}{x_{B}-x_{C}}\right.
$$


E finalmente o objetivo é alcançado determinando-se as coordenadas $x_{f}$ e $y_{f}$ da fonte sonora, que é a posição do ponto $P$, em função das duas posições de audição e das medidas em um anteparo:

$$
\begin{aligned}
& \left\{\begin{array}{l}
y_{f}=a_{1} x_{f}+b_{1} \\
y_{f}=a_{2} x_{f}+b_{2}
\end{array} \Rightarrow\right. \\
& x_{f}=\frac{b_{2}-b_{1}}{a_{1}-a_{2}} \\
& y_{f}=a_{1} x_{f}+b_{1}
\end{aligned}
$$

